\title{
Sulfur-bound biomarkers of a Monterey shale and a Greenland lake sediment
}

\author{
Joshua Gallant Stern \\ Submitted in partial fulfillment of the requirements for the degree of \\ Bachelor of Science in Geology-Biology at \\ Brown University.
}

May, 2009

Advisor: Prof. Yongsong Huang 


\section{Acknowledgements}

I am especially grateful to Dr. Yongsong Huang for advising me on this senior thesis. Thank you to Dr. James Russell and Dr. Timothy Herbert for reading this thesis and providing helpful feedback. Thank you to Dr. Jan Tullis for helpful discussions and writing advice.

I am indebted to Dr. Marcelo Alexandre for helpful discussions and for teaching me laboratory techniques. Thank you to Mr. Rafael Tarozo for help with GC-MS analysis.

Dr. Alex L. Sessions and Dr. William J. D'Andrea generously supplied the rock and sediment samples, as well as helpful advice. Thank you to Dr. Stefan Schouten for helpful suggestions.

Thank you to Ms. Li Gao, Mr. Jonathan Nichols, and Ms. Jaime Toney for helpful discussions and laboratory instruction. Thank you to Mr. Jeffrey Salacup and Mr. Daniel Scheinerman for helpful advice.

Thank you to my Dad, Mom, Sister, Uncle, and friends for their love, support, and draft reading.

I am grateful to NASA's Rhode Island Space Grant Consortium for financial support during the summer of 2008. 


\begin{abstract}
Seeking to reconstruct the biogeochemical processes that produced organic sulfur compounds in two unique depositional environments, we used the nickel boride desulfurization reaction to release hydrocarbons from sulfur-bound macromolecules not otherwise amenable to chromatographic analysis. We desulfurized two geochemical extracts: one sample is a Monterey shale of late Miocene age, and the other sample is a surface sediment from the Greenland lake Brayas $\emptyset$. Both samples contained organic sulfur compounds, but the Monterey shale was biologically and thermally modified after deposition. A comparison of the free and sulfur-bound hydrocarbons from each sample revealed a precursor-product relationship between tocopherol and pristane, for Monterey. Greenland's composition may indicate that photochemical sulfurization occurs in the Brayas $\varnothing$ oxic zone. We found that sulfurization may proceed at different rates for different compound families; for example, we did not see any sulfurized alkenones in Brayas $\emptyset$, but we found an abundance of sulfurized isoprenoids. Greenland's relatively high overall desulfurization yield suggests that sulfurization in Brayas $\varnothing$ occurs in under 40 years. Our Greenland findings suggest that photochemical sulfurization may be more widespread than previously thought, and that sulfurization might not interfere with alkenone paleotemperature reconstructions.
\end{abstract}




\section{Contents}

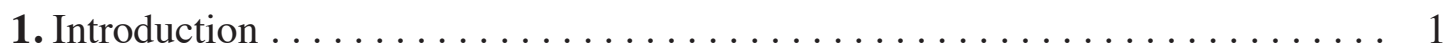

Section 1 endnotes . . . . . . . . . . . . . . . 7

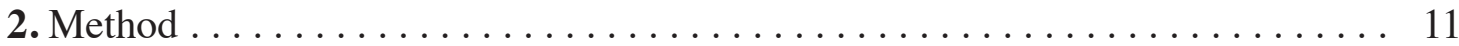

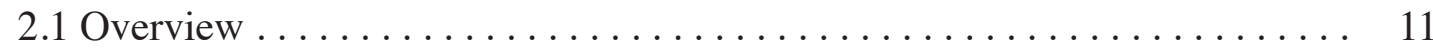

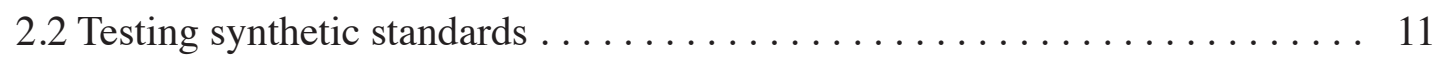

2.3 Organics extraction and fractionation $\ldots \ldots \ldots \ldots \ldots \ldots \ldots \ldots \ldots \ldots \ldots$

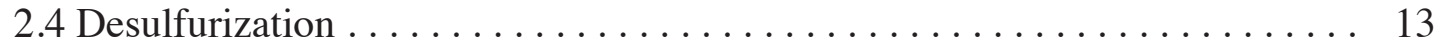

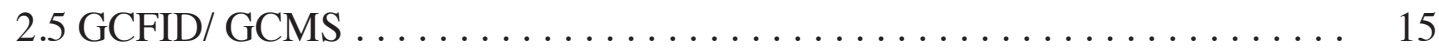

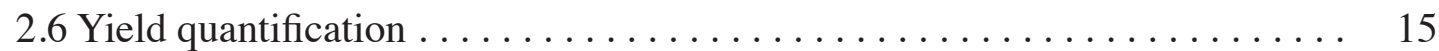

2.7 Experimental control . . . . . . . . . . . . . . . . . . . . . 16

Section 2 endnotes . . . . . . . . . . . . . . . . 17

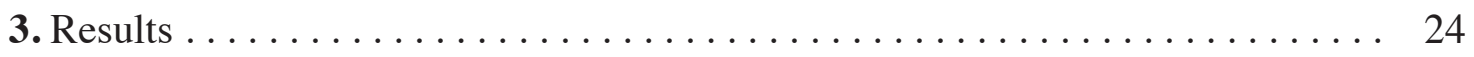

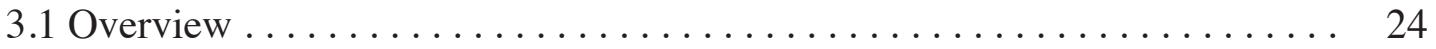

3.2 Standards . . . . . . . . . . . . . . . . . . . . 24

3.3 Monterey desulfurization fraction $\ldots \ldots \ldots \ldots \ldots \ldots \ldots \ldots \ldots \ldots \ldots \ldots \ldots$

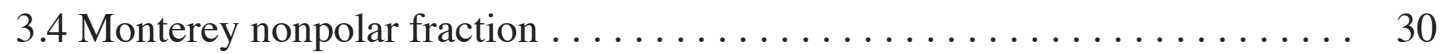

3.5 Greenland desulfurization fraction $\ldots \ldots \ldots \ldots \ldots \ldots \ldots \ldots \ldots \ldots \ldots \ldots$

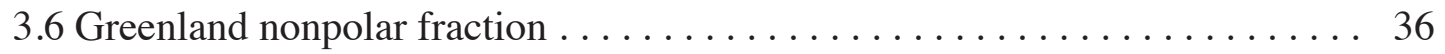

3.7 Minor-nonpolar fractions and experimental control . . . . . . . . . 38

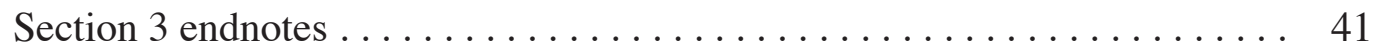

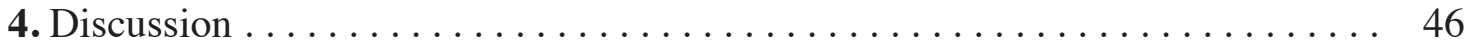

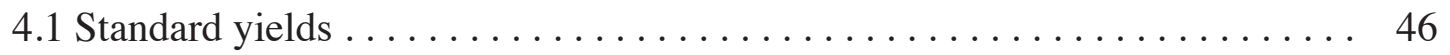

4.2 Sample yields . . . . . . . . . . . . . . . . . . . 47

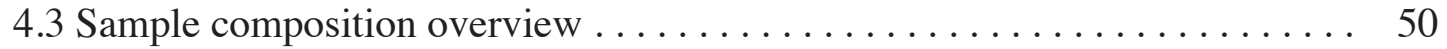

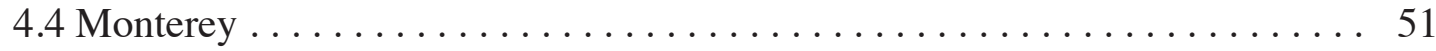

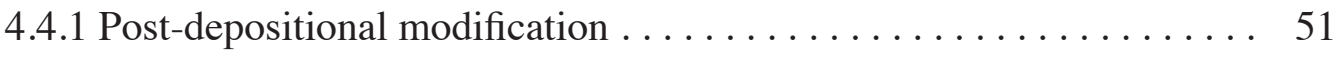

4.4 .2 Paleobiology . . . . . . . . . . . . . . . . . . 54

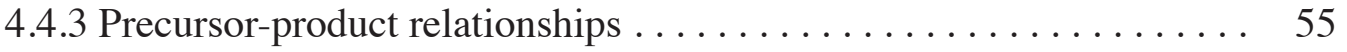

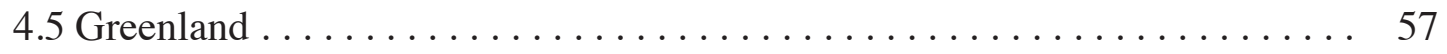

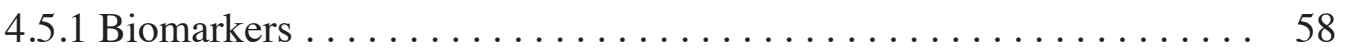

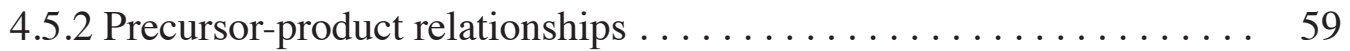

4.6 Sulfurization potential $\ldots \ldots \ldots \ldots \ldots \ldots \ldots \ldots \ldots \ldots \ldots \ldots \ldots \ldots \ldots \ldots$

Section 4 endnotes . . . . . . . . . . . . . . . . 63

5. Conclusion ................................ 71

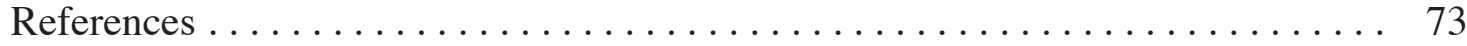




\section{List of figures}

Figure 1. Biomarker examples . . . . . . . . . . . . . . . . 1

Figure 2. Base-catalyzed nucleophilic addition $\ldots \ldots \ldots \ldots \ldots \ldots \ldots \ldots$

Figure 3. Light-induced free radical addition $\ldots \ldots \ldots \ldots \ldots \ldots \ldots \ldots \ldots$

Figure 4. Desulfurization of 1-octadecanethiol and S-benzylthioglycolic acid . . . . 5

Figure 5. Water column zonation for each depositional environment . . . . . . . 6

Figure 6. Hopanoid and isoprenoid fragmentation . . . . . . . . . . . . 9

Figure 7. Overall workflow . . . . . . . . . . . . . . . . . 12

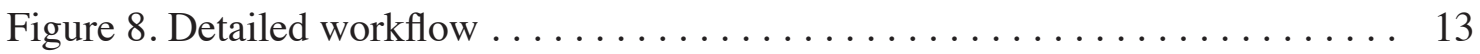

Figure 9. HMB calibration curves for samples . . . . . . . . . . . . . . 15

Figure 10. Additional Monterey and blank fractions . . . . . . . . . . . . . . 20

Figure 11. HMB calibration curves for standards . . . . . . . . . . . 21

Figure 12. GC-FID chromatograms for standard desulfurization yields . . . . . . 26

Figure 13. Monterey desulfurization fraction, GC-FID trace . . . . . . . . . . 27

Figure 14. Monterey desulfurization compound structures and names . . . . . . . . 29

Figure 15. Monterey nonpolar fraction, GC-FID trace . . . . . . . . . . . 30

Figure 16. Monterey nonpolar compound structures and names . . . . . . . . 32

Figure 17. Greenland desulfurization fraction, GC-FID trace . . . . . . . . . 33

Figure 18. Greenland desulfurization compound structures and names . . . . . . 35

Figure 19. Greenland nonpolar fraction, GC-FID trace . . . . . . . . . . . 36

Figure 20. Greenland nonpolar compound structures and names . . . . . . . . 37

Figure 21. Greenland and Monterey chromatographic data reconsidered . . . . . . 40

Figure 22. Blank DS-0, GC-FID trace . . . . . . . . . . . . . . 41

Figure 23. Ion chromatograms showing an unconvoluted component . . . . . . . 41

Figure 24. Ion chromatograms showing convoluted components . . . . . . . . . 42

Figure 25. Comparison of compound-characteristic ions from Monterey DS-3 . . . 42

Figure 26. Baseline comparison between Monterey-0 and Monterey fractions . . . . 43

Figure 27. Biodegradation of Monterey nonpolar fraction . . . . . . . . . . . 44

Figure 28. Greenland nonpolar and desulfurization GC-FID trace comparison . . . . 44

Figure 29. Yields of standard desulfurizations . . . . . . . . . . . . 46

Figure 30. Desulfurization yield of each sample . . . . . . . . . . . 47

Figure 31. Model for organic sulfur compound formation in Brayas $\varnothing \ldots \ldots \ldots 2$ 


\section{List of tables}

Table 1. Desulfurizations of synthetic standards and reaction yields . . . . . . . 24

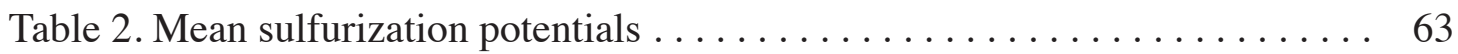

Table 3. Normalizing the desulfurization yields . . . . . . . . . . . . . . . 64

Table 4. Raw GC-FID measurements . . . . . . . . . . . . . . . . . 68

Table 5. Corrected GC-FID measurements . . . . . . . . . . . . . . . . . . 68

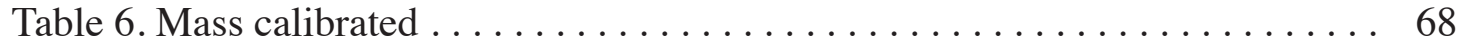

Table 7. Procedural blank subtracted $\ldots \ldots \ldots \ldots \ldots \ldots \ldots \ldots \ldots \ldots$ 
The notation "E-n" refers to a section endnote, where $\mathrm{n}$ is the number of the endnote. 


\section{Introduction}

We aim to reconstruct biogeochemical processes that produced sedimentary organic sulfur compounds sampled from two unique depositional environments. Microbial, weathering, and photochemical processes each have roles in converting sulfur between its many forms, which range from the most oxidized sulfate to the most reduced sulfide. The oxidation state of an organic sulfur compound (OSC) would fall somewhere between the opposite states of sulfate and sulfide. OSCs are biomarkers that have been geochemically sequestered using sulfide linkages (E-1). Biomarkers are the molecular remains of algae and other organisms, which help reconstruct the history of Earth's ecology and climate. Sulfur-bound biomarkers can provide a fuller inventory of the precursor biochemicals and their sources than free (non-sequestered) biomarkers provide by themselves. This section introduces the diagenetic process of sulfurization, and several of the mechanisms by which it operates. We also introduce the analytical technique of desulfuriza-

tion. Later, we describe our experimental work on Monterey shale and sediment from the Greenland lake Brayas $\varnothing$, and we offer paleoenvironmental

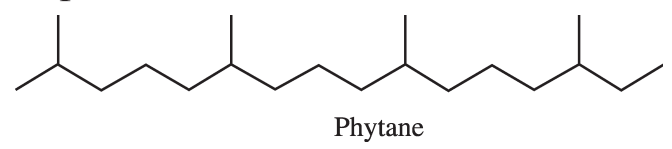
and mechanistic explanations for the free and sulfur-bound compounds in these samples.

Organic carbon can comprise as much as $17 \%$ of a sedimentary rock's mass; however, this

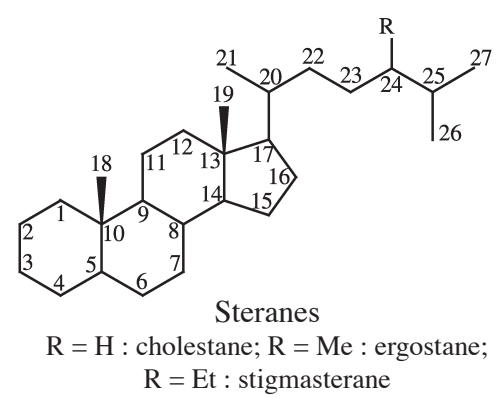
material is $1 \%$ of rock mass on average (Katz and Royle, 2001). Organic compounds are the

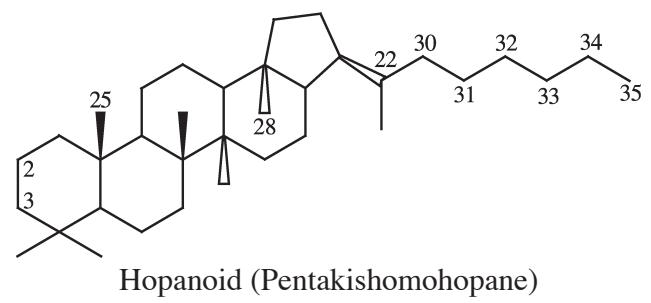

Figure 1. Some biomarkers whose precursors composed lipid membranes or photosynthetic pigment. Structures reproduced from Brocks \& Summons, 2004. 
remains of once-living systems. Carbon is by far the most abundant constituent of this material by mass; hydrogen and other bioelements are also present. Steranes, phytanes, and hopanes exemplify the compounds found in sedimentary organic matter (Fig. 1). As photosynthetic organisms exit the productive surface water and move down through the water column to the sediment, most of them are intercepted and metabolized by heterotrophs (E-2). Biomolecules vary in their ability to withstand decomposition. Membrane lipids such as cholesterol and long-chain fatty acids tend to be the most durable. On the other hand, nucleic acids and proteins are poorly preserved (E-3). The degree to which molecular "fossils" escape remineralization (that is, microbial or thermal decomposition) determines the ensuing rock's fraction of total organic carbon (TOC). Particles accumulating at the sediment-water interface gradually compact the underlying sediment into rock, creating a net downward movement of the sediment with respect to the plane of deposition. Sediment burial can help the deposited organics escape respiration by benthic life.

Another preservative process that occurs during diagenesis is sulfurization. In this geochemical reaction, reduced sulfur species attack the reactive functionalities on biomolecules, yielding a compound in which one or more sulfur atoms comprise an intraor inter-molecular bridge (Fig. 2). The sulfides originate from sulfate-reducing bacteria, which respire using sulfate as a terminal electron acceptor instead of oxygen (Werne et al., 2004). The sulfate ion is abundant in the ocean and some lakes, but it is not reactive under the mild conditions of the surface sediment (Aizenshtat et al., 1995). The availability of sulfides depends on the extent of bacterial sulfate reduction, the degree to which pyrite formation competes with this process for the available sulfate, the flux of iron 2 

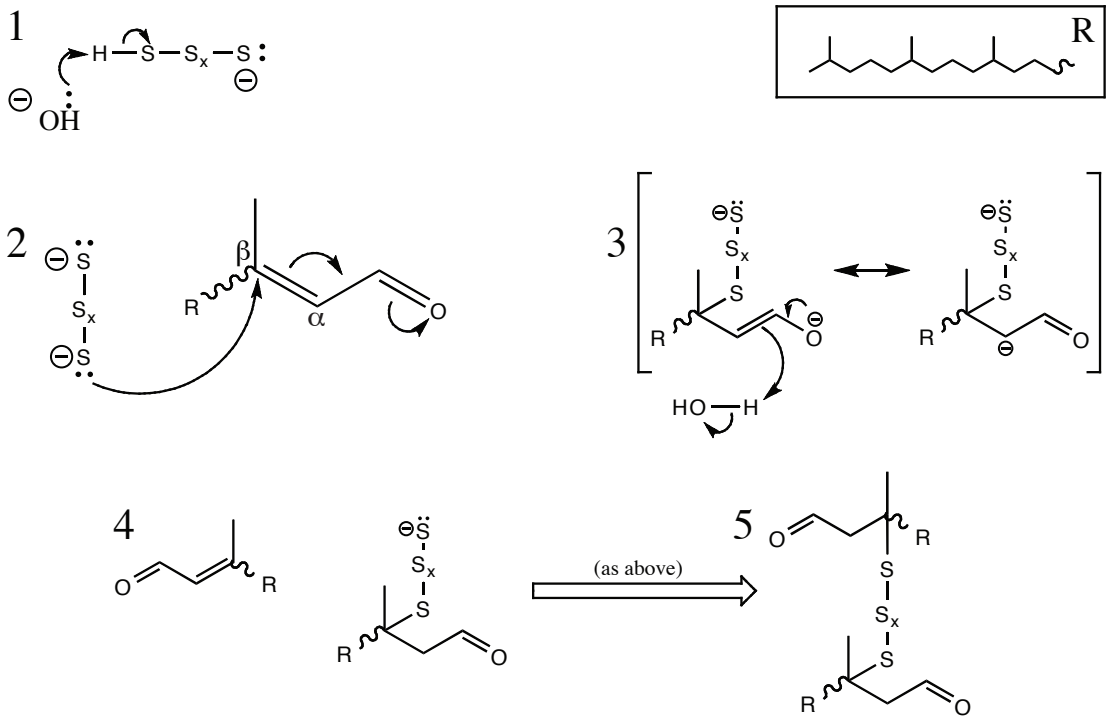

Figure 2. Base-catalyzed nucleophilic addition. $\mathrm{OH}$ - is the base, which deprotonates the polysulfide nucleophile (1). The polysulfide reacts with the activated bond (2) to form a carbanion whose lone pair is delocalized (3). The carbanion intermediate deprotonates a water molecule, yielding a polysulfidic organic compound, which can react with another phytenal $(4,5)$. Based on Aizenshtat et al. (1995).

oxides to the water column, and the concentration of highly functionalized organic matter (Werne et al., 2004; Russell and Werne, 2009). Sulfate-reducing bacteria are typically anaerobic, so organic sulfur compounds are often thought to indicate anoxia. However, some workers have found evidence of aerobic sulfate-reducing species (Amrani \& Aizenshtat, 2004).

The abiotic chemical mechanisms by which sulfur incorporates into organic matter is an area of active research (Werne et al., 2008). As we will argue, there are two chief mechanisms that pertain to our locations of study. The first mechanism, basecatalyzed nucleophilic addition, is well-established (Aizenshtat et al., 1995). The second mechanism, light-induced free-radical addition, seems to be gaining popularity (Amrani \& Aizenshtat, 2004). The base-catalyzed mechanism is thought to occur in marine sediments, because the waters in these areas tend to be mildly basic (Aizenshtat et al., 1995). The light-induced mechanism has been argued to occur in anoxic photic zones (Adam et 
al., 1998). Figure 2 shows the nucleophilic addition mechanism, and

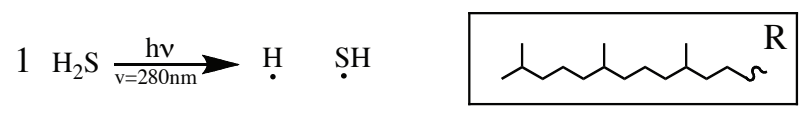

figure 3 shows the mechanism for free-radical addition. Several other mechanisms not shown in these figures may also be important to abiotic

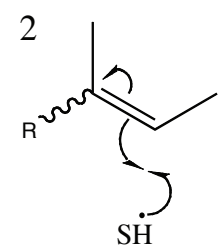

Figure 3. Light-induced free-radical addition, based on Vaughan and Rust (1942). Light abstracts a sulfide radical (1), initiating a radical chain reaction that yields thiophytane (2-4). Adam et al. (1998) suggest that a similar mechanism forms polysulfide radicals and intermolecular sulfur.

sulfurization. Adam et al. (1998)

found that ketones catalyze the photochemical sulfurization reaction, probably because they radicalize at a longer wavelength of light (Vaughan and Rust, 1942). Schneckenburger et al. (1998) found evidence that a radical mechanism facilitates the reaction of sulfides and ketones to form thioketones, which may be intermediates in OSC synthesis pathways. Adam et al. (1998) found that photochemical sulfurization occurred in less than one day, under laboratory conditions.

Natural sulfurization can occur rapidly, as shown by OSCs found in surface sediments of Ace Lake, Antarctica, (Kok et al., 2000) and Lake Cadagno, Switzerland (Putschew et al., 1995). Werne et al. (2004) point to evidence of both rapid sulfurization (days), and less rapid sulfurization (thousands of years). Either way, sulfurization occurs early in diagenesis, and multiple reactions of different rates probably happen simultaneously (Ibid.)

Sulfurized biomarkers can be important to paleoreconstructions, as Werne et al. (2004) explain. Sulfurization can affect the distribution of free compounds. Despite the rapid pace of sulfurization, not all biomolecules are sulfurized quantitatively, so their descendents can occur as OSCs, as defunctionalized hydrocarbons, as both, or as neither. 4 
Reconstructing the history of life at a particular depositional environment often involves interpreting trends in the relative abundance of certain biomarkers over time. Similar trends suggest similar sources. Therefore, failing to consider the sulfurized biomarkers can produce an erroneous trend, or overlook a compound altogether. In some sediments, sulfurized biomarkers compose the majority of the soluble organic matter (Schaeffer et al., 1995). Sulfurization can preserve carbohydrates (Werne et al., 2004), a class of compounds that would be metabolized rapidly outside of a macromolecular network.

Decoding OSCs requires instruments that isolate, identify and measure them. We used two analytical instruments: the Gas Chromatograph- Mass Spectrometer (GC-MS) and the Gas Chromatograph- Flame Ionization Detector (GC-FID) (E-4). Identifying and measuring the abundance of macromolecular, polar organic sulfur compounds (OSCs) with the GC-MS and -FID is difficult. OSCs are challenging to analyze because the S atom is electronegative, and sulfurization often forms macromolecular, sulfide-linked networks of multiple biomolecules that can contain other electronegative substituents. Because OSCs tend to be heavy (of a large size) and polar, they often elute slowly or not at all on a polar GC column. As a workaround, organic geochemists developed a degradative chemical reaction that replaces sulfide bonds with hydrogen atoms (Schouten et al., 1993). This “desulfurization” reaction allows us to release, measure and identify potential biomarkers previously trapped as OSCs (Fig. 4).

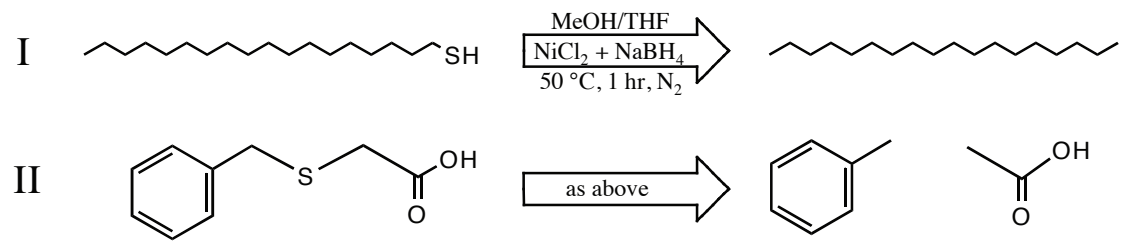

Figure 4. I. Desulfurization of 1-octadecanethiol yields octadecane. II. Desulfurization of S-benzylthioglycolic acid yields toluene and acetic acid (acetic acid unconfirmed; see Results). 
We desulfurized and analyzed synthetic standards and geochemical extracts with two goals. We sought to optimize this technique's experimental and analytical methodology to facilitate future work in our laboratory. In addition, we aim to infer features of our samples' depositional environment. The first sample is from an outcrop on the eastern end of Sulfur Mountain in Monterey, California. The outcrop is part of the upper member of the Monterey Formation, which deposited somewhere between 6.7 and 7.8 million years ago, about $100 \mathrm{~km}$ off the late-Miocene coast. At that time, the area of deposition was under 1000-1500 m of seawater (Fig. 5) (Isaacs, 2001). Our second sample is surface sediment from the permanently stratified, oligosaline Greenland lake Brayas $\varnothing$ (Fig. 5) (0-1 cm below the sediment-water interface, at a water depth of 57 feet).

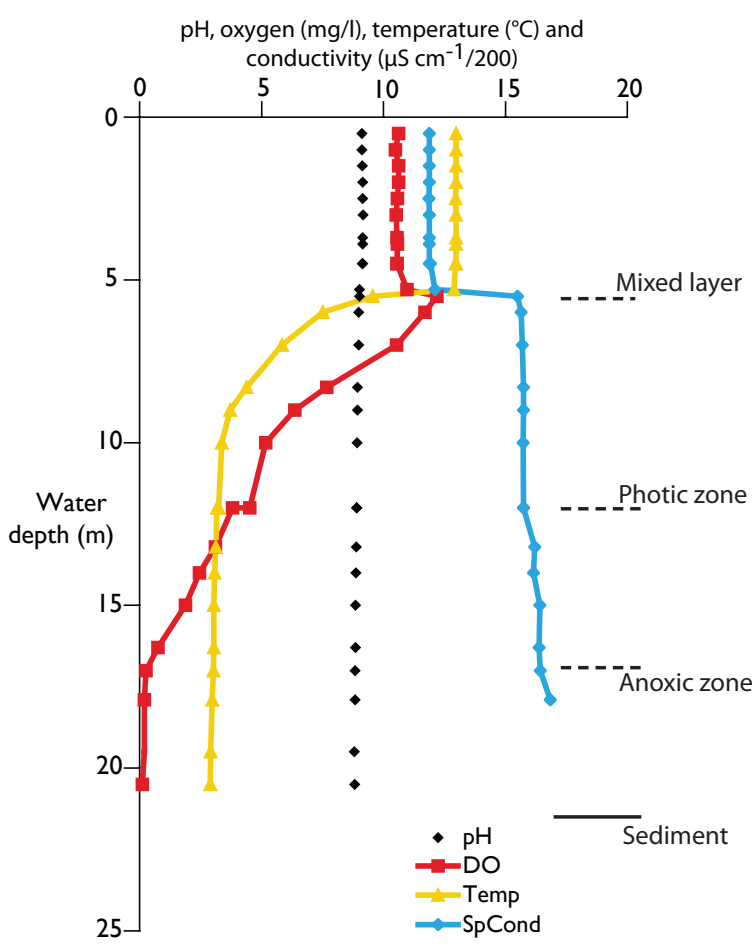

A) Greenland, Brayasø Lacustrine

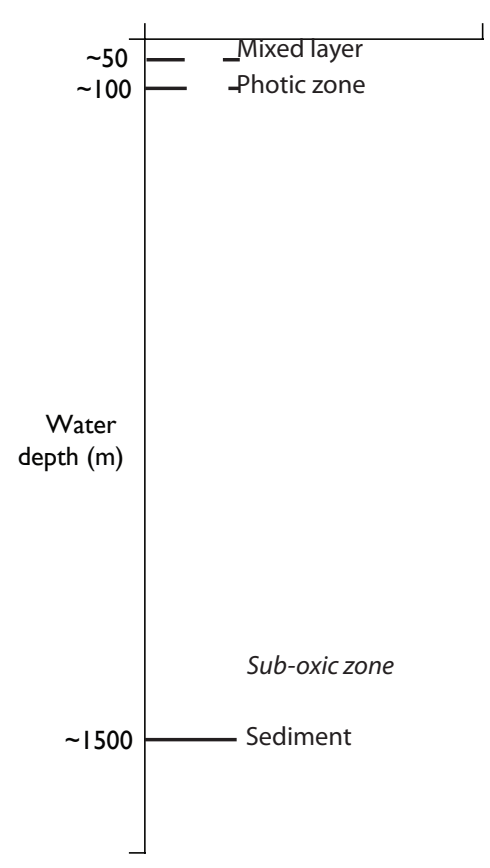

B) Monterey Hemipelagic

Figure 5. (A) Water column zonation for the Greenland sediment's depositional environment, inferred by measurements of the lake taken in August 1997 (reproduced from Anderson et al., 1999). (B) Water column zonation of the Monterey shale's likely depositional environment, inferred from Isaacs, 2001. 
The lake sediment is less than 910 years old, and probably less than 40 years old (E-5). Our blank sample is sand baked overnight at $500{ }^{\circ} \mathrm{C}$.

\section{$\underline{\text { Section } 1 \text { endnotes }}$}

1. Not all organic sulfur compounds are formed through a geochemical reaction. Some OSCs are formed through "assimilatory sulfate reduction", that is, cellular sulfate uptake and biosynthetic utilization. Measurements of the ${ }^{34} \mathrm{~S}$ depletion in sedimentary OSCs indicate that $20-25 \%$ of marine sedimentary OSC mass is biogenic (Werne et al., 2004).

2. Most marine life is too small and too buoyant to fall from the surface ocean to the abyss. However, ocean circulation exports this material (dissolved organic matter and small particulate organic matter) to depth. Additionally, calcite and opal shells aggregate buoyant organic matter and drag it to the ocean floor (Sarmiento and Gruber, 2006).

3. Barring favorable circumstances such as a deposition environment that has been cold for an unusually long time, DNA should degrade about 10,000 years after deposition (D’Andrea et al., 2006). Nucleic acids and proteins are made with phosphodiester and amide bonds, respectively. Phosphorus and nitrogen are biolimiting nutrients; their terrestrial paucity makes them highly coveted, so any biopolymer that they are part of is vulnerable to microbial attack. Moreover, phosphodiester and amide bonds are vulnerable to hydrolytic decomposition, so even if microbes do not eat them, these compounds tend 
to decompose rapidly on geologic timescales (Bada, 1991). Carbohydrates are another readily metabolized group of compounds not expected to preserve well (Werne et al, 2004).

4. Chromatography is a laboratory technique that takes advantage of a compound's unique chemical properties in order to physically isolate it. Compound isolation is crucial if we wish to understand what makes up a mixture of hundreds or thousands of unidentified compounds from a geochemical extract. Gas Chromatography (GC) separates compounds based on size and polarity. The machine injects an aliquot of sample at the beginning of a column, and, over the course of about 40 minutes, increases the temperature from about $40^{\circ} \mathrm{C}$ to about $315^{\circ} \mathrm{C}$. Small, nonpolar molecules such as hexane travel through the column the fastest, eluting at the beginning of the run. Large, polar molecules such as functionalized cholesterol travel through the column the slowest, eluting at the end of the run. The column is a coiled tube $\sim 60 \mathrm{~m}$ in length and $\sim 0.5 \mathrm{~mm}$ in diameter. The column's inner wall is coated with a polar stationary phase, which attracts polar compounds from the sample and acts in concert with the gradually rising temperature to ensure that polar compounds have longer retention (elution) times.

GC is mostly used for fine separation of individual compounds (e.g., nonane, $\mathrm{C}_{9} \mathrm{H}_{20}$, from decane, $\mathrm{C}_{10} \mathrm{H}_{22}$, whereas liquid chromatography is used for both the gross fractionation of broad groups of compounds (e.g., polar versus nonpolar), and fine separation. Liquid chromatography (LC) and thin layer chromatography (TLC), like gas chromatography, exploit the fact that different compounds have different polarities. However, LC and TLC do not use a temperature gradient, and the mobile phase is liquid 8 
as opposed to gas. For this report we used gas

chromatography to analyze, identify and measure

individual compounds obtained from sedimentary

extracts that we prepared by separating the extracts

into polar and nonpolar fractions with liquid

chromatography.

We can couple a Gas Chromatograph to a
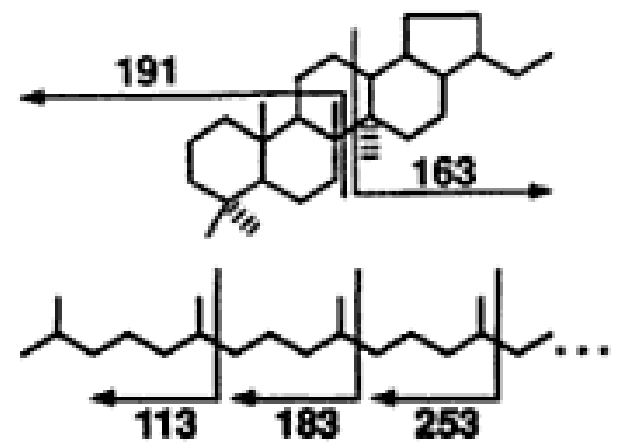

Figure 6. Top, hopanoid fragmentation. Bottom, regular isoprenoid fragmentation. Drawings reproduced from Peters et al. (2007).

Mass Spectrometer (MS), so that once a compound

elutes from the GC column, it passes into the MS for further identification. The MS

outputs a spectrum several times per second showing the mass distribution (ion intensity

versus ion mass) for whatever compounds are entering the MS. The mass distribution

helps identify the compound. In our particular setup, the mass spectra are patterns of ion

fragmentation. The instrument breaks the molecule into several pieces, and since each

compound has a unique and predictable fragmentation pattern, we deduce the molecular

structure by comparing the MS detector's output to a library of fragmentation patterns

for known compounds. (Other types of mass spectrometers do not fragment the ions and

instead provide exact mass data.)

Ion chromatograms are another way to infer the identity of an unknown

compound. In contrast to a mass spectrum, which shows the distribution of ionized

masses at a certain time, an ion chromatogram shows the abundance of a single ion over

the course of the run. The total ion chromatogram (TIC) shows how the sum of all the

ion signals changes over the course of the run. Chromatograms of one or a few ions are 
useful for detecting common biomarker ion fragments, such as m/z 191, for hopanes, or m/z 183, for regular isoprenoids (Fig. 6).

To obtain accurate abundance data for hydrocarbon compounds, we use a Flame Ionization Detector (FID), which burns compounds as they elute off of a GC column and detects the resulting $\mathrm{CO}_{2}$ gas. Because different compounds have different ionization efficiencies, using a GC-MS to find a compound's total ion intensity is an inaccurate way to compare the abundances of unidentified compounds from diverse samples. Moreover, the FID is better equipped to analyze large numbers of samples and samples with high compound abundances.

5. The 40 year estimate is an interpolation based on the radiocarbon date of 910 years for Brayas $\varnothing$ sediment between $22.4 \mathrm{~cm}$ and $22.5 \mathrm{~cm}$ depth (Anderson and Leng, 2004). We assume that the lake's sedimentation rate has been constant over the past 910 years, and that the sediment-water interface was unperturbed during this time. Assuming no perturbation is reasonable since the sediments are laminated and the lake is meromictic (Anderson et al., 1999). 


\section{Method}

\subsection{Overview}

We used the nickel boride desulfurization reaction to release sulfur-bound biomarkers from the organic extracts of sedimentary rock samples. We prepared the organic extract for desulfurization using an Accelerated Solvent Extractor (ASE) and liquid column chromatography. After the desulfurization reaction, we isolated the nonpolar yield with another column fractionation. We measured and identified the most abundant compounds in the nonpolar yield using GC-FID and GC-MS. To optimize the efficiency of the desulfurization reaction, we performed desulfurizations of synthetic standards under a variety of conditions.

\subsection{Testing synthetic standards}

In order to measure the yield of the desulfurization reaction and confirm its efficacy, we desulfurized the synthetic standards 1-octadecanethiol and S-Benzylthioglycolic acid (Sigma-Aldrich). For each experiment, we dissolved 1-20 mg of standard in a 2-4 mL solution of methanol:tetrahydrofuran 1:1, and followed one of our four distinct desulfurization procedures, which we explain below.

\section{$\underline{2.3 \text { Organics Extraction and Fractionation }}$}

We obtained a Total Organic Extract (TOE) for the Monterey and blank samples by using an Accelerated Solvent Extractor (ASE) (E-1). We obtained the Greenland TOE by extracting $1.56 \mathrm{~g}$ loose sediment in $15 \mathrm{~mL}$ DCM:MeOH 9:1 under ultrasonication at 


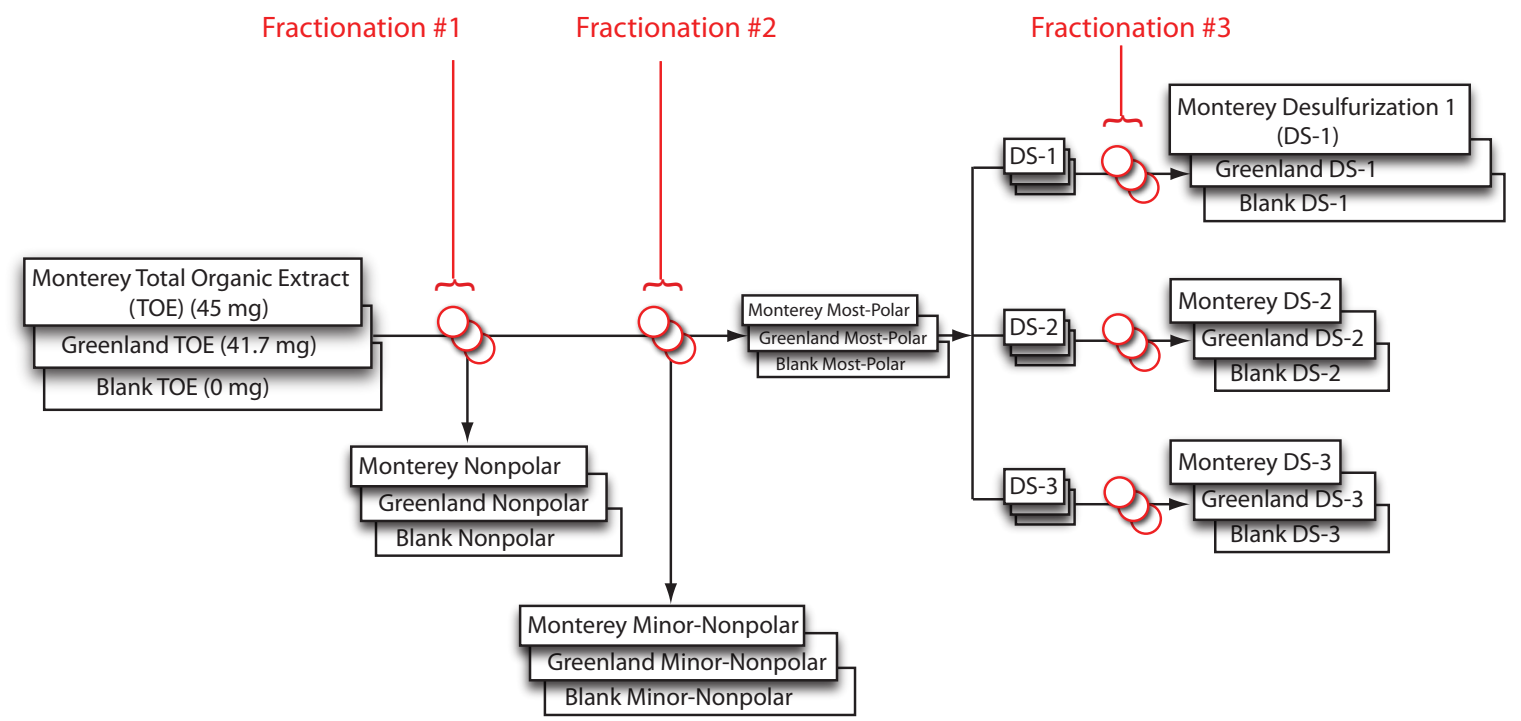

Figure 7. Overall workflow. Red circles indicate chromatographic separations. We do not show the "Polar" fractions resulting from Fractionation \#1. For more details on the chromatographic separations (fractionations), see Figure 7. See E-7 for additional Monterey and Blank fractions not shown in this schematic.

$\sim 30^{\circ} \mathrm{C}$ for 30 minutes (E-2). The Extractable Organic Matter (EOM), as a percentage of the rock mass, was $1.3 \%$ for Monterey and $2.7 \%$ for Greenland (E-3).

In order to isolate the organic sulfur compounds and remove free hydrocarbons, we fractionated each total organic extract (TOE) into a nonpolar and polar fraction on an alumina gel $\left(\mathrm{Al}_{2} \mathrm{O}_{3}\right)$ column, using hexane:dichloromethane 9:1 (Hex:DCM 9:1) for the nonpolar fraction and dichloromethane:methanol 1:1 (DCM:MeOH 1:1) for the polar fraction. (Fractionation \#1, indicated on Fig. 7 and Fig. 8).

Unfamiliar with the practice of asphaltene precipitation, we did not perform it before the first column fractionation. Omitting this step led us to modify our column fractionation procedure. This modification had the unintended consequence of introducing nonpolar cross-contaminants into polar fractions. We controlled for these cross-contaminants by performing a second fractionation on the polar fraction. Our second fractionation resulted in a "Most-Polar" fraction and a "Minor-Nonpolar" fraction (Fractionation \#2, indicated on Fig. 7 and Fig. 8). For a detailed explanation of asphaltene 


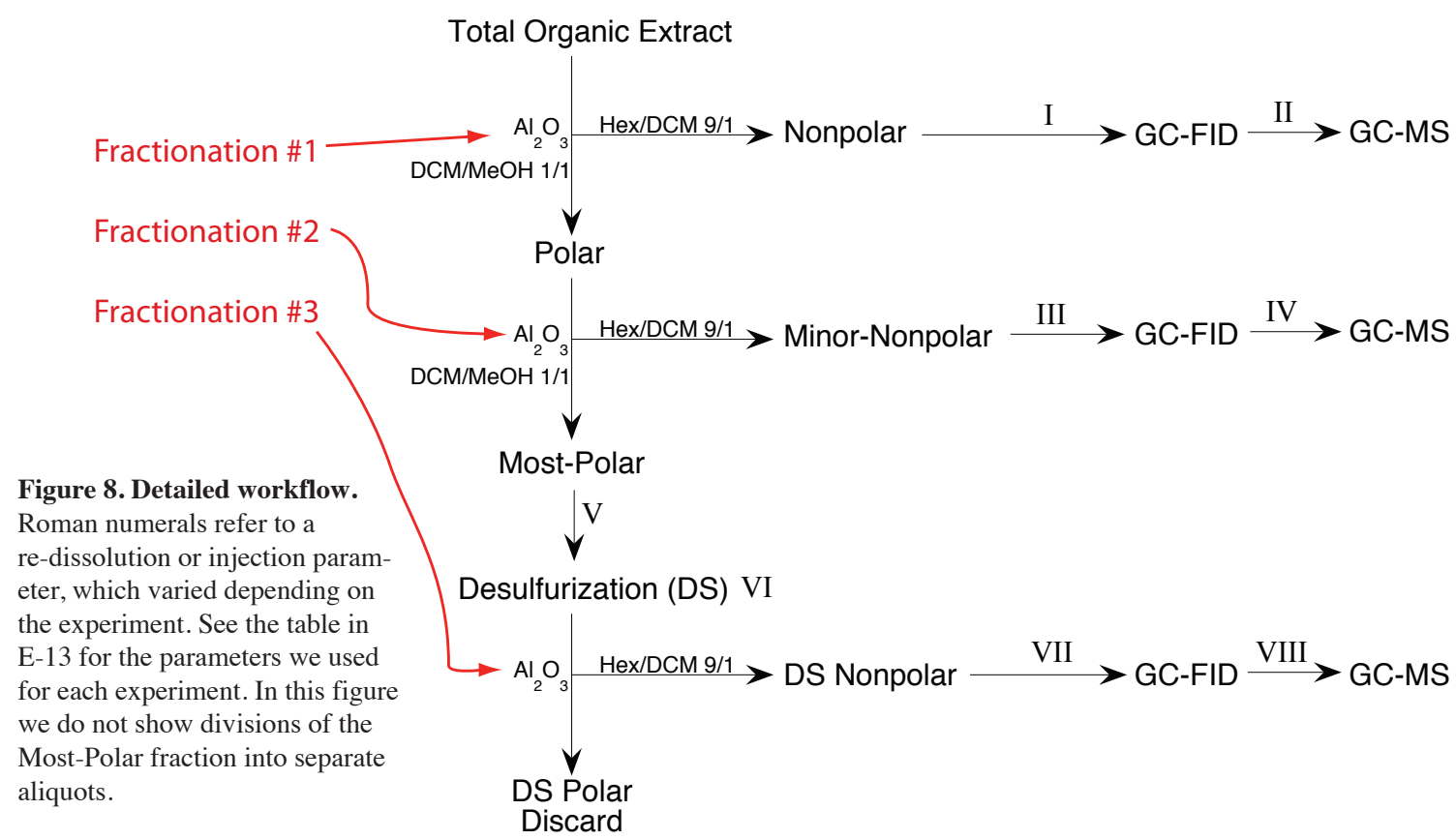

precipitation, our modification of the column fractionation procedure, and the resulting non-polar cross-contamination, see Endnote 4.

\subsection{Desulfurization}

We had three different TOEs (Monterey, Greenland, and Blank). For each TOE aliquot we produced one Most-Polar fraction (Figs. 7, 8). For the majority of our experiments, we split the Most-Polar fraction into three aliquots and desulfurized each aliquot (Fig. 7). For a few of our experiments, we desulfurized the entire Most-Polar fraction at once (E-7). After the desulfurization reaction, we isolated the nonpolar yield with another column fractionation (Fractionation \#3, indicated on Fig. 7 and Fig. 8).

We produced each desulfurized fraction using one of four distinct desulfurization procedures. We designed these procedures based on the descriptions in Schaeffer et al. (1995), Schouten et al. (1993), and Schouten (personal communication, 2008). 
The four methods were very similar to one another. To prevent water from degrading the reagent sodium borohydride $\left(\mathrm{NaBH}_{4}\right)$, we prepared the reaction solvents, methanol $(\mathrm{MeOH})$ and tetrahydrofuran (THF), by drying with $\mathrm{Na}_{2} \mathrm{SO}_{4}$ for 15 min or overnight with 5A molecular sieves. We dissolved 1-20 mg of sample or standard with 2-4 mL THF:MeOH 1:1 in a test tube with a magnetic stir bar. To the dissolved sample we added 10-100 mg nickel chloride $\left(\mathrm{NiCl}_{2}\right)$, and (slowly) a roughly equal amount of $\mathrm{NaBH}_{4}$. To hasten the desulfurization reaction, we heated the mixture to $50-70^{\circ} \mathrm{C}$. We used a gentle nitrogen stream to isolate the reaction from water vapor. After 1 hour, we used $\mathrm{Al}_{2} \mathrm{O}_{3}$ isolation of the nonpolar fraction to extract from the reaction mixture any hydrocarbons released by desulfurization (Fractionation \#3, indicated on Fig. 7 and Fig. 8) (E-5).

Three of the desulfurization methods we used are called DS-1, DS-2, and DS-3; we performed each of these methods on separate aliquots of all three extracts (Fig. 7). For DS-1, we attempted to reflux the reaction mixture at $\sim 70^{\circ} \mathrm{C}$ in a long test tube $(\mathrm{E}-6)$, and used $\mathrm{MeOH}$ dried with $\mathrm{Na}_{2} \mathrm{SO}_{4}$ for 15 min. For DS-2, we used a THF:MeOH mixture that we had dried overnight with 5A mole sieves. For DS-3, we used the 5A mole dried solvents and also added $\sim 100 \mathrm{mg}$ additional sodium borohydride 30 minutes after the reaction start. The fourth desulfurization method we call DS-0, and we performed it only on aliquots of the Monterey TOE and the Blank TOE (E-7). In DS-0, we heated the reaction to $50{ }^{\circ} \mathrm{C}$, and used $\mathrm{MeOH}$ dried with $\mathrm{Na}_{2} \mathrm{SO}_{4}$ for $15 \mathrm{~min}$.

We used some of our blank fractions to test standard desulfurization efficiency, in addition to using them as procedural controls (E-10). 


\subsection{GC-FID/ GC-MS}

In order to determine each sample's abundance of volatile compounds, we evaporated the nonpolar fractions, redissolved them, and transferred them to $2 \mathrm{~mL}$ vials for GC-FID analysis. We optimized the volume of solvent in the GC vials, as well as the injector split mode, to obtain peak heights between 20 and 500 pA (E-8). To identify the compounds in these samples, we performed GC-MS analysis on most of the samples. Endnotes 11 and 12 describe the GC-FID and GC-MS temperature programs (labelled with Greek letters in other parts of this report). We determined the compounds present in each fraction by searching the NIST 2005 mass spectra library with the spectra from our data.

\subsection{Yield Quantification}

To quantify the absolute desulfurization yield (the mass of volatile organic carbon isolated from the reaction mixture), we measured

a hexamethylbenzene (HMB) standard at various known concentrations with the GC-FID. We observe a linear relationship between $\mathrm{HMB}$

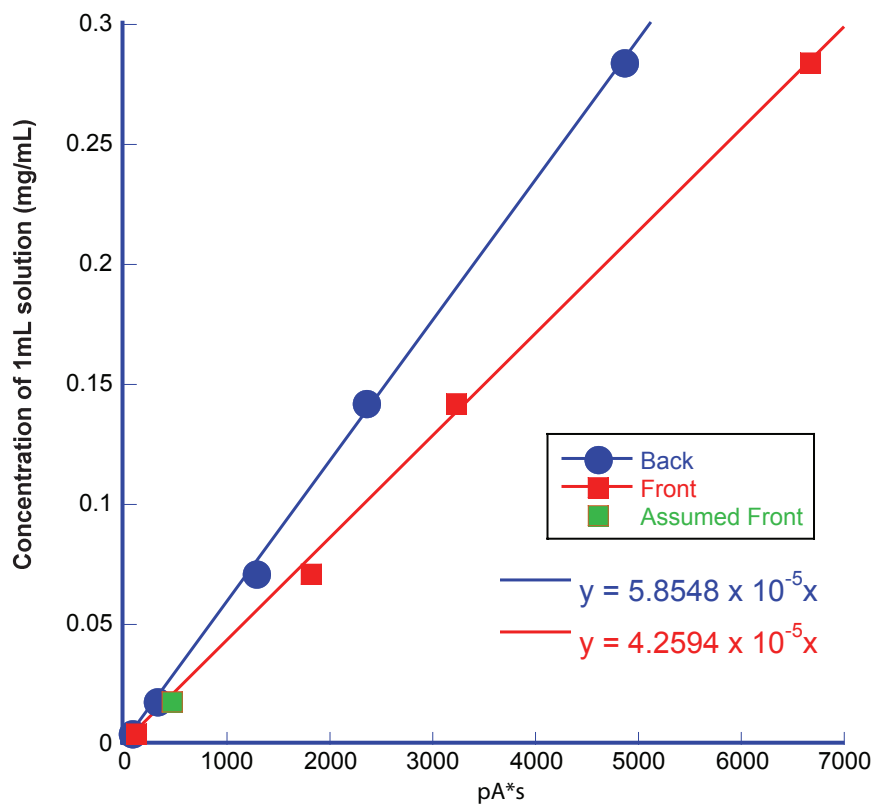

Figure 9. Hexamethylbenzene (HMB) calibration curves. Our mass on column and peak area (Fig- GC-FID has two columns and two detectors (called "Back" and "Front"), so we collected standard data for each column-detecure 9). For standard concentrations tor setup. The "Assumed Front" point is in lieu of missing data, and we base it on the typical ratio for these two detectors, for a higher than the ones that we meaparticular mass loading, which we observed over the course of our experiments. 
sured, Krupcík et al. (2004) report a linear FID response to increasing mass on column. We used the figure 9 curves to quantify the sample desulfurization yield, and we used similar curves to quantify the standard desulfurization yield (E-9).

\subsection{Experimental Control}

How will we know that the compounds we detect after desulfurization were actually released through desulfurization? We performed the desulfurization on the polar fraction of the total organic extract (TOE) because OSCs are most abundant in the polar fraction. We expected the desulfurization of this polar fraction to release nonpolar hydrocarbons. Isolating the nonpolar fraction from the reaction mixture after desulfurization should therefore isolate only nonpolar hydrocarbons released by desulfurization. However, we were concerned that the polar fraction contained nonpolar cross-contaminants before the desulfurization. If that were the case, we would have difficulty distinguishing contaminant compounds from desulfurized compounds.

Our sample preparation procedure used alumina-gel column fractionation to separate nonpolar free compounds from polar sulfur-bound compounds. Initially, we expected this separation to be complete. However, preliminary GC-FID traces of desulfurized fractions bore an uncanny resemblance to the GC-FID traces of the nonpolar fractions. This puzzling observation led us to modify our original procedure so that we could test the hypothesis that our fractionations were incomplete. We introduced a second alumina-gel column fractionation, shown in Figures 7 and 8, which produced "MinorNonpolar" fractions. 
If we were to observe that the Minor-Nonpolar fraction contained similar compounds to those in the Nonpolar fraction, then we would conclude that the first fractionation was incomplete. We would also suspect that the second fractionation was incomplete, since it followed the same method as the first fractionation. Even after two purifications of the polar fraction, we would expect to find a small remainder of nonpolar cross-contaminants in the Most-Polar fraction. If these contaminants were present in the desulfurization fraction, they would be difficult to distinguish from desulfurized hydrocarbons - unless we could deduce a released compound's authenticity using its retention time, abundance, or mass spectrum.

\section{$\underline{\text { Section } 2 \text { Endnotes }}$}

1. The ASE pumps solvent (DCM:Methanol 9:1) into a vessel containing the crushed rock sample (10.24 grams). The vessel is next heated to $\sim 100^{\circ} \mathrm{C}$ and pressurized to several atmospheres (double-check). After about 1 hour, the vessel depressurizes and the solvent flows out of the vessel, through a glass wool filter, and into a collection vial.

2. After removing the supernatant, we performed an additional series of 3x 3mL extractions in DCM:MeOH 9:1.

3. We determined the \% EOM by weighing the dried rock powder in a tared sample bag, and weighing the dried total organic extract in a tared $4 \mathrm{~mL}$ vial. 
4. The purpose of asphaltene precipitation is to separate compounds that are not amenable to GC analysis (asphaltenes) from compounds that are more likely to be amenable to GC analysis (maltenes). Asphaltenes have high molecular weights, are highly functionalized, and are heavily sulfide-linked. Maltenes are less funtionalized, lightly sulfide-linked, and often have lower molecular weights (Kohnen et al., 1991). Maltenes are soluble in a light hydrocarbon solvent such as heptane or hexane, in addition to more powerful (and more polar) solvents such as dichloromethane (DCM) or methanol $(\mathrm{MeOH})$. On the other hand, asphaltenes are only soluble in DCM or MeOH. Asphaltenes are nonvolatile (Sessions, pers. comm., 2009). Injecting nonvolatile compounds into a Gas Chromatography (GC) system will lead to a residual buildup on the inlet liner at the beginning of the column, eventually interfering with data quality.

Since maltenes and asphaltenes alike contain organic sulfur compounds (OSCs) (Sinninghe Damsté et al., 1988), we did not attempt to separate them before our first fractionation. We were indifferent to the possibility of asphaltenes eluting with our polar fraction, and thought that they could provide more material to desulfurize. Since we would only analyze the nonpolar yield of the desulfurization, we would not run the risk of dirtying the equipment with asphaltenes.

Modifying the usual alumina-gel column fractionation procedure, we loaded the column twice, not once, as follows: we washed the column with 4 mL DCM:MeOH 1:1 followed by 4 mL Hexane:DCM 9:1. We did a 3x 200 ul extraction in Hex:DCM 9:1 of the dry TOE, loaded the extract on to the column, and eluted it with $3.5 \mathrm{~mL} \mathrm{Hex:DCM}$ 9:1 to obtain the nonpolar fraction. Then, rather than immediately eluting the polar fraction with DCM:MeOH, we performed a second 3x $200 \mathrm{ul}$ extraction of the remaining 18 
TOE, using DCM:MeOH 1:1. We loaded the extract on to the column, and then eluted it with 3.5 mL DCM:MeOH 1:1 to obtain the polar fraction (Figs. 7, 8).

We loaded the column a second time because the first extractions with Hex/DCM 9/1 did not completely dissolve the TOE, and they left a lot of material in the sample vial. We assumed that this residual material contained polar organic sulfur compounds, which we wanted to desulfurize. We dissolved this (mostly asphaltene) residuum in DCM/ $\mathrm{MeOH}$ and loaded it on to the column.

During these experiments, we did not realize that the asphaltene-rich residue probably contained a small amount of nonpolar (maltene) compounds. Since the first extractions for column loading did not dissolve the entire dry TOE, they probably left behind a small amount of nonpolar (maltene) compounds in the asphaltene-rich residue. When we performed the second set of extractions using DCM:MeOH 1:1, we loaded a solution rich in polar asphaltenes and tinged with nonpolar maltenes on to a column that already contained polar maltenes. The second extraction unintentionally loaded a small amount of the nonpolar compounds (cross-contaminants), which eluted with the polar fraction.

5. We changed our procedure for isolating the reaction yield because someone discarded our centrifuge. For the Monterey-0, Blank-0, and standard desulfurizations A-D, we centrifuged the reaction test tube, transferred the supernatant to a $4 \mathrm{~mL}$ vial, and then performed 2x $2 \mathrm{~mL}$ DCM:MeOH 1:1 extractions on the solids remaining in the test tube, centrifuging as needed. We obtained the nonpolar yield fraction from this extract by $\mathrm{Al}_{2} \mathrm{O}_{3}$ fractionation. For all other desulfurizations (after the centrifuge 
became unavailable), we waited $\sim 10$ minutes for the nickel boride particles to settle, and transferred the supernatant to a $4 \mathrm{~mL}$ vial using a Pasteur pipet. We performed $2 \mathrm{x} 2 \mathrm{~mL}$ DCM extractions on the solids remaining in the test tube, allowing time for the particles to settle before supernatant transfer. We dried the yield extract in the $4 \mathrm{~mL}$ vial, and then loaded its nonpolar fraction on to a washed $\mathrm{Al}_{2} \mathrm{O}_{3}$ column with 3x 300 ul Hex:DCM 9:1 extractions. We eluted this fraction with $3 \mathrm{~mL}$ Hex:DCM 9:1.

6. However, the solvent dried out within 15 minutes because of either too high a temperature or too strong a nitrogen flow. We added additional solvent, lowered the temperature to $60^{\circ} \mathrm{C}$ (below reflux), and reduced the $\mathrm{N}_{2}$ stream.

7. We show in Fig. 10 additional Monterey and Blank fractions (not shown in Figure 7). We desulfurized the most-polar fractions of these aliquots using the procedure DS-0 (described in the text).

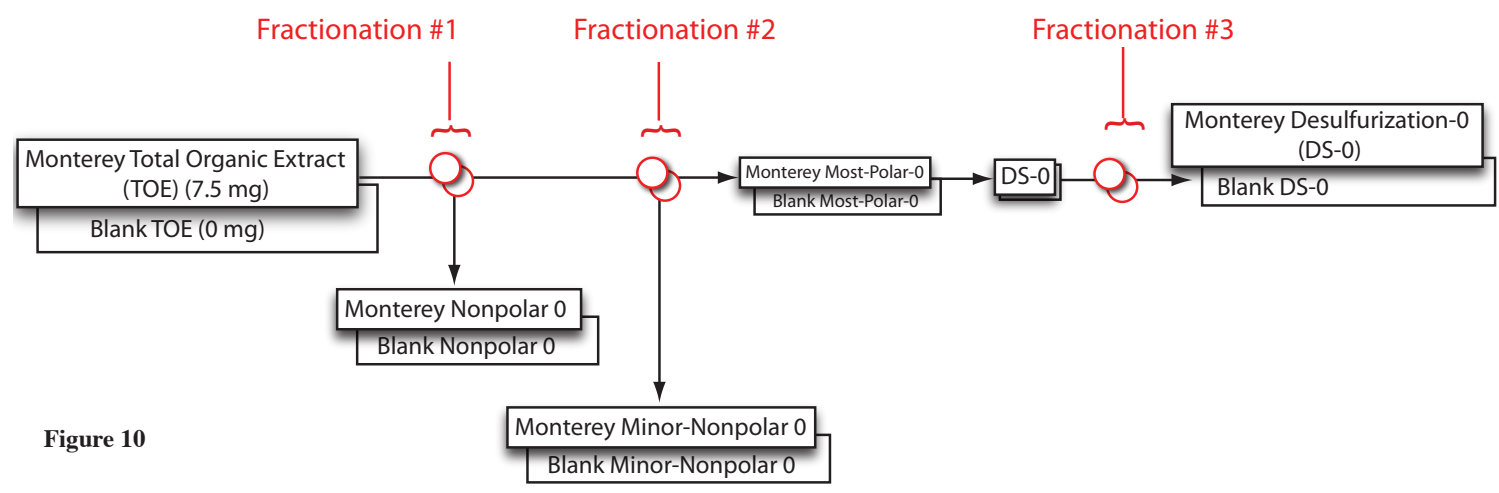

8. Samples with FID peaks lower than 20 pA may be too dilute for the GC-MS' sensitivity, while peaks taller than 500 pA can accumulate on the MS source and eventu20 
ally interfere with the instrument's function. For fractions with FID

chromatograms showing heights

outside this range, we concentrated

or diluted the sample as appropri-

ate.

9. We made two different

sets of calibration curves, and

applied each to a different part of

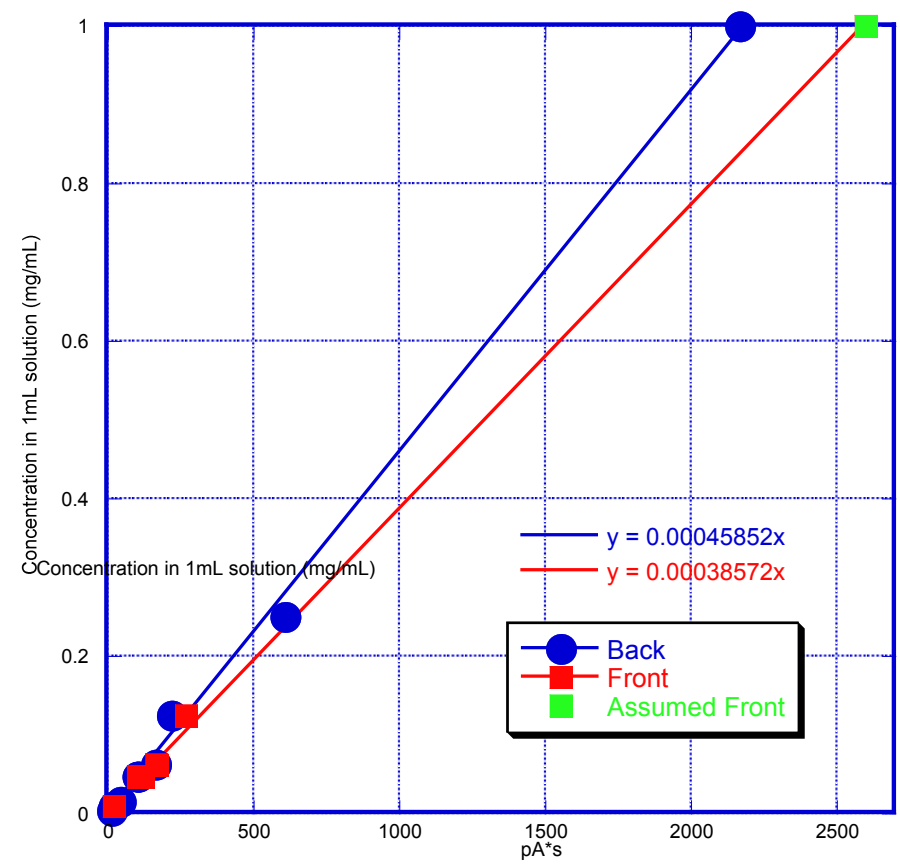

Figure 11. Calibration curves for the HMB standard, used to quantify the standard desulfurizations. "Assumed front" point as explained in figure 8 .

our data. We used the calibration

curves in figure 9 to quantify the desulfurization yield for our geochemical extracts, because we performed all of the GC-FID analyses for these data (samples and serial HMB dilutions) within the same 24 hours. We used the calibration curves shown in figure 11 to quantify the desulfurization yield for our standards, because we performed our standard reactions over the course of $\sim 2$ months, and we also measured HMB at different concentrations during this time period (6/12/08 to 8/24/08). The HMB measurements for the standards were made in 10:1 split mode, and the measurements for the samples were made in splitless mode.

10. Our blank extracts served both as a procedural control and as a test of standard desulfurization efficiency. Before dividing the Blank Most-Polar fraction into three aliquots, we added $3 \mathrm{mg}$ 1-octadecanethiol and $3 \mathrm{mg}$ S-Benzylthioglycolic acid to the 4.5 
$\mathrm{mL}$ solution. On the other hand, our blank-0 extracts served only as procedural controls (E-7), since we did not add any synthetic standard to these fractions.

11. GC-FID Methods

\begin{tabular}{l|l}
$\begin{array}{l}\text { Program } \alpha \\
\text { 10:1 Split } \\
\text { time, min }\end{array}$ & temp ${ }^{\circ} \mathrm{C}$ \\
\hline 0 & 40 \\
\hline 1 & 40 \\
\hline 19.33 & 315 \\
\hline 24.33 & 315
\end{tabular}

12. GC-MS Methods

\begin{tabular}{|c|c|}
\hline $\begin{array}{l}\text { Program } \varepsilon \\
\text { Splitless } \\
\text { time, min }\end{array}$ & temp \\
\hline 0 & 40 \\
\hline 1 & 40 \\
\hline 28.5 & 315 \\
\hline 38.5 & 315 \\
\hline
\end{tabular}

Program $\beta$

10:1 Split

\begin{tabular}{l|l} 
time, min & temp \\
\hline 0 & 40 \\
\hline 1 & 40 \\
\hline 25 & 100 \\
\hline 46.5 & 315 \\
\hline 56.5 & 315
\end{tabular}

\section{Program $\zeta$}

Splitless

\begin{tabular}{l|l} 
time, $\min$ & temp \\
\hline 0 & 40 \\
\hline 1 & 40 \\
\hline 37.67 & 315 \\
\hline 47.67 & 315
\end{tabular}

Program $\gamma$ - Splitless;

Program ס- 10:1 Split

\begin{tabular}{l|l} 
time, $\min$ & temp \\
\hline 0 & 40 \\
\hline 1 & 40 \\
\hline 28.5 & 315 \\
\hline 38.5 & 315
\end{tabular}

Program $\eta-10: 1$ Split

Program $\theta-20: 1$ Split

\begin{tabular}{l|l} 
time, min & temp \\
\hline 0 & 40 \\
\hline 1 & 40 \\
\hline 28.5 & 315 \\
\hline 38.5 & 315
\end{tabular}


13. Reference table for desulfurization and GC injection parameters. Much of the information in this table is explained throughout the text as necessary. Greek letters refer to GC-FID or GC-MS temperature programs, described in E-11 and E-12.

\begin{tabular}{|c|c|c|c|c|c|c|c|c|}
\hline \multirow[t]{2}{*}{ Sample } & \multicolumn{7}{|c|}{ Step of Workflow } & \multirow[b]{2}{*}{ VIII } \\
\hline & I & II & III & IV & $\mathbf{V}$ & VI & VII & \\
\hline & Nonpol FID & Nonpol MS & Min-Nonpol FID & $\begin{array}{l}\text { Min-Non- } \\
\text { pol MS }\end{array}$ & Division of Most-Polar & $\begin{array}{l}\text { Desulf reaction } \\
\text { conditions }\end{array}$ & Desulf FID & Desulf MS \\
\hline $\begin{array}{l}\text { Monterey } \\
\text { DS-1 }\end{array}$ & $\begin{array}{l}\text { Redissolve in } \\
50 \mathrm{uL} \mathrm{Hex/} \\
\text { DCM 9/1; } \\
\text { Inject 1uL } \\
\text { splitless (SL) } \\
(\gamma)\end{array}$ & $\begin{array}{l}\text { (No GC-MS } \\
\text { data) }\end{array}$ & $\begin{array}{l}\text { Redissolve in } \\
50 \text { uL Hex/ } \\
\text { DCM 9/1; } \\
\text { Inject 1uL } \\
\text { splitless (SL) } \\
(\gamma)\end{array}$ & $\begin{array}{l}\text { (No } \\
\text { GC-MS } \\
\text { data) }\end{array}$ & $\begin{array}{l}\text { Take } 1.5 \mathrm{~mL} \text { aliquot } \\
\text { (One-third of the ini- } \\
\text { tial } 4.5 \mathrm{~mL} \text { Most-Polar } \\
\text { solution) }\end{array}$ & $\begin{array}{l}\text { Heat reaction to } \\
60-70{ }^{\circ} \mathrm{C} \text {; use } \\
\mathrm{MeOH} \text { dried } \\
\text { with } \mathrm{Na}_{2} \mathrm{SO}_{4} \text {. }\end{array}$ & $\begin{array}{l}\text { Redissolve in } 50 \\
\text { uL Hex/DCM } \\
9 / 1 ; \text { Inject } 1 \mathrm{uL} \\
\text { splitless (SL) }(\gamma)\end{array}$ & $\begin{array}{l}\text { Redissolve in } \\
10 \text { uL Hex/ } \\
\text { DCM 9/1; } \\
\text { Manualinject } \\
\text { 1uL SL }(\varepsilon)\end{array}$ \\
\hline $\begin{array}{l}\text { Green- } \\
\text { land } \\
\text { DS-1 }\end{array}$ & $\begin{array}{l}\text { Redissolve } \\
\text { in } 1 \mathrm{~mL} \mathrm{Hex/} \\
\text { DCM 9/1; } \\
\text { Inject 1uL } \\
\text { SL }(\gamma)\end{array}$ & $\begin{array}{l}\text { Inject } 1 \mathrm{uL} \\
10: 1 \text { split } \\
(\eta)\end{array}$ & $\begin{array}{l}\text { Redissolve } \\
\text { in } 1 \mathrm{~mL} H e x / \\
\text { DCM } 9 / 1 ; \\
\text { Inject } 1 \mathrm{uL} \\
\text { SL }(\gamma)\end{array}$ & \begin{tabular}{|l|} 
(No \\
GC-MS \\
data)
\end{tabular} & $\begin{array}{l}\text { Take } 1.5 \mathrm{~mL} \text { aliquot } \\
\text { (One-third of the ini- } \\
\text { tial } 4.5 \mathrm{~mL} \text { Most-Polar } \\
\text { solution) }\end{array}$ & $\begin{array}{l}\text { Heat reaction to } \\
60-70^{\circ} \mathrm{C} \text {; use } \\
\mathrm{MeOH} \text { dried } \\
\text { with } \mathrm{Na}_{2} \mathrm{SO}_{4} \text {. }\end{array}$ & $\begin{array}{l}\text { Redissolve in } 1 \\
\mathrm{~mL} H e x / \mathrm{DCM} \\
9 / 1 ; \text { Inject } 1 \mathrm{uL} \\
\mathrm{SL}(\gamma)\end{array}$ & $\begin{array}{l}\text { Redissolve in } \\
100 \text { uL Hex/ } \\
\text { DCM 9/1; } \\
\text { Inject } 1 \text { uL } \\
\text { SL }(\varepsilon)\end{array}$ \\
\hline $\begin{array}{l}\text { Blank } \\
\text { DS-1 }\end{array}$ & $\begin{array}{l}\text { Redissolve in } \\
50 \text { uL Hex/ } \\
\text { DCM 9/1; } \\
\text { Inject 1uL } \\
\text { SL }(\gamma)\end{array}$ & $\begin{array}{l}\text { (No GC-MS } \\
\text { data) }\end{array}$ & $\begin{array}{l}\text { Redissolve in } \\
50 \text { uL Hex/ } \\
\text { DCM 9/1; } \\
\text { Inject } 1 \mathrm{uL} \\
\text { SL }(\gamma)\end{array}$ & \begin{tabular}{|l|} 
(No \\
GC-MS \\
data)
\end{tabular} & $\begin{array}{l}\text { Take } 1.5 \mathrm{~mL} \text { aliquot } \\
\text { (One-third of the ini- } \\
\text { tial } 4.5 \mathrm{~mL} \text { Most-Polar } \\
\text { solution) (E-10) }\end{array}$ & $\begin{array}{l}\text { Heat reaction to } \\
60-70^{\circ} \mathrm{C} \text {; use } \\
\mathrm{MeOH} \text { dried } \\
\text { with } \mathrm{Na}_{2} \mathrm{SO}_{4} \text {. }\end{array}$ & $\begin{array}{l}\text { Redissolve in } 1 \\
\text { mL Hex/DCM } \\
9 / 1 ; \text { Inject } 1 \mathrm{uL} \\
10: 1 \text { split }(\delta)\end{array}$ & $\begin{array}{l}\text { (No GC-MS } \\
\text { data) }\end{array}$ \\
\hline $\begin{array}{l}\text { Monterey } \\
\text { DS-2 }\end{array}$ & $\begin{array}{l}\text { (uses same } \\
\text { Nonpolar } \\
\text { FID data as } \\
\text { Monterey } \\
\text { DS-1) }\end{array}$ & $\begin{array}{l}\text { (No GC-MS } \\
\text { data) }\end{array}$ & $\begin{array}{l}\text { (same Minor- } \\
\text { Nonpolar } \\
\text { FID data as } \\
\text { Monterey } \\
\text { DS-1) }\end{array}$ & $\begin{array}{l}\text { (No } \\
\text { GC-MS } \\
\text { data) }\end{array}$ & $\begin{array}{l}\text { Take } 1.5 \mathrm{~mL} \text { aliquot } \\
\text { (One-third of the ini- } \\
\text { tial } 4.5 \mathrm{~mL} \text { Most-Polar } \\
\text { solution) }\end{array}$ & $\begin{array}{l}\sim 55^{\circ} \mathrm{C} \text {; } \\
\text { solvents dried } \\
\text { overnight with } \\
\text { 5A molecular } \\
\text { sieves. }\end{array}$ & $\begin{array}{l}\text { Redissolve in } 50 \\
\text { uL Hex/DCM } \\
9 / 1 ; \text { Inject } 1 \mathrm{uL} \\
\mathrm{SL}(\gamma)\end{array}$ & $\begin{array}{l}\text { Redissolve in } \\
10 \text { uL Hex/ } \\
\text { DCM 9/1; } \\
\text { Manualinject } \\
\text { 1uL SL }(\varepsilon)\end{array}$ \\
\hline $\begin{array}{l}\text { Green- } \\
\text { land } \\
\text { DS-2 }\end{array}$ & $\begin{array}{l}\text { (uses same } \\
\text { Nonpolar } \\
\text { FID data as } \\
\text { GreDS-1) }\end{array}$ & $\begin{array}{l}\text { (uses same } \\
\text { Nonpolar } \\
\text { MS data as } \\
\text { GreDS-1) }\end{array}$ & $\begin{array}{l}\text { (same Minor- } \\
\text { Nonpolar } \\
\text { FID data as } \\
\text { GreDS-1) }\end{array}$ & \begin{tabular}{|l|} 
(No \\
GC-MS \\
data)
\end{tabular} & $\begin{array}{l}\text { Take } 1.5 \mathrm{~mL} \text { aliquot } \\
\text { (One-third of the ini- } \\
\text { tial } 4.5 \mathrm{~mL} \text { Most-Polar } \\
\text { solution) }\end{array}$ & $\begin{array}{l}\sim 55^{\circ} \mathrm{C} \text {; } \\
\text { solvents dried } \\
\text { overnight with } \\
5 \mathrm{~A} \text { molecular } \\
\text { sieves. }\end{array}$ & $\begin{array}{l}\text { Redissolve in } 1 \\
\mathrm{~mL} \text { Hex/DCM } \\
9 / 1 ; \text { Inject } 1 \mathrm{uL} \\
\mathrm{SL}(\gamma)\end{array}$ & $\begin{array}{l}\text { Inject } 1 \text { uL } \\
\text { SL }(\varepsilon)\end{array}$ \\
\hline $\begin{array}{l}\text { Blank } \\
\text { DS-2 }\end{array}$ & \begin{tabular}{|l|} 
(uses same \\
Nonpolar \\
FID data as \\
Blank DS-1)
\end{tabular} & $\begin{array}{l}\text { (No GC-MS } \\
\text { data) }\end{array}$ & $\begin{array}{l}\text { (same Minor- } \\
\text { Nonpolar FID } \\
\text { data as Blank } \\
\text { DS-1) }\end{array}$ & \begin{tabular}{|l|} 
(No \\
GC-MS \\
data)
\end{tabular} & $\begin{array}{l}\text { Take } 1.5 \mathrm{~mL} \text { aliquot } \\
\text { (One-third of the ini- } \\
\text { tial } 4.5 \mathrm{~mL} \text { Most-Polar } \\
\text { solution) (E-10) }\end{array}$ & $\begin{array}{l}\sim 55^{\circ} \mathrm{C} \text {; } \\
\text { solvents dried } \\
\text { overnight with } \\
\text { 5A molecular } \\
\text { sieves. }\end{array}$ & $\begin{array}{l}\text { Redissolve in } 1 \\
\text { mL Hex/DCM } \\
9 / 1 ; \text { Inject } 1 \mathrm{uL} \\
10: 1 \text { split }(\delta)\end{array}$ & $\begin{array}{l}\text { Inject } 1 \mathrm{uL} \\
20: 1 \text { split }(\theta)\end{array}$ \\
\hline $\begin{array}{l}\text { Monterey } \\
\text { DS-3 }\end{array}$ & $\begin{array}{l}\text { (uses same } \\
\text { Nonpolar } \\
\text { FID data as } \\
\text { Monterey } \\
\text { DS-1) }\end{array}$ & $\begin{array}{l}\text { (No GC-MS } \\
\text { data) }\end{array}$ & $\begin{array}{l}\text { (same Minor- } \\
\text { Nonpolar } \\
\text { FID data as } \\
\text { Monterey } \\
\text { DS-1) }\end{array}$ & \begin{tabular}{|l} 
(No \\
GC-MS \\
data)
\end{tabular} & $\begin{array}{l}\text { Take } 1.5 \mathrm{~mL} \text { aliquot } \\
\text { (One-third of the ini- } \\
\text { tial } 4.5 \mathrm{~mL} \text { Most-Polar } \\
\text { solution) }\end{array}$ & $\begin{array}{l}\text { Same as DS-2 } \\
\text { but } \sim 100 \mathrm{mg} \text { ad- } \\
\text { ditional } \mathrm{NaBH}_{4} \\
\text { added after } 30 \\
\text { mins }\end{array}$ & $\begin{array}{l}\text { Redissolve in } 50 \\
\text { uL Hex/DCM } \\
9 / 1 ; \text { Inject } 1 \mathrm{uL} \\
\text { SL }(\gamma)\end{array}$ & $\begin{array}{l}\text { Redissolve in } \\
10 \text { uL Hex/ } \\
\text { DCM 9/1; } \\
\text { Manualinject } \\
\text { 1uL SL }(\varepsilon)\end{array}$ \\
\hline $\begin{array}{l}\text { Green- } \\
\text { land } \\
\text { DS-3 }\end{array}$ & $\begin{array}{l}\text { (uses same } \\
\text { Nonpolar } \\
\text { FID data as } \\
\text { GreDS-1) }\end{array}$ & $\begin{array}{l}\text { (uses same } \\
\text { Nonpolar } \\
\text { MS data as } \\
\text { GreDS-1) }\end{array}$ & $\begin{array}{l}\text { (same Minor- } \\
\text { Nonpolar } \\
\text { FID data as } \\
\text { GreDS-1) }\end{array}$ & $\begin{array}{l}\text { (No } \\
\text { GC-MS } \\
\text { data) }\end{array}$ & $\begin{array}{l}\text { Take } 1.5 \mathrm{~mL} \text { aliquot } \\
\text { (One-third of the ini- } \\
\text { tial } 4.5 \mathrm{~mL} \text { Most-Polar } \\
\text { solution) }\end{array}$ & $\begin{array}{l}\text { Same as DS-2 } \\
\text { but } \sim 100 \mathrm{mg} \text { ad- } \\
\text { ditional } \mathrm{NaBH}_{4} \\
\text { added after } 30 \\
\text { mins }\end{array}$ & $\begin{array}{l}\text { Redissolve in } 1 \\
\mathrm{~mL} \text { Hex/DCM } \\
9 / 1 ; \text { Inject } 1 \mathrm{uL} \\
\mathrm{SL}(\gamma)\end{array}$ & $\begin{array}{l}\text { (No GC-MS } \\
\text { data) }\end{array}$ \\
\hline $\begin{array}{l}\text { Blank } \\
\text { DS-3 }\end{array}$ & $\begin{array}{l}\text { (uses same } \\
\text { Nonpolar } \\
\text { FID data as } \\
\text { Blank DS-1) }\end{array}$ & $\begin{array}{l}\text { (No GC-MS } \\
\text { data) }\end{array}$ & $\begin{array}{l}\text { (same Minor- } \\
\text { Nonpolar FID } \\
\text { data as Blank } \\
\text { DS-1) }\end{array}$ & \begin{tabular}{|l|} 
(No \\
GC-MS \\
data)
\end{tabular} & $\begin{array}{l}\text { Take } 1.5 \mathrm{~mL} \text { aliquot } \\
\text { (One-third of the ini- } \\
\text { tial } 4.5 \mathrm{~mL} \text { Most-Polar } \\
\text { solution) (E-10) }\end{array}$ & $\begin{array}{l}\text { Same as DS-2 } \\
\text { but } \sim 100 \mathrm{mg} \text { ad- } \\
\text { ditional } \mathrm{NaBH}_{4} \\
\text { added after } 30 \\
\text { mins }\end{array}$ & $\begin{array}{l}\text { Redissolve in } 1 \\
\text { mL Hex/DCM } \\
9 / 1 ; \text { Inject } 1 \mathrm{uL} \\
10: 1 \text { split }(\delta)\end{array}$ & $\begin{array}{l}\text { (No GC-MS } \\
\text { data) }\end{array}$ \\
\hline $\begin{array}{l}\text { Monterey } \\
\text { DS-0 }\end{array}$ & $\begin{array}{l}\text { Redissolve in } \\
50 \text { uL Hex/ } \\
\text { DCM 9/1; } \\
\text { Inject 1uL } \\
\text { SL }(\gamma)\end{array}$ & $\begin{array}{l}\text { Redissolve } \\
\text { in } 250 \mathrm{uL} \\
\text { Hex/DCM } \\
9 / 1 ; \text { Inject } 1 \\
\text { uL SL (६) }\end{array}$ & $\begin{array}{l}\text { Redissolve in } \\
50 \mathrm{uL} \mathrm{Hex} / \\
\text { DCM } 9 / 1 ; \\
\text { Inject } 1 \mathrm{uL} \\
\text { SL }(\gamma)\end{array}$ & $\begin{array}{l}\text { Inject } 1 \\
\mathrm{uL} \mathrm{SL} \\
(\varepsilon, \zeta)\end{array}$ & Entire fraction & $\begin{array}{l}50{ }^{\circ} \mathrm{C}, \mathrm{MeOH} \\
\text { dried with } \\
\mathrm{Na}_{2} \mathrm{SO}_{4}\end{array}$ & $\begin{array}{l}\text { Redissolve in } 50 \\
\text { uL Hex/DCM } \\
9 / 1 ; \text { Inject } 1 \mathrm{uL} \\
\text { SL }(\gamma)\end{array}$ & $\begin{array}{l}\text { Redissolve in } \\
10 \text { uL Hex/ } \\
\text { DCM 9/1; } \\
\text { Manualinject } \\
\text { 1uL SL }(\varepsilon)\end{array}$ \\
\hline $\begin{array}{l}\text { Blank } \\
\text { DS-0 }\end{array}$ & $\begin{array}{l}\text { Redissolve in } \\
50 \text { uL Hex/ } \\
\text { DCM 9/1; } \\
\text { Inject 1uL } \\
\text { SL }(\gamma)\end{array}$ & $\begin{array}{l}\text { Redissolve } \\
\text { in } 250 \mathrm{uL} \\
\text { Hex/DCM } \\
9 / 1 ; \text { Inject } 1 \\
\text { uL SL ( }(\zeta)\end{array}$ & $\begin{array}{l}\text { Redissolve in } \\
50 \text { uL Hex/ } \\
\text { DCM 9/1; } \\
\text { Inject 1uL } \\
\text { SL }(\gamma)\end{array}$ & $\begin{array}{l}\text { Inject } 1 \\
\text { uL SL } \\
(\varepsilon)\end{array}$ & Entire & $\begin{array}{l}50{ }^{\circ} \mathrm{C}, \mathrm{MeOH} \\
\text { dried with } \\
\mathrm{Na}_{2} \mathrm{SO}_{4}\end{array}$ & $\begin{array}{l}\text { Redissolve in } 50 \\
\text { uL Hex/DCM } \\
9 / 1 ; \text { Inject } 1 \mathrm{uL} \\
\text { SL }(\gamma)\end{array}$ & $\begin{array}{l}\text { Redissolve in } \\
10 \text { uL Hex/ } \\
\text { DCM 9/1; } \\
\text { Manualinject } \\
\text { 1uL SL }(\varepsilon)\end{array}$ \\
\hline
\end{tabular}




\section{Results}

\section{$\underline{3.1 . ~ O v e r v i e w}$}

Here we report on the desulfurization of synthetic standards and sedimentary extracts. We show the standard reactions in Table 1 and figure 12. We show the desulfurized compounds for Monterey in figures 13 and 14, and for Greenland in figures 17 and 18. We also report on the compounds found in the nonpolar fractions of these extracts, and compare the free nonpolar hydrocarbons to the nonpolar hydrocarbons released by desulfurization.

\subsection{Standards}

We desulfurized the standards 1-octadecanethiol and S-Benzylthioglycolic acid. (See fig. 4 for the structures of these compounds.) These reactions gave yields between $16 \%$ and $92 \%$ (Table 1).

Table 1. Desulfurizations of synthetic standards and reaction yields.

\begin{tabular}{|c|c|c|c|c|c|}
\hline $\begin{array}{l}\text { Standards and Re- } \\
\text { agents }\end{array}$ & $\begin{array}{l}\text { Procedure (cf. sec- } \\
\text { tion 2.4) }\end{array}$ & 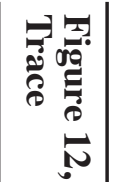 & $\begin{array}{l}\text { Peak Area } \\
\left(\mathrm{pA}^{*} \mathrm{~s}\right) \\
\text { (b)ack column } \\
\text { (f)ront column }\end{array}$ & $\begin{array}{l}\text { Com- } \\
\text { pound } \\
\text { Mass } \\
(\mathrm{mg})\end{array}$ & $\begin{array}{l}\% \text { Yield (Moles } \\
\text { yield/ moles } \\
\text { standard)*100 }\end{array}$ \\
\hline $\begin{array}{l}16.5 \mathrm{mg} \mathrm{1-octade-} \\
\text { canethiol } \\
106.4 \mathrm{mg} \mathrm{NiCl} \\
104.9 \mathrm{mg} \mathrm{NaBH}_{4}\end{array}$ & $\begin{array}{l}\text { DS-0; } 4 \mathrm{~mL} \text { solvent } \\
\text { volume }\end{array}$ & & $\begin{array}{l}\text { (no GC-FID } \\
\text { data) }\end{array}$ & $\mathrm{n} / \mathrm{a}$ & $\mathrm{n} / \mathrm{a}$ \\
\hline $\begin{array}{l}2.19 \mathrm{mg} \mathrm{1-octade-} \\
\text { canethiol } \\
18 \mathrm{mg} \mathrm{NiCl}_{2} \\
14.1 \mathrm{mg} \mathrm{NaBH}_{4} \\
\end{array}$ & $\begin{array}{l}\text { DS- } 0 ; 2 \mathrm{~mL} \text { solvent } \\
\text { volume }\end{array}$ & A & $\begin{array}{l}156.41(\mathrm{~b}) \\
\text { (using a } 10 \% \text { aliquot) }\end{array}$ & 0.717 & $36.9 \%$ \\
\hline $\begin{array}{l}2.1 \mathrm{mg} 1 \text {-octadecane- } \\
\text { thiol } \\
41.1 \mathrm{mg} \mathrm{NiCl}_{2} \\
38.7 \mathrm{mg} \mathrm{NaBH}_{4}\end{array}$ & $\begin{array}{l}\text { DS-0; } 2 \mathrm{~mL} \text { solvent } \\
\text { volume }\end{array}$ & B & $663.2(b)$ & 0.304 & $16.3 \%$ \\
\hline
\end{tabular}




\begin{tabular}{|c|c|c|c|c|c|}
\hline $\begin{array}{l}\text { Standards and Re- } \\
\text { agents }\end{array}$ & $\begin{array}{l}\text { Procedure (cf. sec- } \\
\text { tion 2.4) }\end{array}$ & 官 & $\begin{array}{l}\text { Peak Area } \\
(\mathrm{pA} * \mathrm{~s}) \\
\text { (b)ack column } \\
\text { (f)ront column }\end{array}$ & $\begin{array}{l}\text { Com- } \\
\text { pound } \\
\text { Mass } \\
(\mathrm{mg})\end{array}$ & $\begin{array}{l}\% \text { Yield (Moles } \\
\text { yield/ moles } \\
\text { standard)*100 }\end{array}$ \\
\hline $\begin{array}{l}2.1 \mathrm{mg} \text { 1-octadecane- } \\
\text { thiol } \\
43.8 \mathrm{mg} \mathrm{NiCl}_{2} \\
39.1 \mathrm{mg} \mathrm{NaBH}_{4}\end{array}$ & $\begin{array}{l}\text { DS-0; } 2 \mathrm{~mL} \text { solvent } \\
\text { volume }\end{array}$ & $\mathrm{C}$ & $818.2(\mathrm{f})$ & 0.316 & $16.9 \%$ \\
\hline $\begin{array}{l}2.1 \mathrm{mg} \text { 1-octadecane- } \\
\text { thiol } \\
46.8 \mathrm{mg} \mathrm{NiCl}_{2} \\
49.9 \mathrm{mg} \mathrm{NaBH}_{4}\end{array}$ & $\begin{array}{l}\text { Temp }=25^{\circ} \mathrm{C} ; \\
\text { solvents }=(2 \mathrm{~mL} \\
\mathrm{MeOH}+2 \mathrm{~mL} \\
\mathrm{Hex}) ; \mathrm{MeOH} \text { dried } \\
\text { w. } \mathrm{Na}_{2} \mathrm{SO}_{4}\end{array}$ & $\mathrm{D}$ & $\begin{array}{l}252.5 \text { (f) } \\
\text { (octadecane) } \\
\text { (using a 20\% aliquot) }\end{array}$ & 0.487 & $26.1 \%$ \\
\hline $\begin{array}{l}2.16 \mathrm{mg} \mathrm{S-Benzylth}- \\
\text { ioglycolic acid } \\
46.8 \mathrm{mg} \mathrm{NiCl}_{2} \\
49.9 \mathrm{mg} \mathrm{NaBH}_{4}\end{array}$ & $\begin{array}{l}\text { Temp }=25^{\circ} \mathrm{C} ; \\
\text { solvents }=(2 \mathrm{~mL} \\
\mathrm{MeOH}+2 \mathrm{~mL} \\
\mathrm{Hex}) ; \mathrm{MeOH} \text { dried } \\
\text { w. } \mathrm{Na}_{2} \mathrm{SO}_{4}\end{array}$ & $\mathrm{D}$ & $\begin{array}{l}217.4 \text { (f) } \\
\text { (toluene) } \\
\text { (using a 20\% aliquot) }\end{array}$ & 0.419 & $38.4 \%$ \\
\hline $\begin{array}{l}1 \mathrm{mg} 1 \text {-octadecane- } \\
\text { thiol } \\
108 \mathrm{mg} \mathrm{NiCl}_{2} \\
111 \mathrm{mg} \mathrm{NaBH}_{4}\end{array}$ & $\begin{array}{l}\text { DS-1; } 4 \mathrm{~mL} \text { solvent } \\
\text { volume }\end{array}$ & $E$ & 1980.52 (f) & 0.764 & $86.0 \%$ \\
\hline $\begin{array}{l}1 \mathrm{mg} 1 \text {-octadecane- } \\
\text { thiol } \\
103 \mathrm{mg} \mathrm{NiCl}_{2} \\
103 \mathrm{mg} \mathrm{NaBH}_{4}\end{array}$ & $\begin{array}{l}\text { DS-2; } 4 \text { mL solvent } \\
\text { volume }\end{array}$ & $\mathrm{F}$ & 2112.50 (f) & 0.815 & $91.8 \%$ \\
\hline $\begin{array}{l}1 \mathrm{mg} \mathrm{1-octadecane-} \\
\text { thiol } \\
90 \mathrm{mg} \mathrm{NiCl}_{2} \\
\sim 104 \mathrm{mg} \mathrm{NaBH}_{4} \\
+130 \mathrm{mg} \mathrm{NaBH}_{4} \text { after } \\
30 \mathrm{mins}\end{array}$ & $\begin{array}{l}\text { DS-3; } 4 \mathrm{~mL} \text { solvent } \\
\text { volume }\end{array}$ & G & 1490.29 (f) & 0.575 & $64.7 \%$ \\
\hline
\end{tabular}




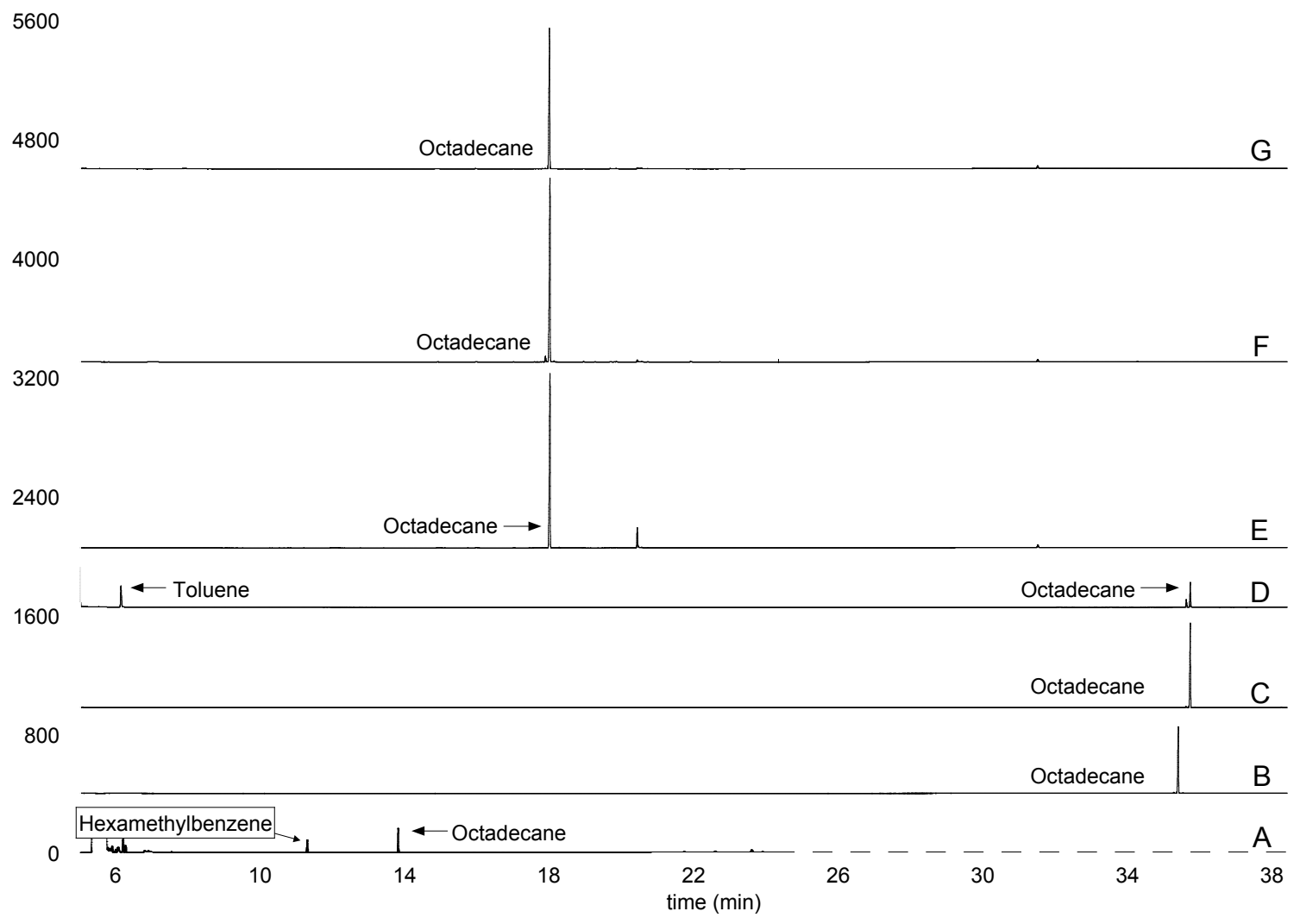

Figure 12. GC-FID chromatograms for standard desulfurizations. The desulfurized standard elutes at different times because we used different temperature programs for some runs (Methods, Endnote 12). Trace A used program $\alpha$. Traces B-D used program $\beta$. Traces E-G used program $\delta$. The octadecane peak elutes slightly sooner in trace B than it does in trace $\mathrm{C}$ because these two runs were each on a different column. 


\subsection{Monterey desulfurization fraction}

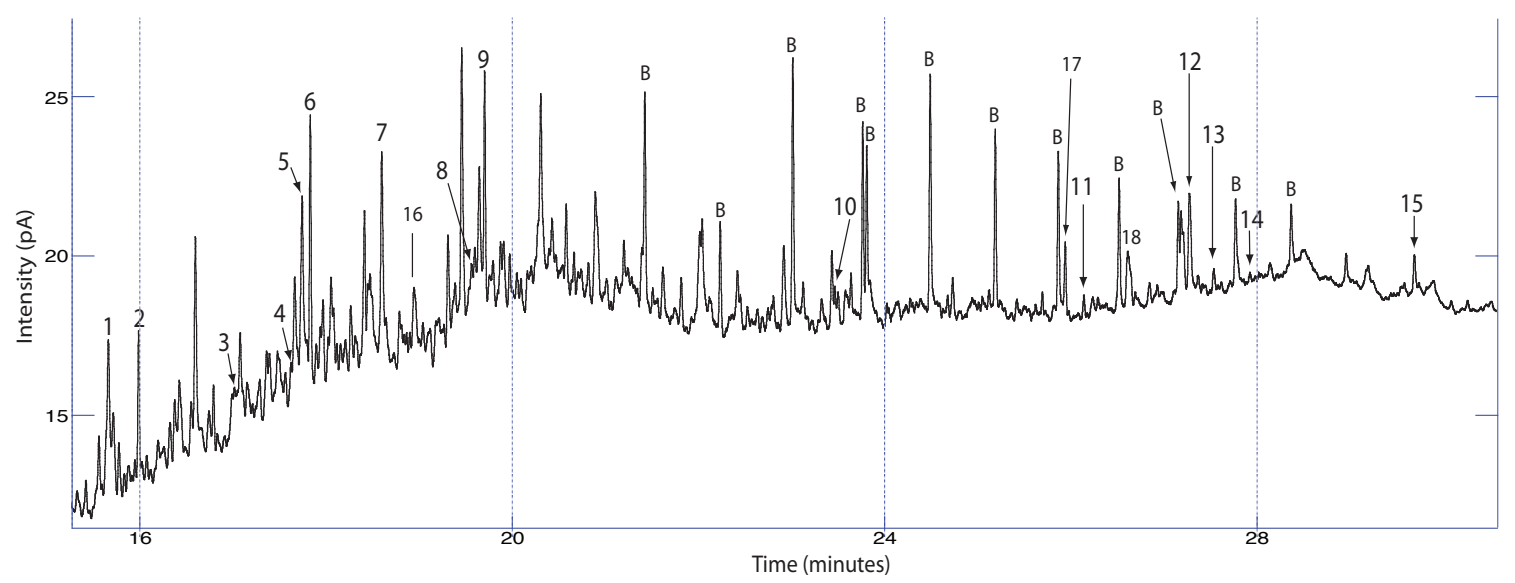

Figure 13. Monterey Desulfurization Fraction, GC-FID Trace. Numbered peaks refer to figure 14. (B) indicates the compound is also present in the blank desulfurization fraction at a similar abundance (E-1). This chromatogram is from analysis of the Monterey DS-3 sample, which typifies the other Monterey samples.

The Monterey desulfurization fraction contains a straight-chain alkane and a branched alkane (compounds 6 and 9). Cholestane and other steroids are present (11, 13-15). Other isoprenoids are beta-Tocopherol (12), delta-Tocopherol (18), and Lycopene (17). Lycopene may also be present in the nonpolar fraction. We see heterocyclic compounds $(3,5,10,16)$ and nitrogenous compounds $(1,8)$. Compounds 12 and 15 may be misidentified terpenoids; their peaks are relatively rich with an ion $(\mathrm{m} / \mathrm{z} 191)$ that is characteristic for this compound class (Forster et al., 2004; Schouten et al., 2001). Convoluted mass spectra reduce our confidence in the compound assignments for the following peaks: 5, 10, and $16(\mathbf{E}-2)$.

Many peaks in the Monterey desulfurization are unidentifiable because a high baseline obscures them in both the GC-MS and the GC-FID chromatograms. For example, unsaturated steroid hydrocarbons may be under-reported here because their characteristic ions (e.g. m/z 257) (Forster et al., 2004) are overwhelmed by the ions of coeluting 
compounds (e.g. m/z 57) (E-3). The high baseline indicates that this fraction contains an unresolved complex mixture (UCM) of coeluting compounds. Sutton et al. (2005) estimated that a UCM could contain 250,000 unique compounds.

Some of the compounds in Monterey DS-3 were not found in other Monterey desulfurized fractions; the DS-0 fraction was particularly disagreeable. We found differences between the baseline shape of the Monterey-0 fractions and the other Monterey fractions (E-4). Such baseline shifts may have affected the signal-noise difference calculation used to extract a mass spectrum for each peak, thereby leading to disagreements over peak identities. 

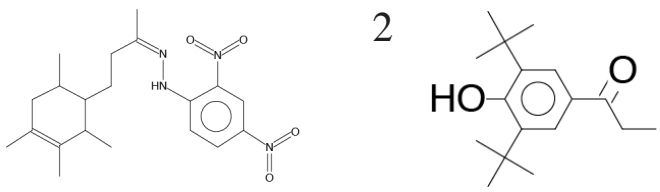

3

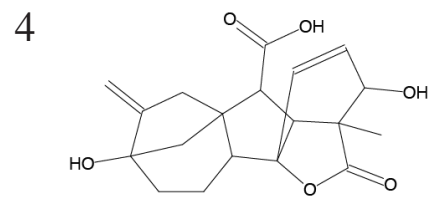

5
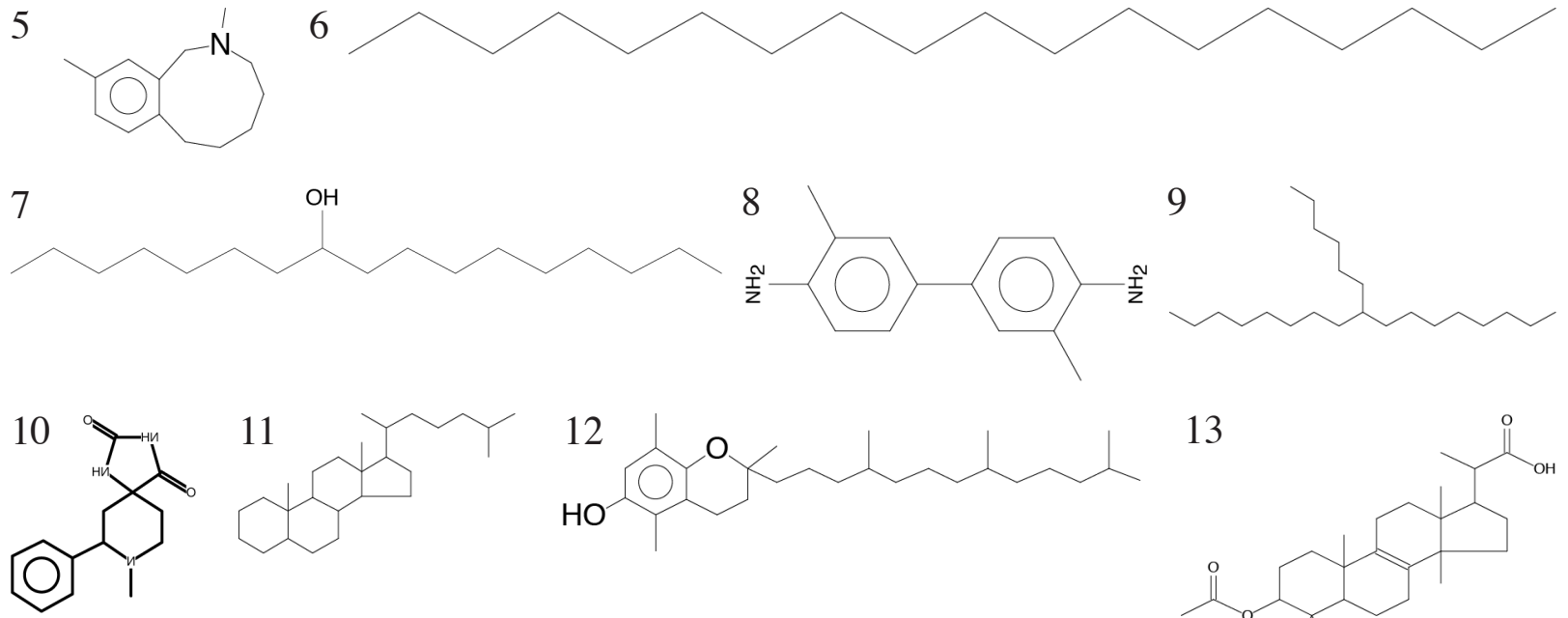

9<smiles>Cc1cc(O)c(C)c2c1OC(C)(CCCC(C)CCCC(C)CCCC(C)C)CC2</smiles><smiles>CC(=O)OC1CCC23CCCC4(C)C(=C2CCC13C)CCC4C(C)C(C)C(=O)O</smiles><smiles>CC(=O)CCC(C)C1CCC2(C)C3=C(CCC12C)C1(C)CCC(CC(C)=O)C(C)(C)C1CC3</smiles>

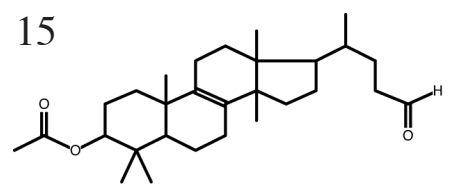

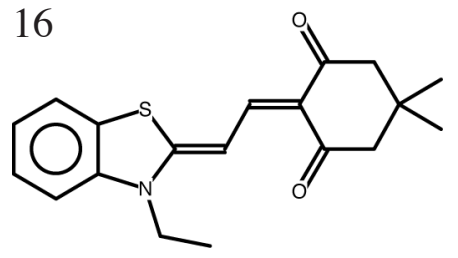<smiles>CC(C)=CCC/C(C)=C\CC/C=C(\C)CC/C=C(\C)CC/C=C(\C)CC/C=C(\C)CC/C=C(\C)CC/C=C(\C)CCC=C(C)C</smiles><smiles>Cc1cc(O)cc2c1OC(C)(CCCC(C)CCCC(C)CCCC(C)C)CC2</smiles>

\begin{tabular}{ll}
\hline 1 & 4-(cis-2,3,4,trans-6-Tetramethyl-3-cyclohexenyl)butan-2-one 2,4-dinitrophenylhydrazone \\
\hline 2 & 2,6-Bis(1,1-dimethylethyl)-4-(1-oxopropyl)phenol \\
\hline $3^{0}$ & 4-Acetyl-1,2,3,4-tetrahydro-2-oxoquinoline \\
\hline $4^{0}$ & Gibberellic acid \\
\hline 5 & 2,10-Dimethyl-2,3,4,5,6,7-hexahydro-1H-2-benzazonine \\
\hline 6 & Octadecane \\
\hline 7 & 8-Heptadecanol \\
\hline $8^{02}$ & [1,1'-Biphenyl]-4,4'-diamine, 3,3'-dimethyl \\
\hline 9 & Heptadecane, 9-hexyl- \\
\hline $10^{0}$ & 8-Methyl-7-phenyl-1,3,8-triazaspiro[4.5]decan-2,4-dione \\
\hline 11 & Cholestane \\
\hline 12 & beta-Tocopherol \\
\hline 13 & Propanoic acid, 2-(3-acetoxy-4,4,14-trimethylandrost-8-en-17-yl)- \\
\hline $14^{0}$ & Chol-8-en-24-al, 3-(acetyloxy)-4,4,14-trimethyl-, (3.beta.,5.alpha.)- \\
\hline $15^{012}$ & Chol-8-en-24-al, 3-(acetyloxy)-4,4,14-trimethyl-, (3.beta.,5.alpha.)- \\
\hline 16 & 1-(5,5-Dimethyl-1,3-dioxocyclohexan-2-yli den)-2-(N-ethylbenzthiazol-2-yliden)-ethan \\
\hline 17 & psi.,psi-Carotene, 7,7',8,8',11,11',12,12',15,15'-decahydro- \\
\hline 18 & delta-Tocopherol \\
\hline
\end{tabular}

Figure 14. Monterey desulfurization compound structures and names.

${ }^{0}$ Not found in the Monterey DS-0 fraction; ${ }^{1}$ Not found in the Monterey DS-1 fraction; ${ }^{2}$ Not found in the Monterey DS-2 fraction. 


\subsection{Monterey nonpolar fraction}

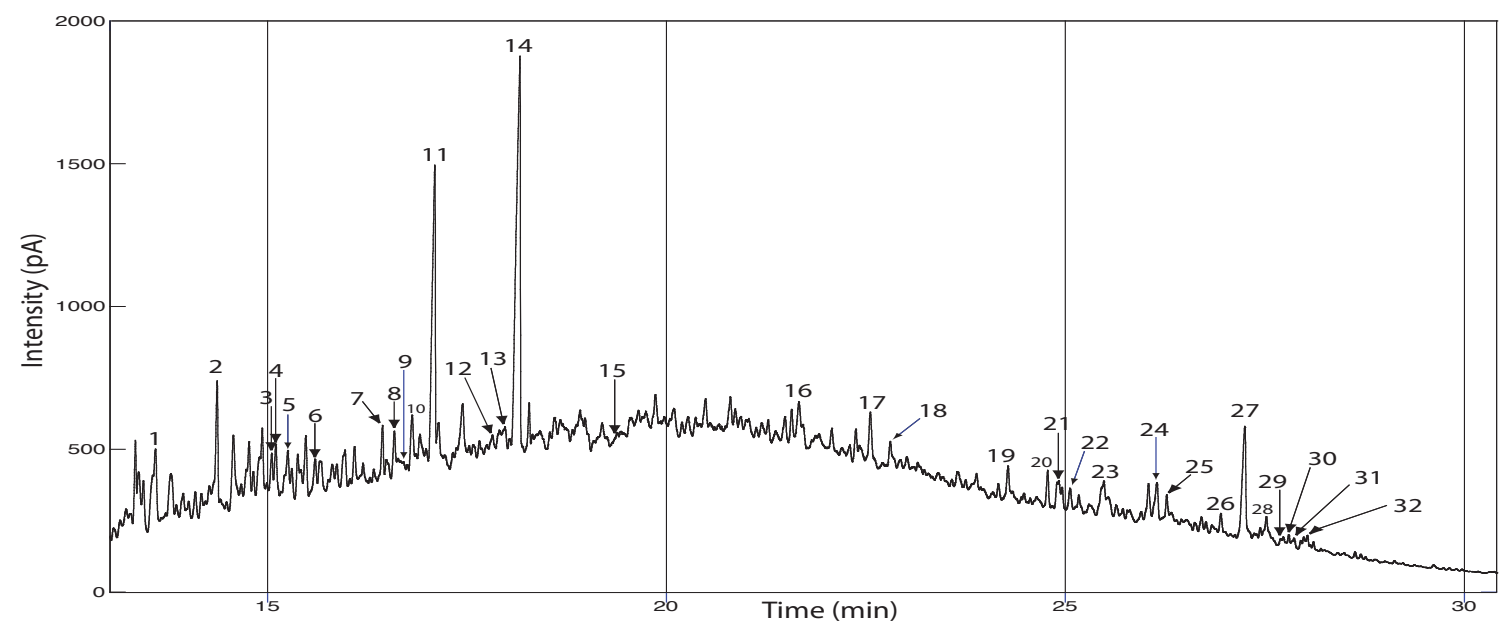

Figure 15. Monterey Nonpolar Fraction, GC-FID Trace. Numbered peaks refer to figure 16.

The Monterey nonpolar fraction contains phytane (14), pristane (11), a trimethyl

alkane (7), and a dimethyl alkane (2). We find a series of methyl- and isopropyl-substituted polycyclic aromatic hydrocarbons $(1,3-5,6,8,9)$. We see a benzothiophene (13), and other heterocyclic compounds $(10,15,26,31)$. We see a phenolic alcohol (22), a phenolic ester (23), and a substituted biphenyl compound (12). We find a series of steroids, whose hydrocarbon skeletons are cholestane (19-21,25), stigmasterane (28), and unusual $(16,24,30)$. We see non-steroid polycyclic terpenoids $(17,1827,29,32)$. Although not detectable by GC-FID, the GC-MS data show that cyclic octatomic sulfur is present in the Monterey nonpolar fraction. Convoluted mass spectra reduce our confidence in the compound assignments for the following peaks: 1, 6, 7, 10, 12, 13, 22, 23, 25, 29, 30, and 32. As is the case for the Monterey desulfurization fraction, the Monterey nonpolar fraction has a UCM with many co-eluting compounds. The $\mathrm{m} / \mathrm{z} 57$ ion is very depleted in the retention range of C15-C35 n-alkanes, although pristane and phytane are abundant (E-5). 
The depletion of long-chain n-alkanes indicates that this sample's biodegradation level is “moderate," using Wenger and Isaksen's (2002) scale.

Figure 15 is a composite of information from two nonpolar fractions. The trace is from GC-FID analysis of the Monterey Nonpolar fraction, and the numbered peaks were selected using GC-MS data for the Monterey Nonpolar-0 fraction (Methods endnote 7). The two fractions contain the same compounds, although compound ratios may differ (Results endnote 4). 


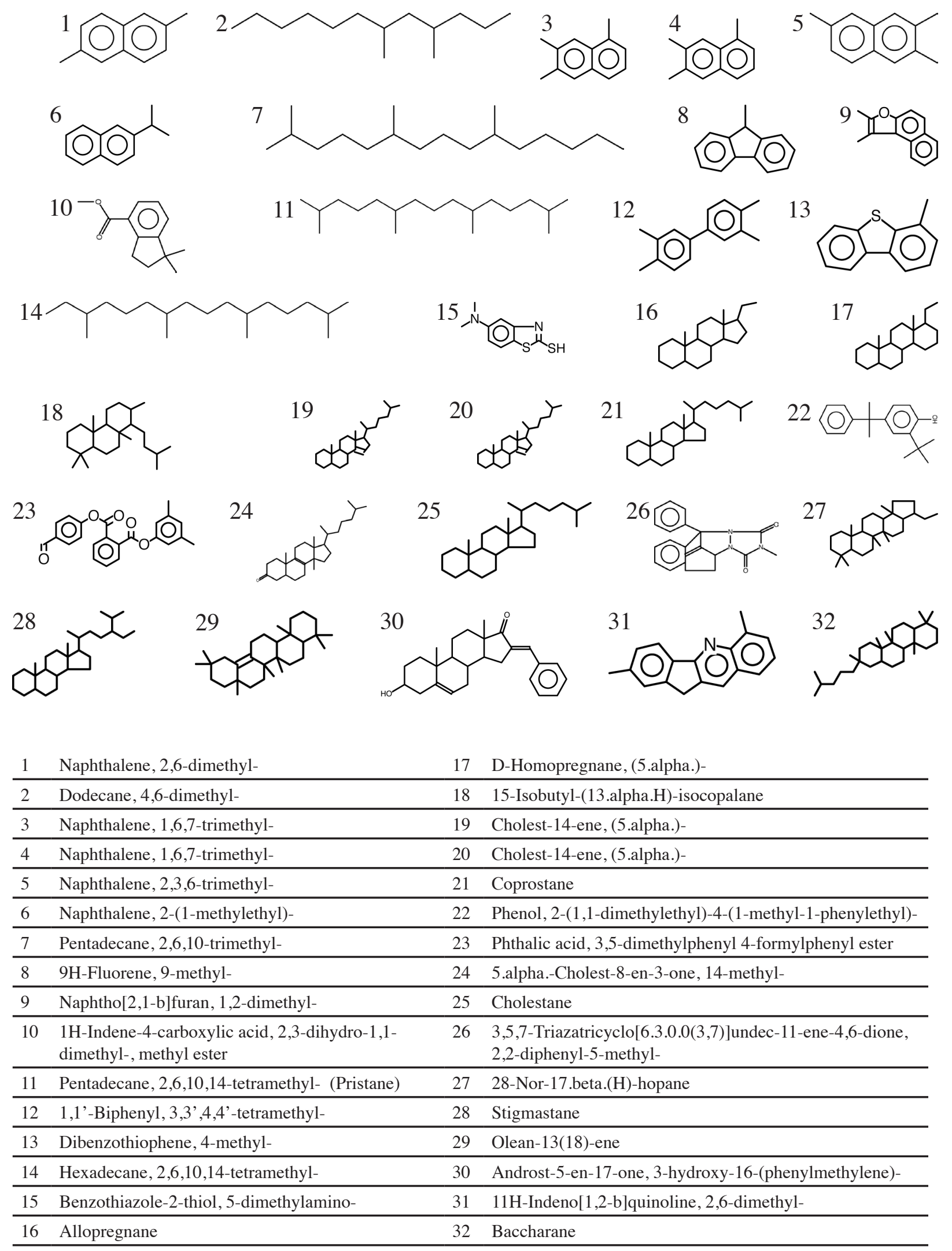

Figure 16. Monterey Nonpolar fraction. Compound structures and names. 


\subsection{Greenland Desulfurization fraction}

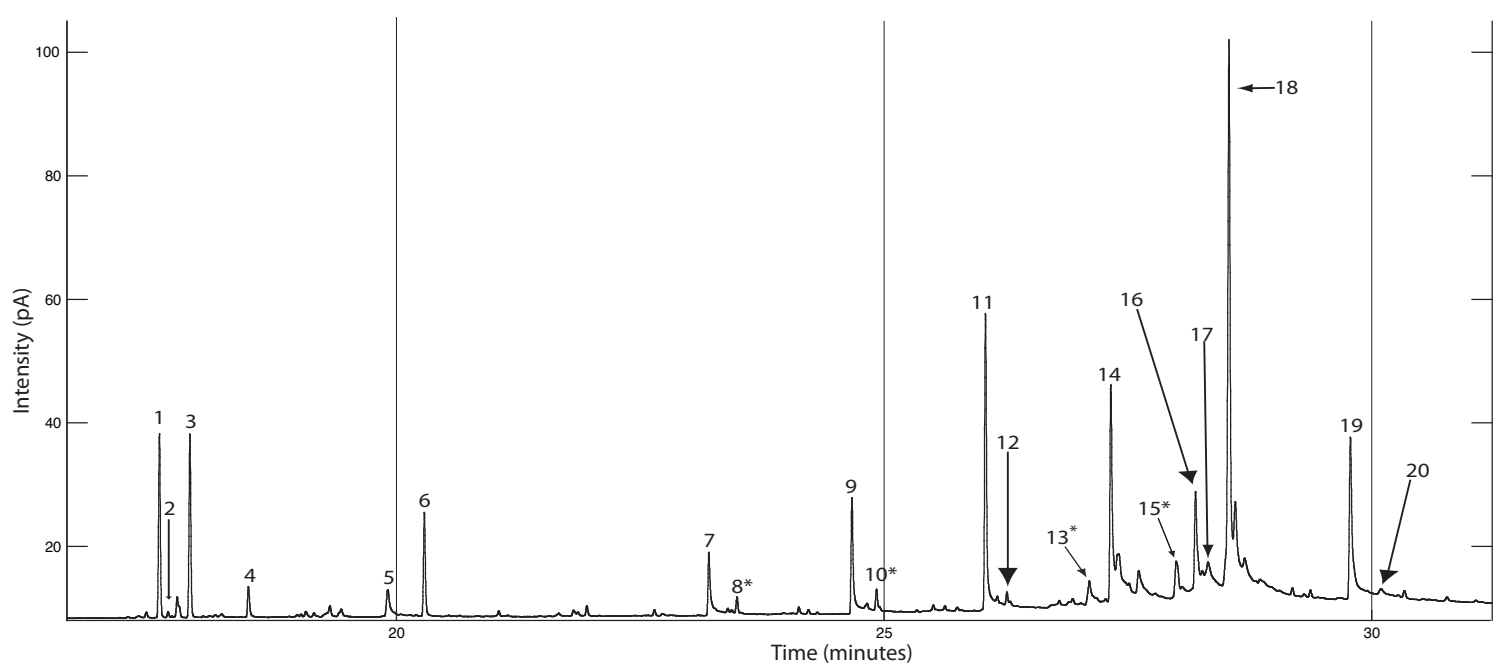

Figure 17. Greenland Desulfurization Fraction, GC-FID Trace. Numbered peaks refer to figure 18. (*) indicates the compound may be present in the Minor-Nonpolar fraction, at a lower abundance. This chromatogram is from analysis of the Greenland DS-1 fraction, which typifies the other Greenland DS fractions.

In the Greenland desulfurization fraction, we find $\mathrm{C}_{20}$ regularly branched isoprenoids (1-3). We find a suite of $\mathrm{C}_{17}-\mathrm{C}_{27}$ alkyl methyl esters $(4,6,8,10,12)$, each with an odd number of carbons. We find a suite of alkanols $(5,7,9,11)$. Alkanol abundance increases with chain length in all three desulfurization fractions, and the alkyl methyl esters do not show a correlation between molecule size and compound abundance. The steroids in this fraction are functionalized and, usually, unsaturated. Their hydrocarbon skeletons are of cholestane $(13,14)$, ergostane $(15,17)$, and stigmasterane $(16,18)$. We observe $\mathrm{a}_{35}$ alkene (19) and a hopanoid (20). All of the compounds found in the DS-1 fraction are also found in the other Greenland desulfurization fractions, except for one of the alkyl methyl esters (4). A convoluted mass spectrum reduces our confidence in the compound assignment for peak 7.

GC-FID retention times suggest that several of the compounds in the Greenland desulfurization fraction may also present in the nonpolar fractions $(8,10,13,15)$. 
A detailed retention time comparison supports the idea of similar but not identical compounds in the two fractions (E-6). For an immature sediment such as Greenland, we expect to see similar compounds in the desulfurized and nonpolar fractions because diagenetic processes may have had little opportunity to modify the free hydrocarbons.

Every compound we identify in the Greenland desulfurized fraction is more abundant than its counterpart in the minor-nonpolar fraction. This relationship suggests that every labelled compound in the above figure 17 was part of an organic sulfur compound in the most-polar fraction (before desulfurization). As we will explain below, the minor-nonpolar fractions provide a "ceiling" for the abundance of nonpolar crosscontamination in the desulfurization fractions. 
<smiles>CC(C)CCCC(C)CCCC(C)CCCC(C)CI</smiles><smiles>CC=C(C)CCCC(C)CCCC(C)CCCC(C)C</smiles>

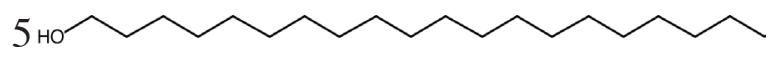

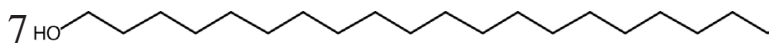

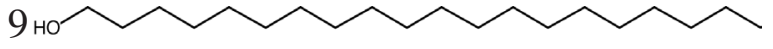

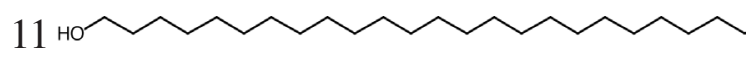

13<smiles>CC(C)CC1CCCCC1COCO</smiles>

17

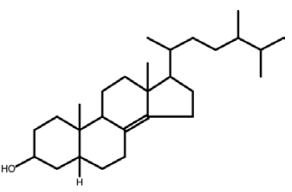

2<smiles>C/C=C(\C)CCCC(C)CCCC(C)CCCC(C)C</smiles><smiles>CCCCCCCCCCCCCCCC(=O)O[14CH3]</smiles>

6<smiles>CCCCCCCCCCCCCC(C)=O</smiles>

8<smiles>CCCCCCCCCCCCCCCCCC(=O)O</smiles>

$12 \mathrm{O}^{\mathrm{O}}$
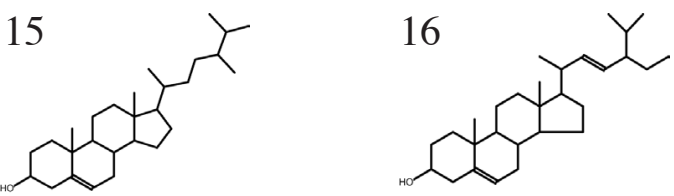

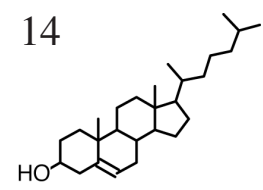

19

18

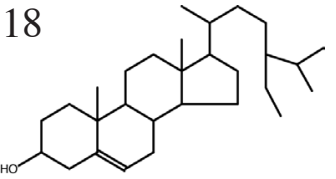

20

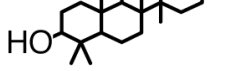

\begin{tabular}{|c|c|c|}
\hline \multirow{20}{*}{$\begin{array}{l}\text { Figure 18. Greenland desulfurization } \\
\text { compound structures and names. } \\
\text { Not found in the other Greenland DS } \\
\text { fractions. } \\
\text { * May be present in the Greenland } \\
\text { Minor-Nonpolar fraction, at a lower } \\
\text { abundance. }\end{array}$} & 1 & Hexadecane, 2,6,10,14-tetramethyl- \\
\hline & 2 & 2-Hexadecene, 3,7,11,15-tetramethyl-, [R-[R*, $\mathrm{R}^{*}$-(E)]]- \\
\hline & 3 & 2-Hexadecene, 3,7,11,15-tetramethyl-, [R-[R*,R*-(E)]]- \\
\hline & $\overline{4}$ & Hexadecanoic acid, methyl ester \\
\hline & 5 & 1-Eicosanol \\
\hline & 6 & Octadecanoic acid, methyl ester \\
\hline & 7 & 1-Eicosanol \\
\hline & $8 *$ & Docosanoic acid, methyl ester \\
\hline & 9 & 1-Eicosanol \\
\hline & $10 *$ & Tetracosanoic acid, methyl ester \\
\hline & 11 & 1-Tetracosanol \\
\hline & 12 & Hexacosanoic acid, methyl ester \\
\hline & $13^{*}$ & (3.alpha.,5.beta.)-Cholestan-3-ol Compare to $\mathrm{Np} 15$ \\
\hline & 14 & Cholesterol \\
\hline & $15^{*}$ & Compare to $\mathrm{Np} 18$ \\
\hline & 16 & Stigmasterol \\
\hline & 17 & .alpha.-Ergostenol \\
\hline & 18 & gamma.-Sitosterol \\
\hline & 19 & 17-Pentatriacontene \\
\hline & 20 & 4,4,6a,6b,8a,11,11,14b-Octamethyl-docosahydropicen-3-o \\
\hline
\end{tabular}




\subsection{Greenland Nonpolar fraction}

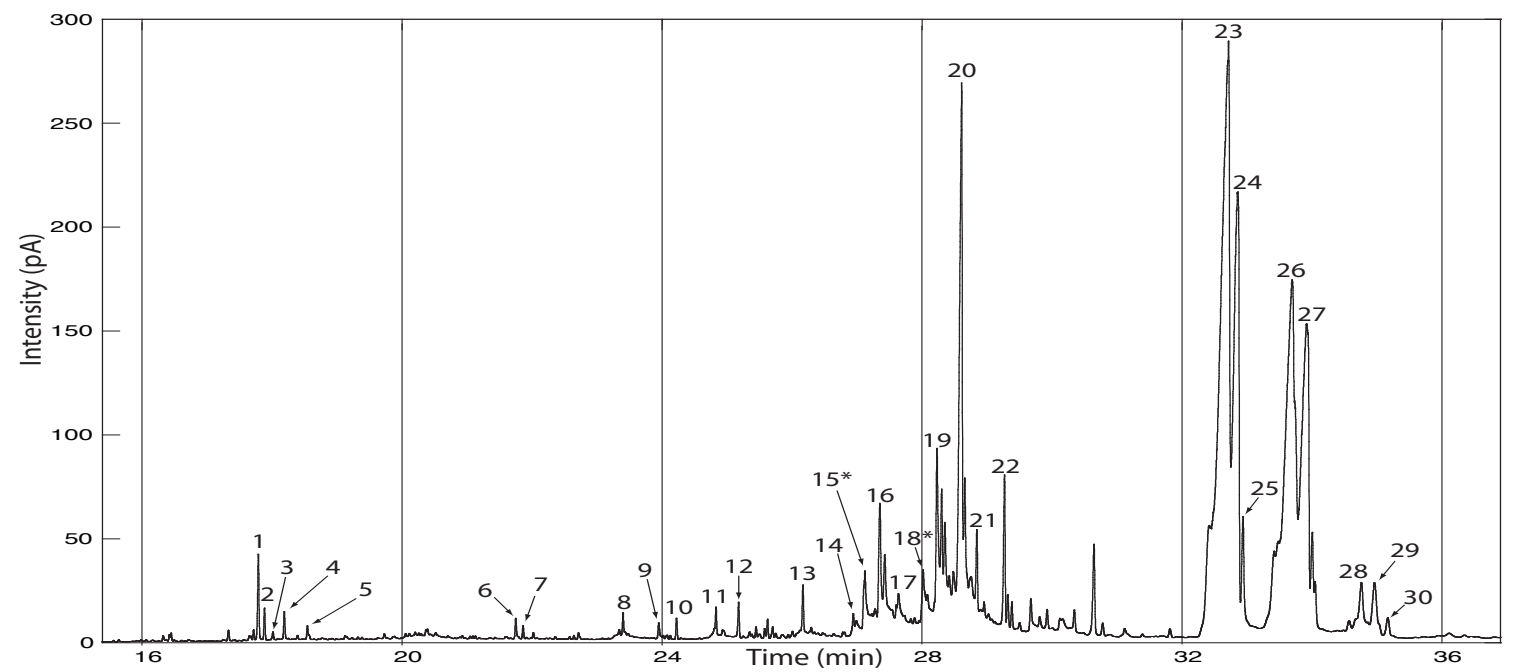

Figure 19. Greenland Nonpolar Fraction, GC-FID Trace. Numbered peaks refer to figure 20. (*) indicates the compound may be present in the Greenland desulfurization fraction.

The Greenland nonpolar fraction contains phytol isomers $(1,3,4)$ and a phytene

(2). We observe straight-chain alkanes $(8,11)$, a branched alkane (7), and a highly

branched alkane (13). We see long-chain alkenes $(10,22)$ and an ethyl ester dialkene (19).

We find a series of $\mathrm{C}_{27}-\mathrm{C}_{29}$ steroids, whose hydrocarbon skeletons are of cholestane (12,

15-17), ergostane (18), and stigmasterane $(14,20,21)$. We see a heterocyclic compound

(9). We find a suite of di-, tri-, and tetra- unsaturated $\mathrm{C}_{37}-\mathrm{C}_{39}$ methyl and ethyl ketones.

Phthalates are present $(5,6)$. The GC-MS data show that cyclic octatomic sulfur is present in the Greenland nonpolar fraction.

Convoluted mass spectra reduce our confidence in the compound assignments for the following peaks: 7, 10, 13-15, 17-19, 21, and 22 . 


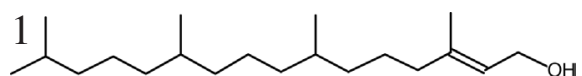<smiles>CC=C(C)CCCC(C)CCCC(C)CCCC</smiles><smiles>C/C(=C\CO)CCCC(C)CCCC(C)CCCC(C)C</smiles><smiles>CC(=CCO)CCCC(C)CCCC(C)CCCC(C)C</smiles><smiles>C=C(OC(C)CCC)c1ccccc1C(=O)CCCCC</smiles><smiles>CCCCCC(CCCC)CCCCCCCCCC(C)c1ccccc1C(C)CCc1ccccc1</smiles><smiles>CC1=CCC(C2(C)CCC(C(C)(C)O)O2)CC1</smiles><smiles>CCCCCCCCCCCCCCCCC/C=C/CCCCCCCCCCCCCCCO</smiles>
11

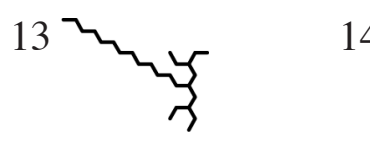<smiles>CCC(C)C(C)CCC12CCC3C4CCC(CC(C)C)CC4CCC3C1CCC2C(C)C</smiles>

$15 *$

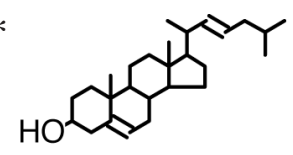

16

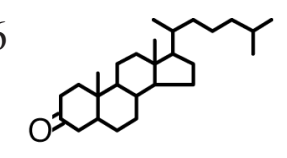

17<smiles>CC(C)CCC1CCC2CC3(CCCC3C)CCC12CCC(C)C</smiles>

$18 *$<smiles>CC(C)CC(C)C1CCC2=C3CC4CC(O)CCC4(C)C3CCC21C</smiles>

19<smiles>CC(C)CCC(C)C1(C)CCC2C3CC=C4C=CCC4(CCC32)C1</smiles><smiles>CCC(C)CCC1CCC23CCC4(CCC(C)C4)CCC2(C)C1C3</smiles><smiles>CCC(CCC1CCC2C1CCC13CCC(C)CC1CCC2C3C)C(C)C</smiles>
22

\begin{tabular}{|c|c|c|c|}
\hline 1 & 3,7,11,15-Tetramethyl-2-hexadecen-1-ol & 16 & Cholestan-3-one, (5.beta.)- \\
\hline 2 & 2-Hexadecene, 3,7,11,15-tetramethyl-, [R-[R*,R*-(E)]]- & 17 & Cholestane, 2,3-epoxy-, (2.alpha.,3.alpha.,5.alpha.)- \\
\hline 3 & 3,7,11,15-Tetramethyl-2-hexadecen-1-ol & $18^{*}$ & Ergost-8(14)-en-3-ol, (3.beta.)- \\
\hline 4 & 3,7,11,15-Tetramethyl-2-hexadecen-1-ol & 19 & Z,Z-4,15-Octadecadien-1-ol acetate \\
\hline 5 & Phthalic acid, butyl 2-pentyl ester & 20 & Stigmasterol, 22,23-dihydro- \\
\hline 6 & Benzyl butyl phthalate & 21 & beta.-Sitosterol \\
\hline 7 & Heptadecane, 9-hexyl- & 22 & 17-Pentatriacontene \\
\hline 8 & Octacosane & 23 & $\mathrm{C}_{37: 4}$ Me ketone \\
\hline 9 & $\begin{array}{l}\text { 2-Furanmethanol, tetrahydro-.alpha.,.alph-[2.alpha.,5.beta.(R*)]]- } \\
\text { a.,5-trimethyl-5-(4-methyl-3-cyclohexen-1-yl)-, [2S }\end{array}$ & 24 & $\mathrm{C}_{37: 3} \mathrm{Me}$ ketone \\
\hline 10 & 17-Pentatriacontene & 25 & $\mathrm{C}_{37: 2}$ Me ketone \\
\hline 11 & Octacosane & 26 & $\mathrm{C}_{38: 4}$ Et ketone and $\mathrm{C}_{38: 4}$ Me ketone \\
\hline 12 & Cholesta-3,5-diene & 27 & $\mathrm{C}_{38: 3}$ Et ketone and $\mathrm{C}_{38: 3}$ Me ketone \\
\hline 13 & Octadecane, 3-ethyl-5-(2-ethylbutyl)- & 28 & $\mathrm{C}_{39: 4}$ Et ketone \\
\hline 14 & Stigmasta-5,22-dien-3-ol, acetate, (3.beta.)- & 29 & $\mathrm{C}_{39: 3}$ Et ketone \\
\hline $15^{*}$ & Cholesta-5,22-dien-3-ol, (3.beta.)- & 30 & $\mathrm{C}_{39: 2}$ Et ketone \\
\hline
\end{tabular}

Figure 20. Greenland nonpolar fraction: compound structures and names. Assignments for \#23-30 are based on relative retention times and peak shapes from D'Andrea and Huang (2005).

*May be present in the Greenland Desulfurization fraction 


\subsection{Minor-Nonpolar fractions and experimental control}

The first fractionation (Figs. 7, 8) did not isolate all of the nonpolar compounds (compare the Nonpolar fractions with the Minor-Nonpolar fractions, in figure 21). Consequently, nonpolar cross-contaminants may be present in the Desulfurization fractions. Since our fractionation procedure is inherently compromised (see endnote 4 of Method section, and "Experimental control," Method section), the second fractionation may have been just as incomplete as the first. If the second fractionation were incomplete, then we would assume that a third nonpolar fraction would contain 4-19\% of the total volatile organic carbon (VOC) found in the Minor-Nonpolar fraction. We base this assumption on the total amount of VOC found in the Minor-Nonpolar fraction compared to the total amount of VOC found in the Nonpolar fraction (bar graphs, figure 21). The Desulfurization fraction is also the third nonpolar fraction (fig. 7). Some compounds are easier to fractionate than others, as shown by the alkenone (32-35 $\mathrm{min})$ to steroid (27-30 $\mathrm{min})$ ratio difference between Greenland nonpolar and Greenland minor-nonpolar. Owing to this compound-specific uncertainty, a compromised isolation procedure, and an abundance of caution, we conclude: any nonpolar compound that carried through to the minor-nonpolar fraction must also have carried through to the desulfurized fraction. However, a crosscontaminant in the desulfurized fraction will be less abundant than its counterpart in the minor-nonpolar fraction. Therefore, any compound in the desulfurized fraction that is more abundant than its minor-nonpolar counterpart must, to some extent, result from the desulfurization reaction.

These cross-contaminants undermine our confidence that desulfurization explains every compound in the desulfurization fractions. On the other hand, total desulfurization 38 
yields are greater than $19 \%$ of the minor-nonpolar yields (bar graph, fig. 21), suggesting that the reaction released many compounds from sulfur linkages. Moreover, several peaks that are present in the desulfurization fractions are not present in the minor-nonpolar fractions, and several peaks in the desulfurization fractions have smaller counterparts in the minor-nonpolar fractions. These new or enlarged peaks in the desulfurization fractions, most noticeable for the Greenland extract, suggest the release of sulfur-bound hydrocarbons. 


\section{Greenland}
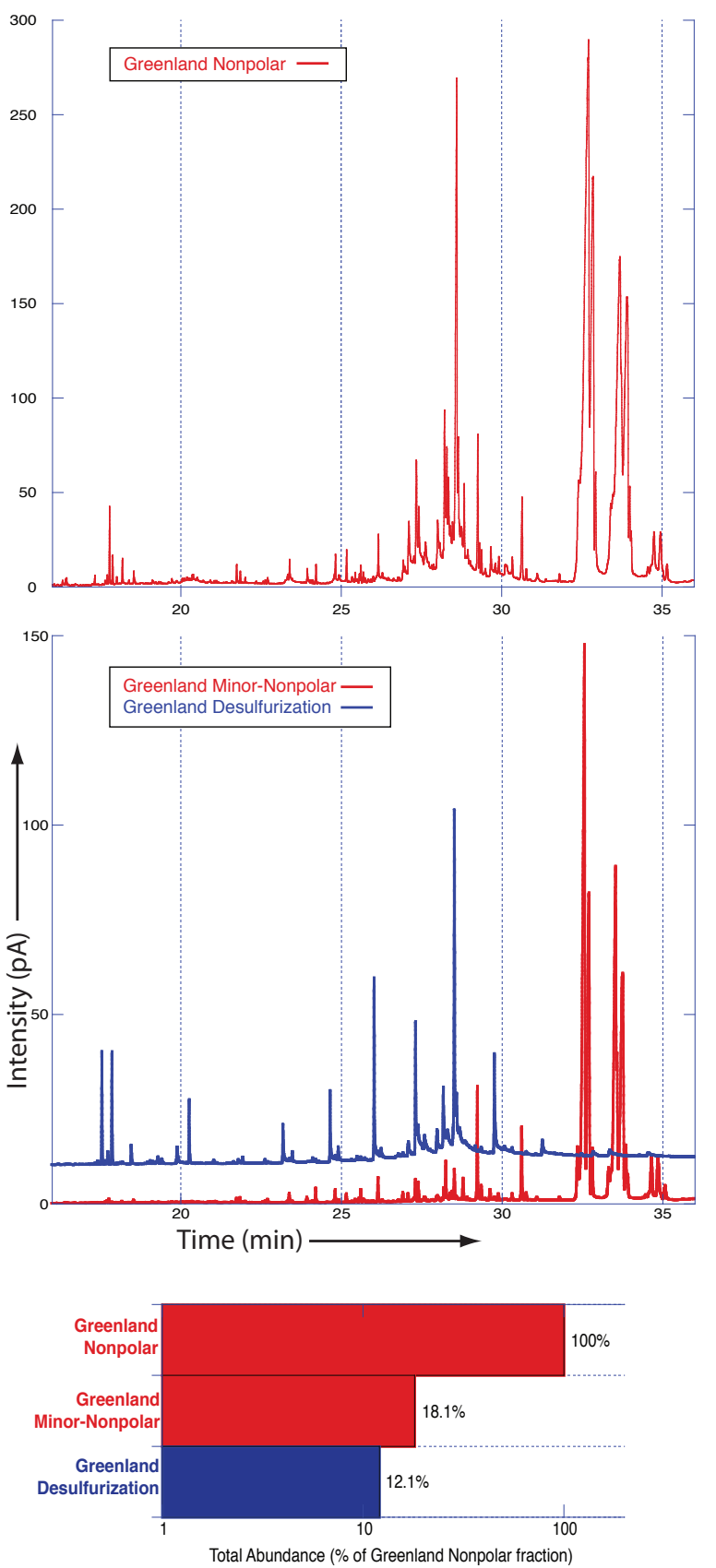

\section{Monterey}
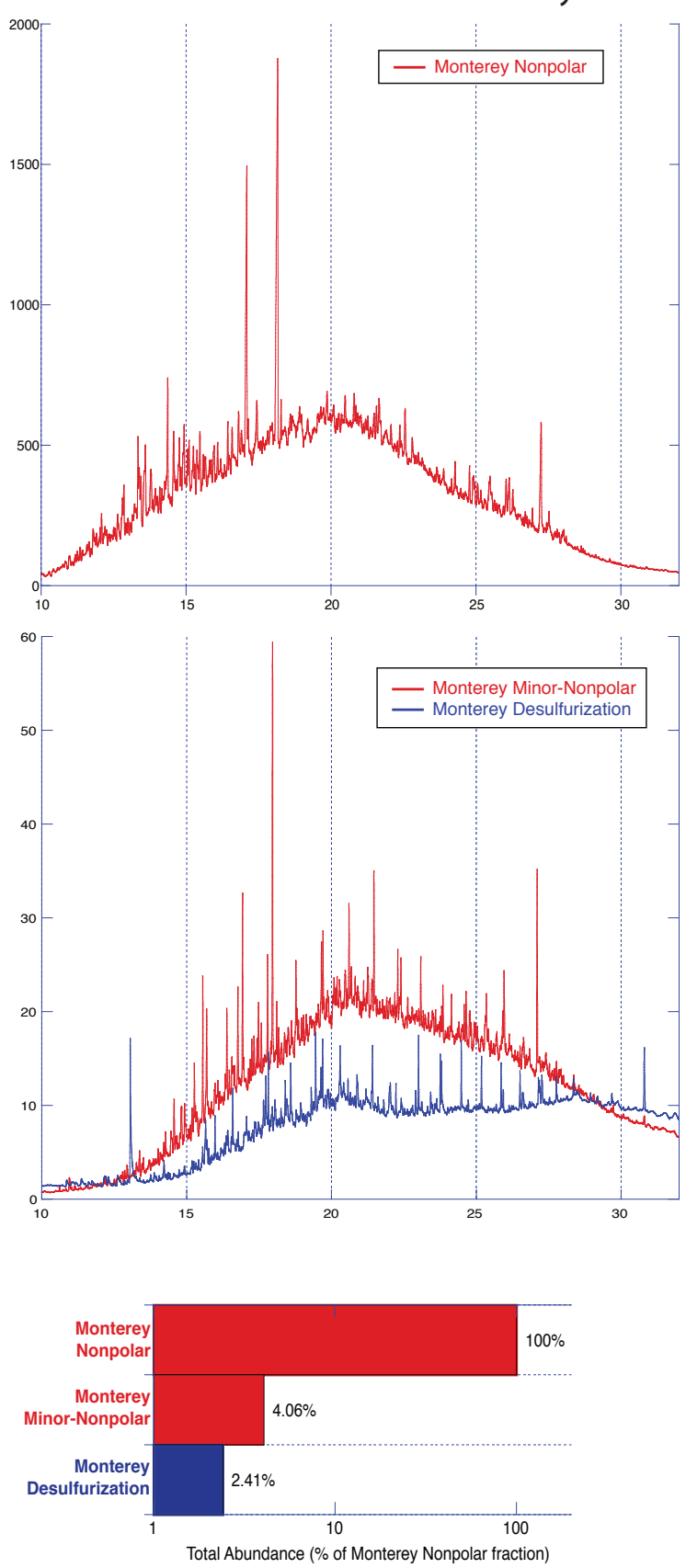

Figure 21: Greenland and Monterey chromatographic data reconsidered. Nonpolar and Desulfurization chromatograms (shown previously in figures 13,15, 17, and 19) are reprinted here with the Minor-Nonpolar chromatograms. This figure allows a direct comparison of the volatile hydrocarbon abundance between the fractions of each extract. For the Greenland extract, we dissolved each fraction in $1 \mathrm{~mL}$ solvent, and injected $1 \mathrm{uL}$ splitless. We dissolved each Monterey fraction in $50 \mathrm{uL}$ of solvent, and injected $1 \mathrm{uL}$ splitless. See E-7 for more on instrument conditions and the formatting of this figure. 
$\underline{\text { Section } 3 \text { Endnotes }}$

1. Figure 22 shows a GC-FID trace of Blank DS-0.

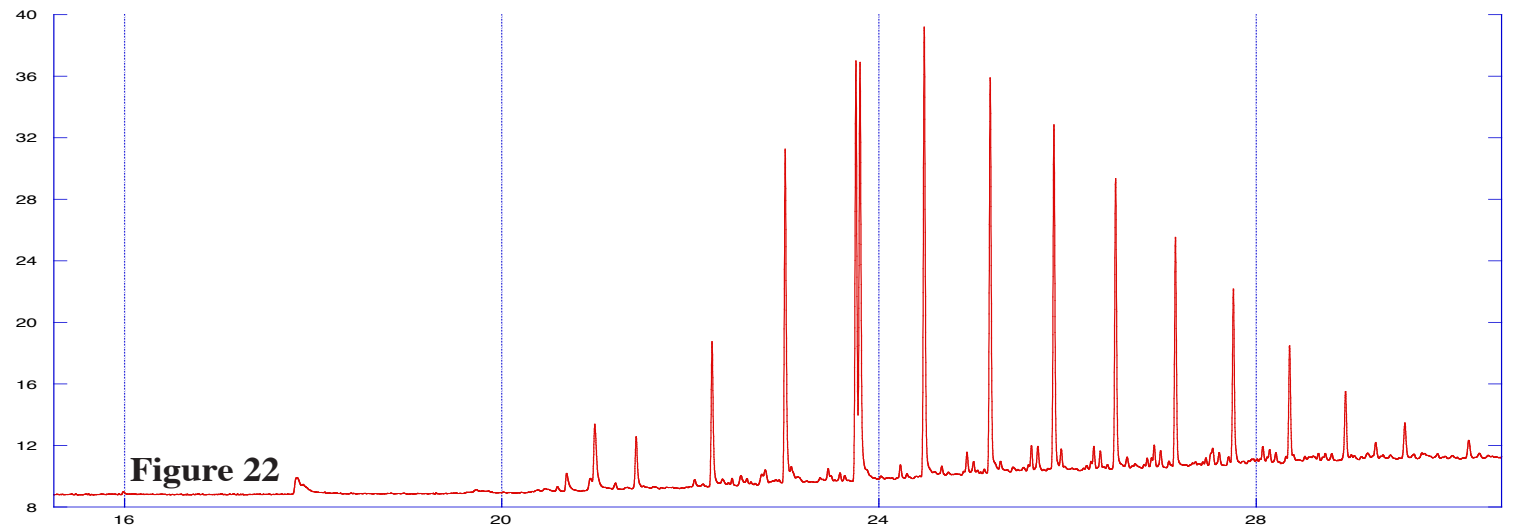

2. When more than one compound elutes at the same time, the mass spectrometer fragments them simultaneously and they appear together as convoluted mass spectra (Colby, 1992). It is possible to identify coeluting compounds because their major ions often have different peak shapes or slight peak offsets, which are visible by extracting the ion chromatogram. For example, figure 23 shows a peak for which we could not find evidence for coelution. On the other hand, figure 24 shows three peaks from the Monterey DS-3 data for which we did find evidence of coelution. At least two compounds compose

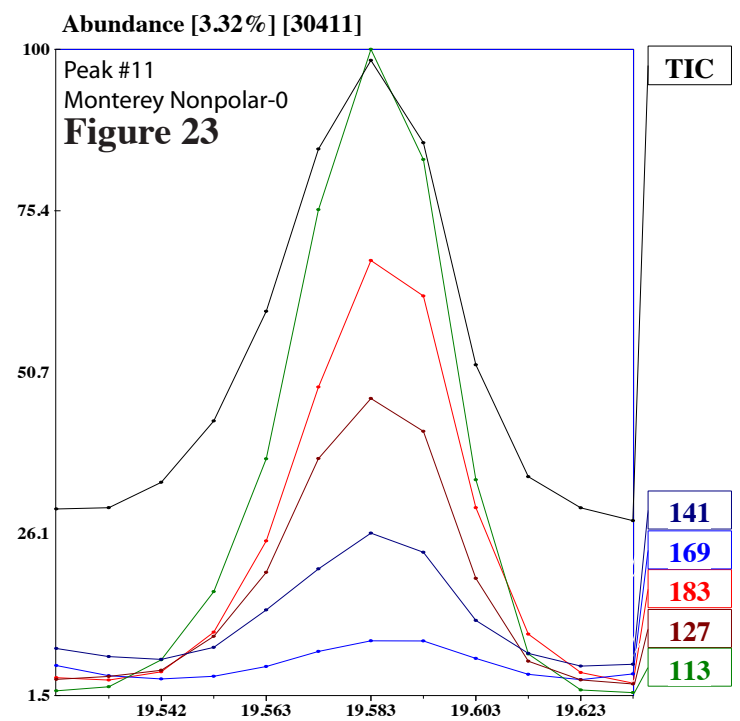

peak 5; one has major fragments with $\mathrm{m} / \mathrm{z}$ $=189,146$, and $160 ;$ the other has major fragments with $\mathrm{m} / \mathrm{z}=83$ and 174. Fragment $\mathrm{m} / \mathrm{z}=203$ may be from a third compound. At least two compounds compose peak 16; one has major fragments with $\mathrm{m} / \mathrm{z}=186$ and 201; the other has the major fragment 149 , and the $\mathrm{m} / \mathrm{z}=175$ ion may be from a 

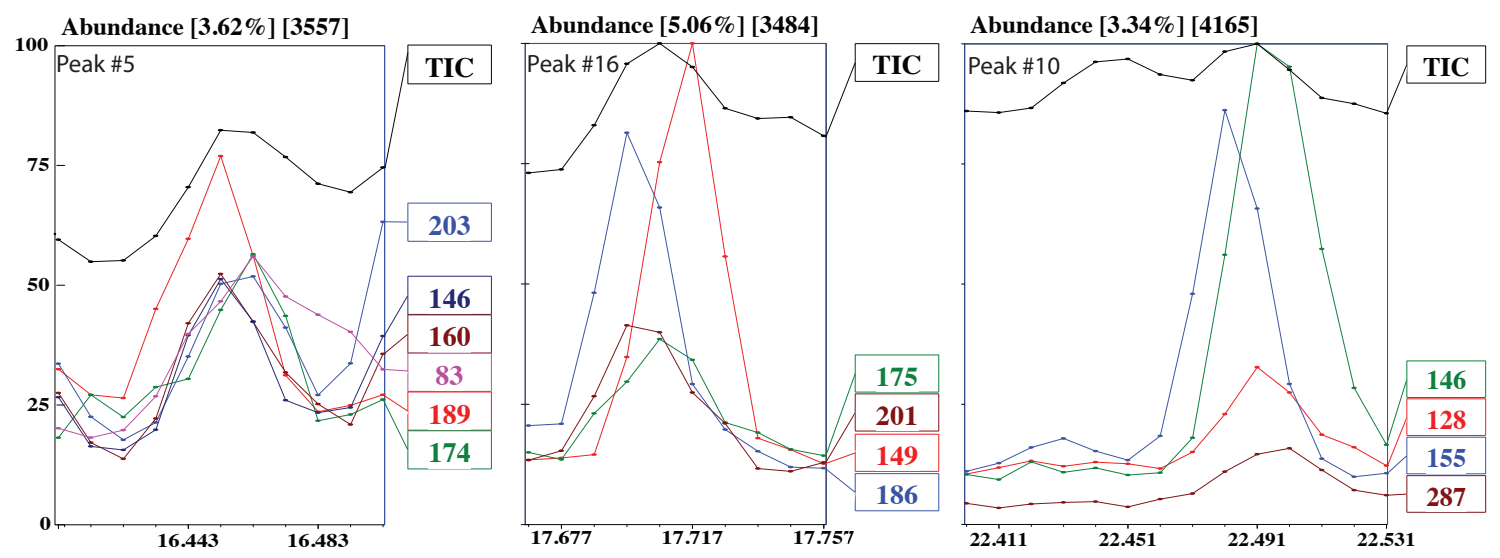

Figure 24

third compound. The same reasoning applies to peak 10. By extracting major ion chromatograms, we searched for evidence of coelution in every peak identified in the Results section.

3. Figure 25 shows how small the $\mathrm{m} / \mathrm{z} 257$ ion abundance is compared to other ions from coeluting compounds, in GC-MS data for the Monterey DS-3 fraction. In typical mass spectra for unsaturated steroid hydrocarbons, the $\mathrm{m} / \mathrm{z}$ 257 ion abundance dwarfs the $\mathrm{m} / \mathrm{z} 57$ ion abundance (e.g., this is the case for Monterey nonpolar compounds 19 and 20).

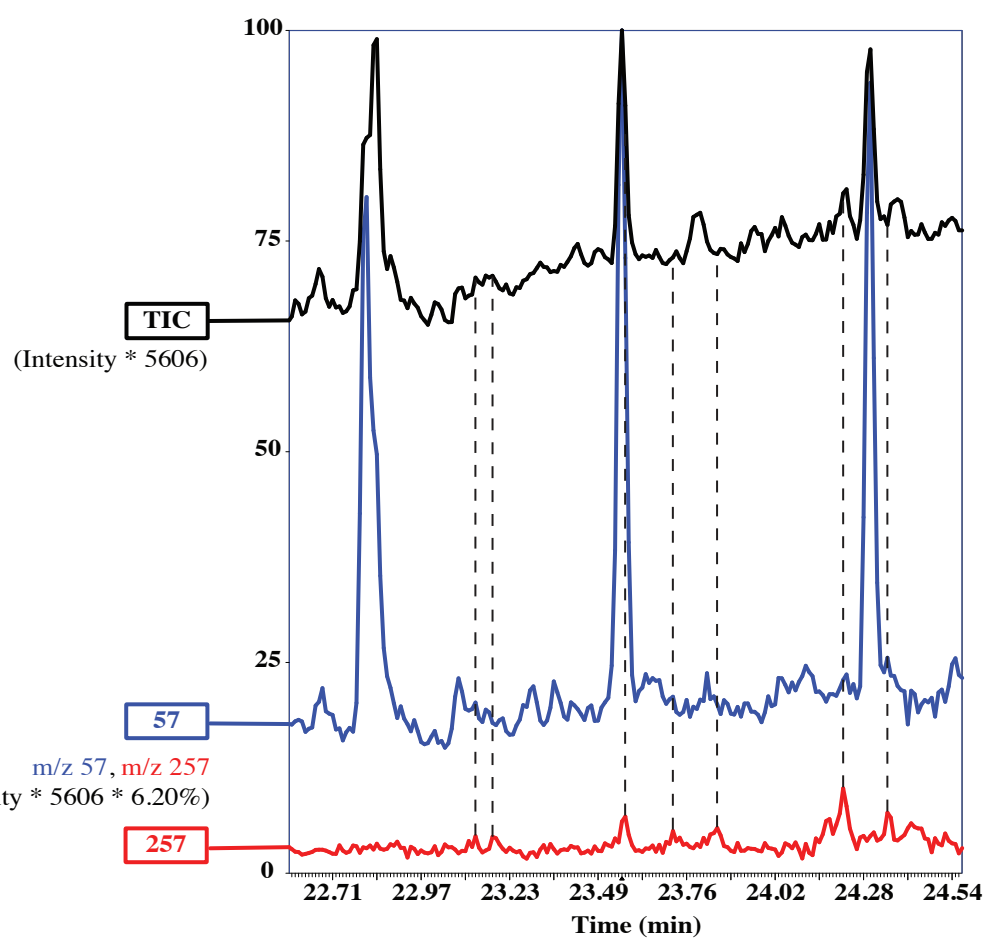

Figure 25 

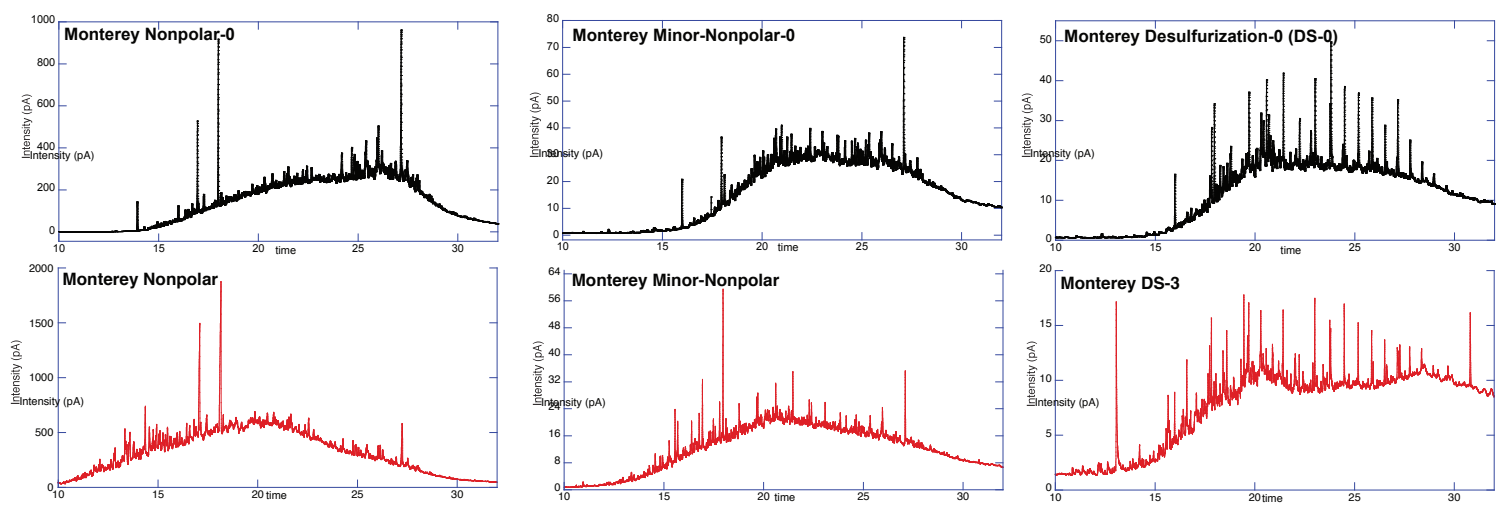

Figure 26

4. Figure 26 shows that light compounds have a higher relative abundance in the Monterey nonpolar fractions than they do in the Monterey- 0 nonpolar fractions. We show the Monterey-0 fractions in black and the Monterey fractions in red. The DS-3 and DS-0 profiles are similar to one another, although DS-0 gives a higher yield than DS-3, and DS-3 has a higher relative abundance of heavy compounds than DS-0. DS-3 has a very similar profile to DS-1 and DS-2 (not shown). By the term "light", we mean compounds with relatively short retention times, and by "heavy" we mean compounds with relatively long retention times.

One possible explanation for the systematic baseline difference between the nonpolar fractions is that the light compounds are vulnerable to evaporative loss. We began each of these two fractionation procedures with an aliquot of Monterey TOE. We produced the Monterey- 0 fractions on $8 / 15 / 08,8 / 18 / 08$, and $8 / 19 / 08$. One month later, we produced the Monterey fractions (on 9/18/08 and 9/22/08). We analyzed all six fractions on the same day (12/16/08) using GC-FID, with the same column, using the same instrument method. In the evaporation scenario, the fractions that we produced earlier lost more of their light compounds because they had more time to do so. 
5. Figure 27 shows the extracted $\mathrm{m} / \mathrm{z} 57$ ion chromatogram for the Monterey-0 Nonpolar fraction.

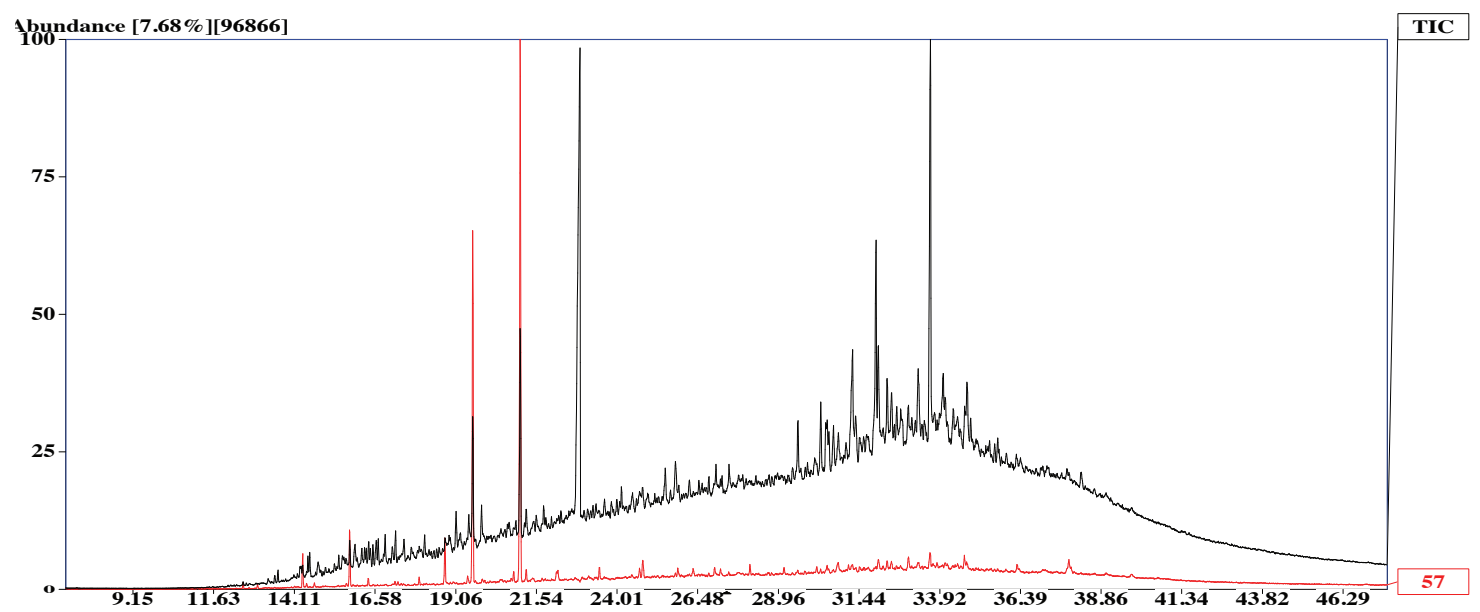

Figure 27

6. Figure 28 compares the Greenland GC-FID traces for the Nonpolar and Desulfurization fractions. Peak Desulf-3 is the same compound as peak Nonpol-2, based on nearly identical retention times and GC-MS data. The desulfurization peaks 13 and 15 appear to have nonpolar counterparts with similar enough retention times that we assume they are identical. On the other hand, the desulfurization peaks 14, 16, 18, 19, and 20 do not have counterparts with similar retention times.

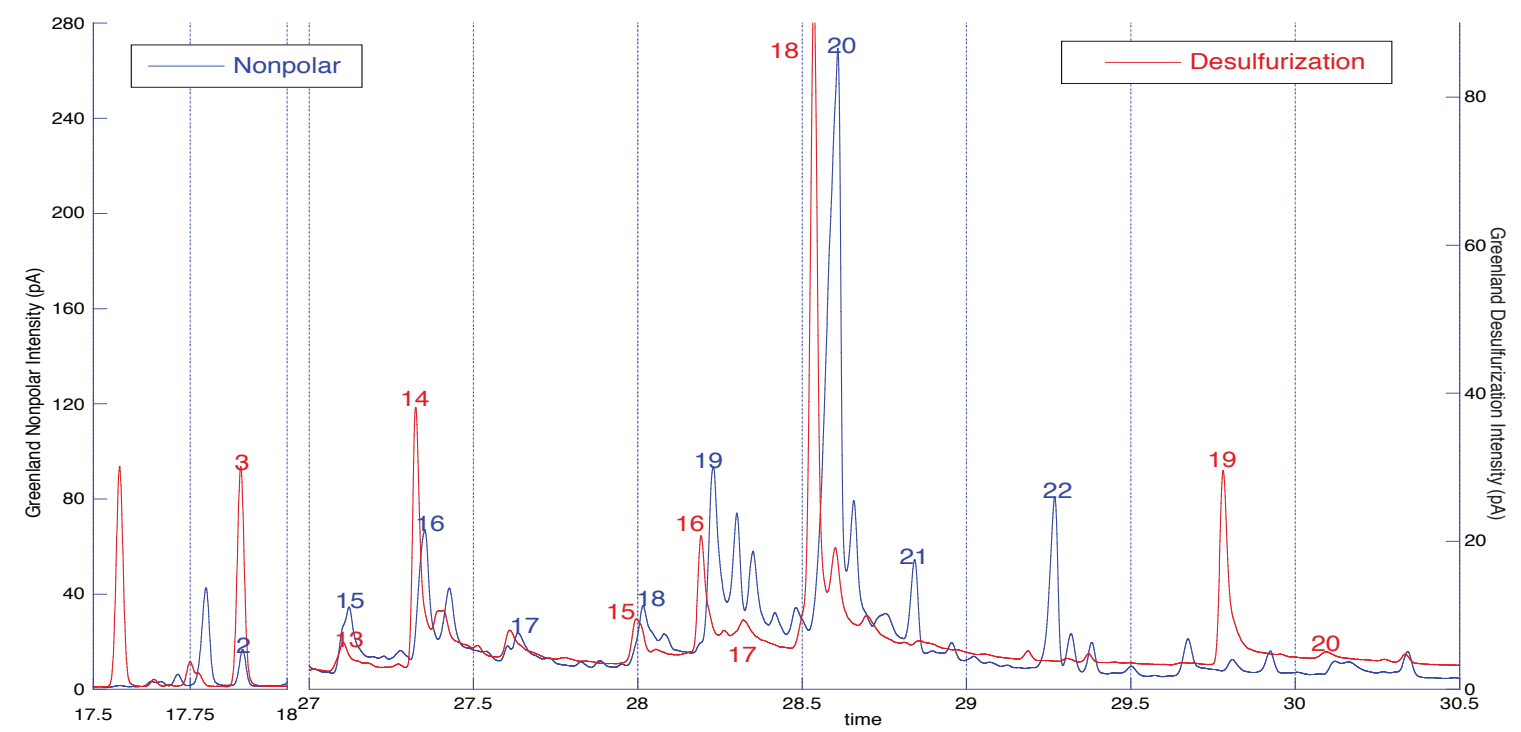

Figure 28 
7. The six chromatograms shown in figure 21 were obtained from GC-FID analysis of six fractions. To allow comparison of volatile compound abundances between different fractions of the same extract (e.g., the Greenland desulfurization fraction and the Greenland minor-nonpolar fraction), the instrument conditions were constant for each extract. For the Greenland extract, we dissolved each fraction in $1 \mathrm{~mL}$ of Hexane:DCM 9:1 and injected $1 \mathrm{uL}$ using program g (splitless). For the Monterey extract, fractions in $50 \mathrm{uL}$ of Hex:DCM 9:1 were injected $1 \mathrm{uL}$ splitless, using program g. The Greenland traces are data for fractions Greenland nonpolar, Greenland minor-nonpolar, and Greenland DS-1. The Monterey traces are data for fractions Monterey nonpolar, Monterey minor-nonpolar, and Monterey DS-3. Each desulfurization started with 1/3 of the most-polar fraction; therefore, to allow a direct abundance comparison between different fractions of the same extract, we scaled the nonpolar and minor-nonpolar intensity measurements to $1 / 3$ of their original size. For visual clarity we offset the Greenland desulfurization trace by $10 \mathrm{pA}$ with respect to the Greenland minor-nonpolar trace. We did not offset the Monterey traces with respect to one another. 


\section{Discussion}

\subsection{Standard yields}

We sought to optimize the desulfurization efficiency by performing several experiments on synthetic standards. For most of our standard experiments, we changed several variables at once. We sought to add $\mathrm{NaBH}_{4}$ at a molar excess to its reactant $\mathrm{NiCl}_{2}$, because the product of this reaction $\left(\mathrm{Ni}_{2} \mathrm{~B}\right)$ decomposes $\mathrm{NaBH}_{4}$ (Back et al., 1992). Higher rates of $\mathrm{Ni}_{2} \mathrm{~B}$ formation per unit volume should make product formation more energetically favorable. Using a graphing program, we determined how well each variable (mass of reagents, solvent volume, reagents/standard, etc.) correlated to the percent yield. Our analysis did not find a distinctive variable or combination of variables that could explain the variance in \% yield (Fig. 29) better than other variables or combinations of variables. However one ratio that has a robust correlation to the \% yield is (mass reagents/mass

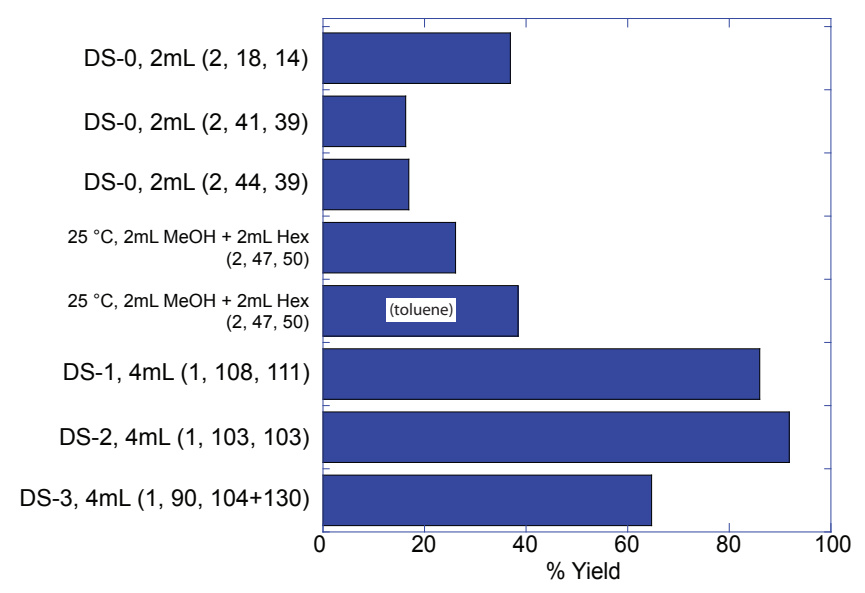

Figure 29. Yields of standard desulfurizations. The experiment labelled "toluene" was a desulfurization of S-benzylthioglycolic acid; all the other experiments desulfurized 1-octadecanethiol. Beside each yield bar, we report: Procedure description, solvent volume (mg standard, $\mathrm{mg} \mathrm{NiCl}_{2}, \mathrm{mg} \mathrm{NaBH}_{4}$ ). We used the solvents $\mathrm{MeOH} / \mathrm{THF} 1 / 1$, unless otherwise noted. standard). To achieve high desul-

furization yields on geochemical

samples, we suggest: that the ratio

of reagents to OSCs should be high

( 100 mg each reagent, $<10 \mathrm{mg}$

sample), the reaction concentra-

tion should be high (4 mL solvent), and the molar excess of $\mathrm{NaBH}_{4}$ to $\mathrm{NiCl}_{2}$ should be about 3:1 (cf. Back et al., 1992). 


\subsection{Sample yields}

We assume that the desulfurized fractions contain volatile cross-contaminants with abundances between $4 \%$ and $19 \%$ of the minor-nonpolar fraction (Results, MinorNonpolar section). These best and worst-case contamination assumptions allow us to approximate the actual desulfurization yield and compare it to the yields achieved by other workers (Fig. 30). Our yields are on the same order of those reported elsewhere, except

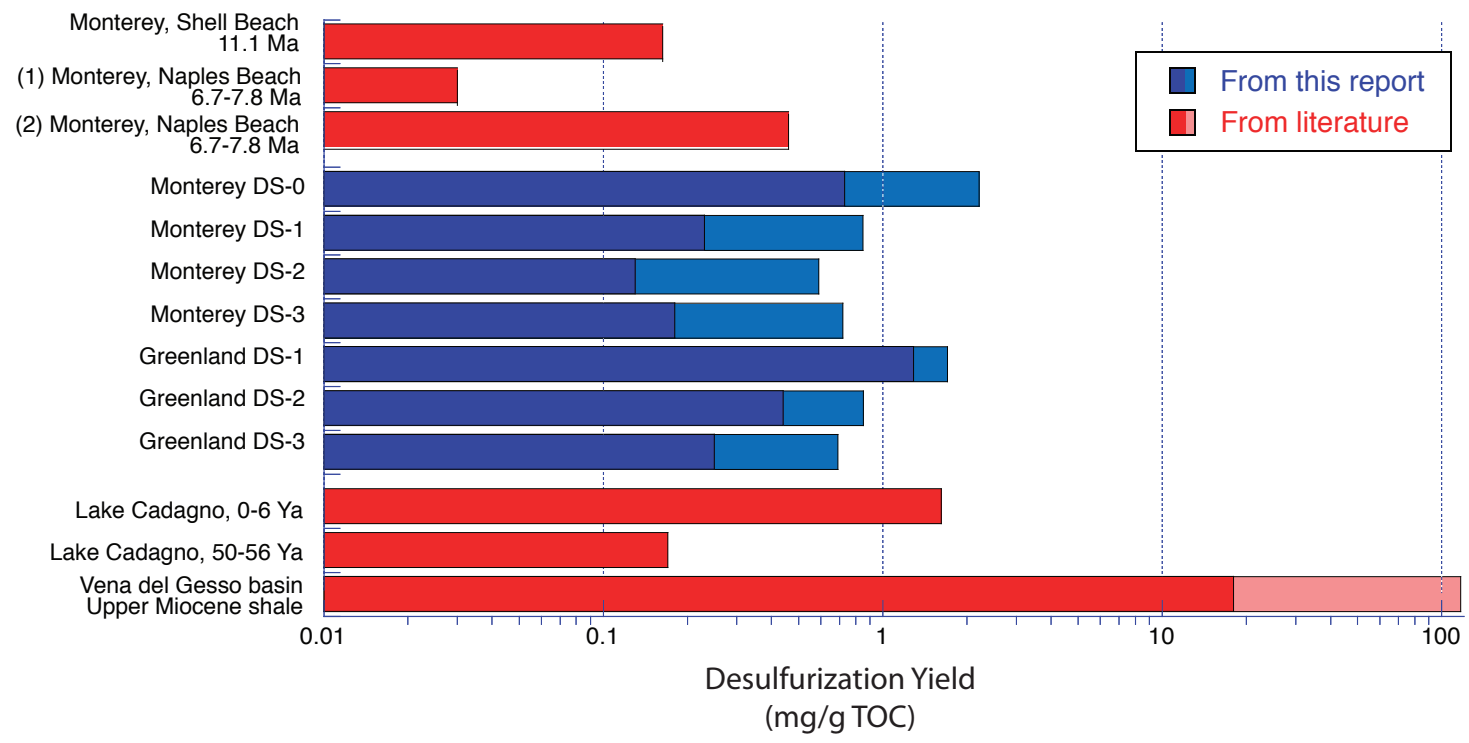

Figure 30. Desulfurization yield of each sample, normalized to the total organic carbon (TOC). Darker bars indicate the minimum yield, and lighter bars indicate the maximum yield. See E-3 for the procedure we used to calculate these yields.

for Schouten et al.'s (1993) desulfurization of a shale from the Vena del Gesso basin, and we suggest that this discrepancy relates to the Messinian salinity crisis. Intra-sample variations within our own data are probably due to procedural inconsistencies. Our Greenland sample tends to give higher desulfurization yields than our Monterey sample gives, indicating the rapidity of sulfurization in Brayas $\varnothing$. Organic matter concentration is relatively high for both Greenland and Monterey, consistent with each sample's oxygenpoor depositional environment. 
The Vena del Gesso shale gives a desulfurization yield an order of magnitude higher than every other sample shown in Fig. 30. Such a large enrichment of released hydrocarbons cannot easily be explained by experimental variability; this sample's diagenetic conditions must have been significantly different from those of the other samples. Since this sample is from the Gessoso-solfifera formation outcropping in a northern Italy evaporitic basin (Kohnen et al., 1991; Vai and Ricci Lucchi, 1977), its age is between 5.5 and 6 Mya (Roveri et al., 2003). This time coincides with the Messinian salinity crisis, when the Mediterranean sea became isolated from the Atlantic ocean. This isolation contributed to evaporitic conditions throughout the Mediterranean basin (Krijgsman et al., 1999), including in the Vena del Gesso area (Roveri et al., 2003). Evaporitic conditions, coupled with anoxic bottom waters (Vai and Ricci Lucchi, 1977) may have been an ideal setting for prolific bacterial sulfate reduction and an anomalously high sulfurization efficiency in the Vena del Gesso basin. Another Messinian evaporitic sample, desulfurized by Schaeffer et al. (1995) also seems to record a very high sulfurization efficiency. These authors found that a desulfurized TOE yielded alkanes at an abundance 20-30 times greater than the abundance of free saturated hydrocarbons. On the other hand, the Monterey samples deposited $\sim 1$ Myr before the Messinian salinity crisis, and outside of the Mediterranean basin. In our Monterey samples, we did not observe any desulfurized compounds that were more abundant than any of the free hydrocarbons.

Among our Monterey desulfurizations, DS-0 seems to have been significantly more effective than DS 1-3. The increased yield may be due to a difference between the method we used to isolate the desulfurization yield for DS-0 and the method we used for the six other sample desulfurizations (Method endnote 5) (E-1). Among our Monterey 48 
and Greenland desulfurizations, the DS-1 yields tend to be higher than those of DS-2 and DS-3. We suspect that the DS-1 yields are higher than those of DS-2 and 3 because the DS-1 reactions began with slightly more sample than the other two reactions (E-2). Greenland desulfurization yields are 1.5x-3.5x higher than Monterey yields, when the maximum or minimum yields are averaged and Monterey DS-0 is excluded from the comparison. Since the Greenland sample is very young, sulfurization occurred rapidly in its depositional environment (the lake Brayas $\varnothing$ ).

Desulfurization yield can vary significantly even between samples from the same stratigraphic unit (Fig. 30, Monterey Naples Beach samples). Sedimentary compounds amenable to desulfurization have a heterogeneous distribution.

Our Greenland extractable organic matter (EOM), relative to the rock mass, is higher than our Monterey EOM (2.7\% versus 1.3\%). The Greenland sediment has a Total Organic Carbon abundance (TOC) of $11.7 \%$ (D’Andrea, pers. comm., 2009), which is higher than the TOC for Monterey (probably 2-5\%; cf. Katz and Royale, 2001). This relationship is consistent with the observation that, generally, lake rocks have a higher TOC than ocean rocks (Peters et al., 2007,pp. 15-16). The same authors reason that lakes have relatively high organics preservation because higher lacustrine sedimentation rates provide less opportunity for aerobic remineralization than the lower marine sedimentation rates provide. Although our Greenland lake probably does have a higher sedimentation rate than our hemipelagic Miocene shale, we hesitate to suggest that this difference caused Greenland to have a higher TOC than Monterey. The depositional environment of Monterey was suboxic, and dissolved oxygen was not an important influence on organic matter preservation in the Monterey sequence (Isaacs, 2001). The Greenland 
lake's bottom waters are anoxic (Anderson et al., 1999). Aerobic remineralization was not the dominant threat to organic matter preservation in the benthic waters and surface sediments of these two environments. Perhaps anaerobic remineralization (e.g., bacterial sulfate reduction) occurs in our two environments, which might explain the TOC relationship. Since our Greenland sample is surface sediment, such a process may not have had time to reduce this sample's TOC.

\subsection{Sample composition overview}

The diagenesis of sediment into sedimentary rock involves thermochemical processes that add layers of complexity to the already difficult puzzle of geochemical sulfurization. When a mature sample has been uplifted into a terrestrial environment, it may be subject to further modification by microbes (Sec. 3.4). The lacustrine Greenland compounds are fewer in number and easier to identify than the marine Monterey compounds (Secs. 3.3-3.6). This difference may reflect a more diverse paleobiota during the Monterey sample's deposition (Sec. 4.4.2) than has recently been present at the Greenland lake. The Monterey sample also shows more signs of biological and thermal postdepositional modification (Sec. 4.4.1) than does the Greenland sample.

The Greenland sample (surface sediment from the oligosaline, meromictic lake Brayas $\varnothing$ ) is much younger than the $\sim 7$ million year old Monterey shale (Sec. 1). Normatively, such a young sediment provides a window into the sulfurization process that relatively mature sediments may not. Greenland's nonpolar fraction should contain OSC precursors and its desulfurized fraction should contain OSC degradative products. A 
surface sediment's organic material should have undergone much less alteration than the organics in a relatively mature rock.

\subsection{Monterey}

The chromatographic and mass-spectral data for the Monterey sample indicate that this rock underwent biological and thermal modification, after and possibly during organic sulfur formation. Bacterial, eukaryotic, and terrestrial sources contributed to the free and bound organic matter from Monterey. Although the paleobiotic information revealed by desulfurization is more limited than we had initially expected, this fraction may uncover a precursor-product relationship not previously reported for Monterey bitumens.

\subsubsection{Post-depositional modification}

Both the desulfurization fraction and the nonpolar fraction give a high baseline. For the nonpolar fraction, this baseline reflects biodegradation, as we discussed in section 3.4. Heterotrophs, probably aerobic microbes, metabolized the $\mathrm{C} 15-\mathrm{C} 35$ straight-chain alkanes in the Monterey nonpolar fraction. The nonpolar fraction contains a regular isoprenoid that seems to be missing a methyl group (Nonpolar-7) (Np-7), possibly suggesting biodegradation. However, Np-7 also has a convoluted mass spectrum.

The desulfurization fraction is more difficult to interpret. Organic sulfur compounds are thought to be more resistant to biodegradation than free hydrocarbons (Schouten et al., 2001), so we are hesitant to interpret the high baseline as indicating microbial metabolism of organic sulfur compounds. Many of the organic sulfur compounds in this Monterey sample may not be macromolecules. Rather, these OSCs may be 
polar sulfoxides, which Schouten et al. (2001) report may comprise $40 \%$ of polar OSCs in Monterey. Perhaps polar sulfoxides are less resistant to microbial attack than sulfide macromolecules are. Another possibility is that the biodegraded free hydrocarbons carried through as cross-contaminants to the desulfurized fraction. However, reasonable estimates of the amount of cross contamination (section 3.7) imply that the latter scenario is unlikely.

The nonpolar fraction containes cholestoids and stigmasteroids, which are also reported by Schouten et al. (2001). Each of these compounds (Nonpolar 16, 19-21, 24, $25,28,30)$ seems to have undergone some modification. The C5-C6 unsaturation is not present in any of these steroids, except for in Nonpolar-30 (Np-30). The structure of Np30, however, shows an aromatic substituent on the D-ring, which is unusual for biogenic steroids. Aromatized steroids are considered indicative of diagenetic or catagenetic thermal alteration (Brocks and Summons, 2004), although usually the aromatic ring is part of the sterane skeleton. (Np-30's identification is based on a convoluted mass spectrum, so this compound's diagnostic power is questionable.) The steroid Np-16 is missing much of its alkyl side chain, which may indicate biodegradation or thermally-induced cracking. The cholestenone Np-24 may be the product of anaerobic biohydrogenation, a pathway known to produce keto-steroids (Kok et al., 2000), and Np-24 would be a good candidate for sulfurization due to the reactivity of the ketone group.

Monterey's nonpolar fraction also may contain a substituted dibenzothiophene (Np-13). In contrast to Schouten at al. (2001), we did not find thiophenes with long-chain alkyl groups. However, we only sought to identify the most abundant peaks, so we do not suggest that these compounds are absent from our nonpolar fraction. The relatively 52 
abundant dibenzothiophene may originate from the catagenesis of less-mature macromolecular OSCs (Aizenshtat et al., 1995). Since the upper member of the Monterey formation is thought to be thermally immature (Sessions, personal communication, 2008), the possibility of intense thermal modification to our sample is surprising. Np-13's identity is obfuscated by a convoluted mass spectrum.

Aizenshtat et al. (1995) suggested that, while sulfide $\left(\mathrm{H}_{2} \mathrm{~S}\right)$ and polysulfides $\left(\mathrm{S}_{\mathrm{x}}{ }^{2-}\right)$ are reactive with functionalized organics at low temperatures, elemental sulfur (e.g. $\left.\mathrm{S}_{8}\right)$ is only reactive at high temperatures. The authors reasoned that elemental sulfur required a homolytic cleavage $\left(220-250{ }^{\circ} \mathrm{C}\right)$ to become reactive. Although we found elemental sulfur $\left(\mathrm{S}_{8}\right)$ in the Monterey nonpolar fraction, it does not necessarily indicate thermal maturity for our sample, because we also found $S_{8}$ in the Greenland nonpolar fraction, which is (extremely immature) surface sediment. Although our samples are not both thermally mature, their diagenetic environments may have both activated $S_{8}$ through a homolytic pathway. In the case of Monterey, this pathway may have been thermolytic, and in the case of Greenland, this pathway may have been photolytic.

Phenolic alcohols and esters (Np-22, Np-23) present in the nonpolar fraction would suggest an immature sediment, because alcohol groups and $\mathrm{C}-\mathrm{O}$ bonds tend to be thermally unstable. We suggest that these compounds are misidentified, because they have convoluted mass spectra. Alternatively, the Monterey sample contains non-endogenous compounds, a possibility that would confound our reconstruction of Monterey's diagenetic environment. 


\subsubsection{Paleobiology}

Bacterial, eukaryotic, terrestrial, and photosynthetic organisms contributed to the organic compounds observed in the Monterey sample. Bacteria are the likely parent organism(s) of 28-norhopane (Np-27), which is commonly found in Monterey sediments (Yamamoto et al., 2005). The biochemical precursors to hopanoids are poorly characterized, however, hopanoids are rarely found in eukaryotes and widely found in bacteria (Brocks and Summons, 2004). Bacterial hopanoids are thought to regulate the fluidity of cell membranes in a similar manner to eukaryotic steroids (Ibid.). Hopanoids have anaerobic synthetic pathways, although they have so far been observed mostly in aerobic bacteria (Ibid.). A similar compound to Np-27 is 28,30-dinorhopane, which Schouten et al. (2001), identified as a free hydrocarbon in Monterey. This compound is associated with euxinic environments and sulfidic water columns, but its parent organism is unknown (Brocks and Summons, 2004). We suspect that anaerobic sulfate-reducing bacteria are the parent organisms of 28-norhopane and 28,30-dinorhopane in the Monterey sample. Steroids, which we found in both the desulfurized and nonpolar Monterey fractions, as did Schouten et al. (2001), are diagnostic for eukaryotic organisms (Brocks and Summons, 2004).

The nonpolar fraction also containes a series of substituted PAHs (Np 1, 3-5, 6, 8, 9). We suspect that these PAHs are of biogenic, terrestrial origin. Since they are substituted, they probably do not result from combustion (Jiang et al., 1998). The same authors identified cadalene, simonellite, and retene as plant-derived biomarkers. Although we do not detect these PAHs, the ones we identified are structurally similar. While we interpret these PAHs as indicators of terrestrial input, exogenous contamination cannot be ruled 54 
out, since this sample is from an exposed outcrop. Moreover, oil-rich formations are known to have organics diffusion across stratigraphic layers.

We observe phytane in the nonpolar fraction, as does Schouten et al. (2001). This compound is abundant as a side-chain to chlorophyll, which is the photosynthetic pigment used by algae and plants (Brocks and Summons, 2004).

\subsubsection{Precursor-product relationships}

Pristane, which we found in the Monterey nonpolar fraction (Np-11), has two biological precursors: the phytyl side-chain of chlorophylls (Brocks and Summons, 2004), and tocopherols (Goossens et al., 1984). Tocopherols occur as ether-linked lipids in the algae Botryococcus braunii, and these compounds may have a role as anti-oxidants (Metzger and Rager, 2002). We observed beta-tocopherol and delta-tocopherol in Monterey's desulfurized fraction (Ds-12, Ds-18; Ds-12's mass spectrum is convoluted), but we did not find these compounds in the nonpolar fraction. We suggest that tocopherols are a precursor to pristane in this part of the Monterey formation. The precursor to sulfurized tocopherol must have had an additional functionality, since geochemical sulfurization operates by replacing reactive functionalities with C-S bonds. Such a functionality on tocopherol could have occurred as conjugated double bonds on the branched side-chain, or as an alcohol or aldehyde group on an alkyl substituent of the compound's aromatic moiety.

Schouten et al. (2001) found lycopane as a free hydrocarbon in Monterey extracts, and they suggested that this compund had a bacterial or algal source. Lycopane may be a diagenetic product of lycopene (Brocks and Summons, 2004), a compound that we 
observed in the desulfurized fraction (Ds-17). Lycopene is a biosynthetic precursor to carotenoids, which are common across several taxa (Brocks and Summons, 2004), notably as photosynthetic pigment in sulfur bacteria. Since Monterey's depositional environment was probably sulfidic, phototrophic, anaerobic sulfide-oxidizing bacteria could be a source for the lycopene. However, such an organism would imply photic zone euxinia, and we are unaware of evidence for large-scale die-offs in the marine photic zone during the late Miocene. Lycopene has many double bonds, and an activating group near any of them could have promoted sulfurization via the base-catalyzed nucleophilic addition mechanism. In the minor-nonpolar fraction at Ds-17's retention time, we found a mass spectrum similar to that of Ds-17. Therefore, desulfurized lycopene may be cross-contamination from the nonpolar fraction. In any case, we suggest a diagenetic relationship between lycopene and lycopane.

Steroids can reveal changes in sulfurization efficiency in the Monterey sediments, because they occur as mono- and di-unsaturated forms in both nonpolar and desulfurized fractions (Schouten et al., 2001). For example, the abundance of a free diasterene in some sample may be lower than its abundance in a slightly older sample. Perhaps this compound's sulfurized counterpart (if it could be found) is more abundant in the younger sample than it is in the older sample. Such a relationship would be consistent with sulfurization efficiency increasing with time. Unfortunately, practical constraints do not allow us to make such an interpretation for our Monterey sample. We only have data for the extract of one Monterey rock, and the steroids that we do identify have problematic mass spectra. We find cholestane in the desulfurized and nonpolar fractions (Ds-11 and Np21), consistent with Schouten et al. (2001). These authors found cholestanes, ergostanes, 56 
and stigmasteranes in the desulfurized fraction. Besides cholestane, we identified two unusual steroids (Ds-14, Ds-15). We are unaware of sedimentary steroids with a dimethyl substitution at carbon \#4. Ds-15 has a convoluted mass spectrum. It is also relatively enriched in the m/z 191 ion, suggesting the presence of a terpenoid, or possibly a hopanoid. Schouten et al. (2001) did identify hopanoids in their desulfurized fraction, suggesting a bacterial contribution to the sulfurized compounds.

The nonpolar fraction contains a C23 tricyclic terpenoid (Np-18), whose structure is similar to a compound that Schouten et al. (2001) found only in their desulfurized fraction. They argued that this terpenoid was a sulfur-bound moiety whose precursor was functionalized, since they did not observe this compound as a free hydrocarbon. However, we suggest that our compound, nonpolar-18, is identical to Schouten et al.'s (2001) desulfurized compound. Therefore, these terpenoids were either biosynthesized as such or are products of a degradative reaction. This interpretation does not preclude the terpenoid from having a functionalized precursor that was incorporated into an organic sulfur compound. If our sample had a more intense thermal history than the samples that Schouten et al. (2001) analyzed, the terpenoid may have historically been part of a sulfur-linked macromolecule that underwent catagenic degradation (cf. Aizenshtat et al., 1995). In this scenario, our terpenoid underwent geochemical desulfurization, and their terpenoid underwent experimental desulfurization.

\subsection{Greenland}

Biomarkers in the Greenland sample suggest that at least two different species of phototrophic algae, as well as two different species of sulfur bacteria, inhabit Brayas $\emptyset$. 
The composition of the desulfurized fraction suggests that the rapid sulfurization in Brayasø may employ a photochemical mechanism.

\subsubsection{Biomarkers}

We found a pentacyclic triterpenoid at low abundance in the desulfurized fraction (Ds-20), but absent from the nonpolar fraction. This compound has a structure identical to $\beta$-amyrin, if $\beta$-amyrin did not have a double bond. $\beta$-amyrin is a terpenoid diagnostic for land plants (Brocks and Summons, 2004), so we interpret Ds-20 as indicative of lowlevel terrestrial input to Brays $\varnothing$.

The C20 regularly branched isoprenoids found in Greenland's nonpolar and desulfurized fractions ( $\mathrm{Np} \mathrm{1-4;} \mathrm{Ds} \mathrm{1-3)} \mathrm{indicate} \mathrm{photosynthetic} \mathrm{parent} \mathrm{organisms,} \mathrm{such} \mathrm{as}$ algae. Steroids, which are also present in Greenland's desulfurized and nonpolar fractions, indicate eukaryotic parent organisms (Brocks and Summons, 2004). Alkenones present in the nonpolar fraction at high abundance are likely the remains of a specific clade of prymnesiophytic algae (D'Andrea et al., 2006). D'Andrea and Huang (2005) argued that the steroids and some other compounds in Brayas $\varnothing$ are produced mostly by non-prymnesiophytic phototrophs, because these compounds are $13 \mathrm{C}$ enriched relative to the alkenones.

Purple sulfur bacteria inhabit Brayas $\emptyset$ 's photic zone (McGowan et al., 2008). These organisms are the likely source for the $\mathrm{S}_{8}$ found in Greenland, since they can produce elemental sulfur by oxidizing $\mathrm{H}_{2} \mathrm{~S}$ (Proctor, 1997). We strongly suspect that sulphate-reducing bacteria inhabit Brayas $\varnothing$, since biological sulfate reduction is the most important pathway to sedimentary sulfide formation (Werne et al., 2004). 58 


\subsubsection{Precursor-product relationships}

We assume that the phytane (Ds-1) and phytenes (Ds 2,3) in the desulfurized fraction were part of an OSC prior to desulfurization. The precursors to these OSCs must have had a reactive functionality additional to any functionalities that the desulfurized compounds have. The phytene in the nonpolar fraction (Np-2) is a plausible precursor to the desulfurized phytane (Ds-1), if photochemical sulfurization occurred. The lake has $\mathrm{pH} \sim 10$, so the nucleophilic base-catalyzed addition reaction would initially seem applicable. However, this reaction is only effective on activated unsaturated bonds, such as $\alpha$, $\beta$-unsaturated carbonyl compounds (Fig. 2) (Aizenshtat et al., 1995). Instead, we invoke a photochemical mechanism for sulfurization (Fig. 3), as proposed by Adam et al. (1998).

Absent a photochemical mechanisms, the desulfurized phytenes (Ds 2,3) would present a similar problem to that of Ds-1: we do not observe phytadienes or phytenals in the nonpolar fraction. Without activated double bonds, nucleophilic addition is unlikely. It is possible that phytadienes or phytenals are present in the nonpolar fraction, but we missed them because they have a low abundance; we do not rule out the base-catalyzed nucleophilic mechanism. Another possibility is that the "desulfurized" phytenes are actually products of a reductive ester cleavage (E-4) rather than desulfurization. However, a

photochemical mechanism would suggest that $\mathrm{Np}-1, \mathrm{~Np}-3$, and $\mathrm{Np}-4$ are the precursors to the desulfurized phytenes. Allylic alcohols such as phytol can become photochemically oxidized to activated aldehydes (Amrani and Aizenshtat, 2004). Such compounds would then be amenable to the sulfide nucleophilic addition reaction. Alternatively, the phytols may enter a bio-hydrogenation pathway (cf. Kok et al., 2000), exit as phytanals (with no 
$\mathrm{C}=\mathrm{C}$ double bonds), and then undergo photochemical sulfurization via a thioketone intermediate (Schneckenburger et al., 1998).

The desulfurized steroids all have alcohol substituents at the third carbon, indicating that the sulfurization did not occur at this functional group. While many steroids have more than one $\mathrm{C}=\mathrm{C}$ double bond, we are not aware of any biogenic steroids with activated double bonds (e.g., $\alpha, \beta$-unsaturated carbonyls or conjugated dienes). Thus we suggest that the precursors to the desulfurized steroids are di- and tri- unsaturated sterols that underwent photochemical sulfurization. The absence of activated double bonds, or activated carbonyls, in the free steroids leads us to rule out the nucleophilic mechanism for these compounds. The desulfurized steroids have the same carbon skeletons as the steroids in the nonpolar fraction, although we are less sure of how steroid functionalities compare between the two fractions. This uncertainty stems from convoluted mass spectra for several of the nonpolar-fraction steroids. We do not interpret these convolutions as indicative of a high baseline (E-5).

The pentacyclic triterpanoid (Ds-20), similar to $\beta$-amyrin, lacks a double bond between $\mathrm{C} 12$ and $\mathrm{C} 13$. We suggest that $\beta$-amyrin is the biological precursor to Ds-20, and that photochemical sulfurization added a sulfide moiety to $\beta$-amyrin's $\mathrm{C} 12=\mathrm{C} 13$ double bond.

We do not find any likely nonpolar-fraction precursor compounds to the mediumchain desulfurized alcohols (Ds-5,7,9,11). However, D’Andrea and Huang (2005) observed free medium-chain monoacids (alkanoic acids) in several oligosaline Greenland lakes, including Brayas $\varnothing$. Trace abundance of monoacids would be consistent with rapid, efficient sulfurization via the photochemical mechanism. Such monoacids would origi60 
nate from non-prymnesiophytes, as those observed by D'Andrea and Huang (2005) are 13C-enriched relative to alkenones.

For the alkanoates in the desulfurized fraction (Ds 6,8,10,12) we do not find any obvious nonpolar-fraction precursors. Alkenoates have been observed as free compounds in other samples from this Greenland lake (D'Andrea, personal communication, 2009), but we do not observe them here, perhaps because they are efficiently sulfurized. We suggest that alkenoates are the precursors to our desulfurized alkanoates. Depending on the position of the unsaturation, alkenoates could have sulfurized by either the nucleophilic or the photochemical mechanism. Marlowe et al. (1984) reported on haptophytes (the taxon in which prymnesiophytes reside) that produce C37-C39 alkenoates, and the alkanoates that we identified have shorter chains (C19-C27).

Consistent with Kok et al.'s (2000) desulfurization of Ace lake sediments, we do not observe long-chain alkenones in our desulfurized fraction. As those authors suggest, the sulfurization reaction could differ drastically in efficiency between classes of compounds. Alternatively, the sulfurized alkenones are part of macromolecular networks too large to elute in the most-polar fraction; they may be present only as asphaltenes or kerogen. In the latter scenario, we did not encounter alkenones in the desulfurized fraction because we did not desulfurize the asphaltenes or the kerogen.

Figure 31 presents a model for sulfurization in the Greenland lake Brayas $\varnothing$, which integrates our results with those of Anderson et al. (1999) (Fig. 5). Adam et al. (1998) suggested that photochemical sulfurization would be limited to anoxic photic zones. If that suggestion were correct, then we would be hard-pressed to explain the sterols released by our desulfurization. Brayas $\varnothing$ 's photic zone is relatively deep (D’Andrea and 
Huang, 2005), but measurements by Anderson et al. (1999) indicate that the entire zone is oxic. We suggest that photochemical sulfurization occurs in the chemocline, where

there are steep gradients of light

penetration, dissolved oxygen, and

presumably, dissolved sulfides,

which would diffuse upward from

the lake's bottom. On the other

hand, sunlight is not the only way

to explain rapid sulfurization, even

if this reaction involves a radical

mechanism (E-7). Sulfurization

in Brayas $\varnothing$ might occur via some

mechanism that we have not re-

viewed (cf. Filley et al., 2002 and

Schneckenburger et al., 1998).

\subsection{Sulfurization potential}

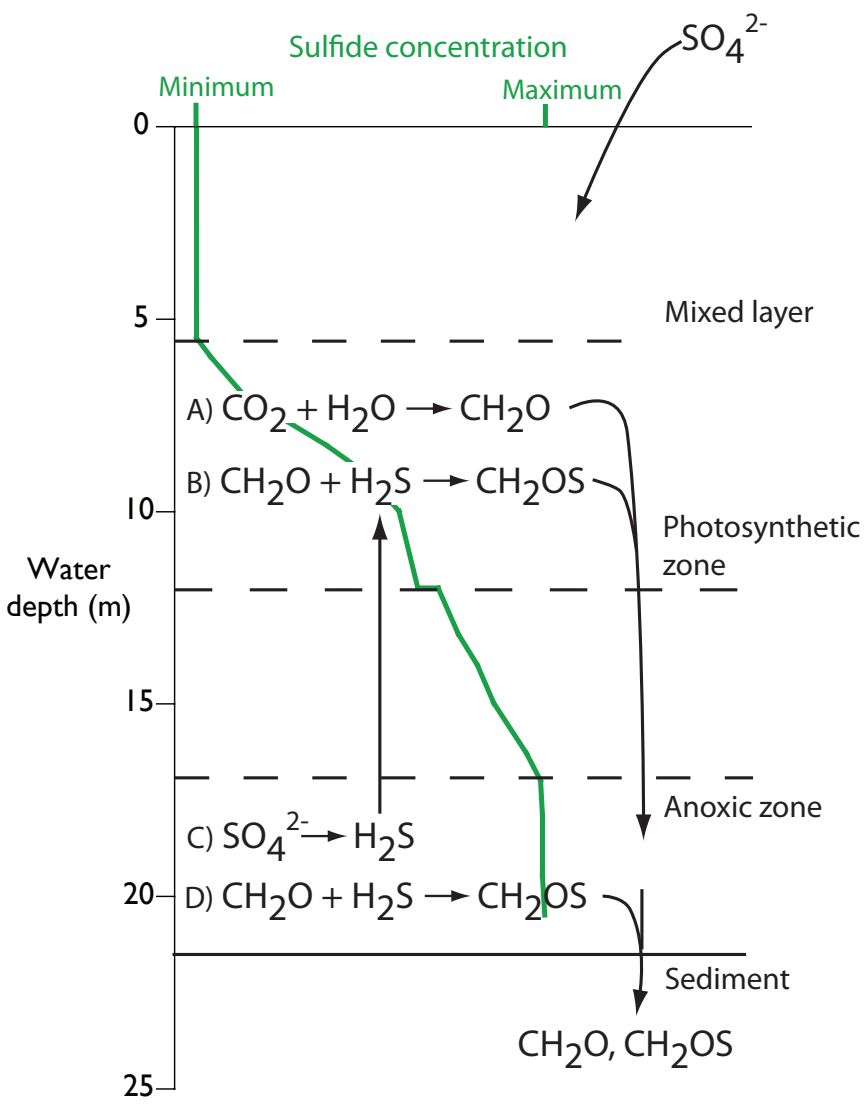

Figure 31. Model for organic sulfur compound formation in the Greenland lake Brayas $\varnothing$. We show four major reactions (A-D). A is the carbon fixation reaction. $\mathrm{B}$ is the photochemical sulfurization of organic matter. $\mathrm{C}$ is bacterial sulfate reduction. $\mathrm{D}$ is the base-catalyzed sulfurization of organic matter. We suggest that the dissolved sulfide has an inverse abundance relationship to the dissolved oxygen, because these two species are reactive with one another.

We estimated the "sulfurization potential" for the major compounds in each of our samples (Table 2; see endnote 8). These values correspond to the amount of a compound that is sulfur-bound relative to the total amount of the compound. Table 2 implies that regular isoprenoids are more susceptible to sulfurization than steroids, that the measured compounds in Greenland are more susceptible to sulfurization than their counterparts in Monterey, and that alkenones are not sulfurized in either environment. ("N/a" indicates 62 
Table 2. Mean sulfurization potential for the major compound families of Monterey and Greenland.

\begin{tabular}{l|l|l|l|l} 
& \multicolumn{2}{|c|}{ Monterey } & \multicolumn{2}{l}{ Greenland } \\
& Mean & S.E. & Mean & S.E. \\
\hline Regular isoprenoids & $1.3 \%$ & $0.5 \%$ & $23.5 \%$ & $5.5 \%$ \\
\hline Steroids & $0.9 \%$ & $0.3 \%$ & $7.8 \%$ & $6.8 \%$ \\
\hline Alkenones & n/a & n/a & $-3.2 \%$ & $2.9 \%$ \\
\multicolumn{3}{l}{ S.E. one standard error of the mean }
\end{tabular}

that we did not identify alkenones in any of the Monterey fractions, whereas the negative value for Greenland indicates that the area in the alkenone retention time was larger in the blank desulfurization than it was in the Greenland desulfurizations.) These sulfurization potentials reflect desulfurization of maltene-dominated fractions; they do not reflect desulfurization of the asphaltene or kerogen fractions, which may contain organic sulfur compounds beyond the scope of this study.

$\underline{\text { Section } 4 \text { endnotes }}$

1. When we did not centrifuge the reaction mixture, we allowed $\sim 10$ mins for the $\mathrm{Ni}_{2} \mathrm{~B}$ particles to settle and transferred the supernatant to a clean vial. However, the supernatant remained cloudy. After drying down the supernatant, a residual of $\mathrm{Ni}_{2} \mathrm{~B}$ remained in the vial. To obtain the nonpolar yield, we extracted this vial with hexane. The $\mathrm{Ni}_{2} \mathrm{~B}$ may have impeded the hexane's dissolution of the nonpolar yield.

2. We intentionally used different reaction conditions between DS-1, 2, and 3 to test their effect on the yield. However, we introduced a confounding variable by inaccurately measuring the volume of solvent used for the Most-Polar sample vials. We assumed each most-polar vial contained $4.5 \mathrm{~mL}$ of solvent, but they actually contained about $4 \mathrm{~mL}$. We performed all of the DS-1 reactions together, followed by the DS-2 
reactions, followed by the DS-3 reactions. We did not realize our error until after we had taken the first $1.5 \mathrm{~mL}$ aliquots.

3. We normalized the desulfurization yield to the Total Organic Carbon (Table 3), using data from several sources, which we explain below Table 3. All of the desulfurization yields from the literature were obtained using a nickel boride reaction on the polar fraction of an asphaltene-precipitated sedimentary extract. For some samples, we report the TOC as a range, in lieu of a measurement of the actual rock whose extract was desulfurized. This range is our estimate based on data from stratigraphically similar samples. For our samples, we report the desulfurization yield as a range (min released/TOE and max released/TOE), which we explain in E-6. A sample that uses one or more measurement ranges requires us to express its TOC-normalized desulfurization yield as a range.

\begin{tabular}{|c|c|c|c|c|c|c|c|c|c|}
\hline $\begin{array}{l}\text { Table } 3 \\
\text { Description }\end{array}$ & $\begin{array}{l}\text { Min } \\
\text { (released } \\
(/ \text { TOE })^{a}\end{array}$ & $\mid \begin{array}{l}\text { Max } \\
\text { (released } \\
/ \text { TOE })^{\mathrm{b}}\end{array}$ & $\begin{array}{l}\text { TOE/ } \\
\text { rock }^{\mathrm{c}}\end{array}$ & $\begin{array}{l}\min \\
\text { TOC/ } \\
\text { rock }^{\text {d }}\end{array}$ & $\begin{array}{l}\max \\
\text { TOC/ } \\
\text { rock }^{e}\end{array}$ & $\begin{array}{l}\min \\
\text { TOE/ } \\
\text { TOC }^{f}\end{array}$ & $\begin{array}{l}\max \\
\text { TOE/ } \\
\text { TOC }^{g}\end{array}$ & $\begin{array}{l}\text { Min } \\
\text { released/ } \\
\text { TOC }^{\text {h }}\end{array}$ & $\begin{array}{l}\text { Max } \\
\text { released/ } \\
\text { TOC }\end{array}$ \\
\hline $\begin{array}{l}\text { Monterey, Shell Beach, } \\
11.1 \mathrm{Ma}\end{array}$ & 0.00265 & & & & & 0.059 & & $1.6 \mathrm{E}-04$ & \\
\hline $\begin{array}{l}\text { Monterey, Naples Beach, } \\
6.7-7.8 \mathrm{Ma}(\mathrm{KG}-7)\end{array}$ & 0.0005 & & 0.002 & 0.037 & & 0.067 & & $3.4 \mathrm{E}-05$ & \\
\hline $\begin{array}{l}\text { Monterey, Naples Beach, } \\
\text { 6.7-7.8 Ma (KG-8) }\end{array}$ & 0.0035 & & 0.008 & 0.058 & & 0.131 & & 4.6E-04 & \\
\hline Monterey DS-0 & 0.0028 & 0.0034 & 0.013 & 0.020 & 0.050 & 0.260 & 0.650 & $7.3 \mathrm{E}-04$ & $2.21 \mathrm{E}-03$ \\
\hline Monterey DS-1 & 0.0009 & 0.0013 & 0.013 & 0.020 & 0.050 & 0.260 & 0.650 & 2.3E-04 & $8.45 \mathrm{E}-04$ \\
\hline Monterey DS-2 & 0.0005 & 0.0009 & 0.013 & 0.020 & 0.050 & 0.260 & 0.650 & $1.3 \mathrm{E}-04$ & $5.85 \mathrm{E}-04$ \\
\hline Monterey DS-3 & 0.0007 & 0.0011 & 0.013 & 0.020 & 0.050 & 0.260 & 0.650 & $1.8 \mathrm{E}-04$ & 7.15E-04 \\
\hline Greenland DS-1 & 0.0056 & 0.0074 & 0.027 & 0.117 & & 0.230 & 0.230 & $1.3 \mathrm{E}-03$ & $1.70 \mathrm{E}-03$ \\
\hline Greenland DS-2 & 0.0019 & 0.0037 & 0.027 & 0.117 & & 0.230 & 0.230 & $4.4 \mathrm{E}-04$ & $8.51 \mathrm{E}-04$ \\
\hline Greenland DS-3 & 0.0011 & 0.003 & 0.027 & 0.117 & & 0.230 & 0.230 & $2.5 \mathrm{E}-04$ & $6.90 \mathrm{E}-04$ \\
\hline Lake Cadagno, 0-6 Ya & 0.0177 & & & & & 0.092 & & $1.6 \mathrm{E}-03$ & \\
\hline Lake Cadagno, 50-56 Ya & 0.00276 & & & & & 0.063 & & 1.7E-04 & \\
\hline $\begin{array}{l}\text { Vena del Gesso basin, } \\
\text { Upper Miocene shale }\end{array}$ & 0.117 & & 0.002 & 0.002 & 0.013 & 0.154 & 1.000 & $1.8 \mathrm{E}-02$ & $1.17 \mathrm{E}-01$ \\
\hline
\end{tabular}




\section{Table 3 footnotes}

a. Monterey, Shell Beach measurement from Schouten et al. (1997): sample "SB-18", from their Figure 7. Monterey, Naples Beach data from Schouten et al. (2001): samples “KG-7" and "KG-8", from their Figure 9.10. Monterey DS and Greenland DS measurements are explained in endnote 6. Lake Cadagno measurements from Putschew et al. (1995): their samples "0-2 [cm]" and "18-20 [cm]”, from their Table III. Vena del Gesso data from Schouten et al. (1993): their sample "VDG polar fraction," from their Table 1.

b. Monterey DS and Greenland DS measurements are explained in endnote 6 .

c. Monterey, Naples Beach data from Katz and Royale (2001), their Table 6.5, samples KG-7 and KG-8. Monterey DS and Greenland DS EOM measurements are explained in section 2.3 of this report. Vena del Gesso datum from Kohnen et al. (1991), "Extraction and Fractionation" section.

d. Monterey, Naples Beach data from Katz and Royale (2001), their Table 6.1, samples KG-7 and KG-8. Monterey DS TOC measurements are from Katz and Royale (2001), their figure 6.2. Greenland DS TOC measurements are from D'Andrea (pers. comm., 2009). Vena del Gesso datum from Lugli et al. (2007), their Table 2.

e. Monterey DS TOC measurements are from Katz and Royale (2001), their figure 6.2. Vena del Gesso datum from Lugli et al. (2007), their Table 2.

f. The Monterey Shell Beach value is from Schouten et al. (1997), their Table 2, sample SB-18. For Monterey Naples Beach, we divided the (TOE/rock) values by the (min TOC/rock) values. For Monterey DS, Greenland DS, and Vena del Gesso, we 
divided the (TOE/rock) values by the (max TOC/rock) values. Lake Cadagno values are from Putschew et al. (1995), their samples "0-2 [cm]" and "18-20 [cm]", from their Table I.

g. For all samples in this column, we divided the (TOE/rock) values by the (min TOC/rock) values. We forced the quotient for Vena del Gesso to 1, since TOE cannot be greater than TOC.

h. For all samples in this column, we multiplied the "Min (released/TOE)" value by the "Min TOE/TOC" value.

i. For all samples in this column, we multiplied the "Max (released/TOE)" value by the "Max TOE/TOC" value.

4. Nickel boride is considered a gentle desulfurization reaction in comparison to alternatives such as raney nickel (Back et al., 1992; Schouten et al., 1993). However, Putschew et al. (1996) found that nickel boride desulfurization can reductively cleave ester bonds in chlorophyll a to produce phytenes. Those authors suggest the nickel boride reaction be subjected to further systematic study.

5. The Greenland nonpolar fraction's convoluted mass spectra are likely an instrument artifact. The GC-MS data for this fraction show much broader peaks after $\sim 22$ minutes than the GC-FID data show, and we are unsure of the reason.

6. The four tables (4-7) shown below are the four steps we used to calculate our desulfurization yields. Table 4 shows the raw data (total area under each GC-FID trace, 66 
omitting the solvent peaks). Beneath the areas are letters indicating a scaling correction (explained below). Table 5 shows the data with the corrections applied to each value. Table 6 shows the mass equivalent for each area in milligrams, which we found using the HMB calibration curves. Table 7 shows the mass of each fraction minus the mass in the procedural blank. Table 7 also shows best- and worst-case estimates of the mass of nonpolar cross-contaminants in the desulfurized fraction (4\% VOC residue and 19\% VOC residue). Table 7 finds the minimum desulfurization yield by subtracting the " $19 \%$ VOC residue" column from the "Desulf" column. We find the maximum desulfurization yield by subtracting the $4 \%$ VOC column from the Desulf column. We find the $\%$ yields by dividing the yield columns by the TOE weight column. 
Table 4. Raw GC-FID measurements (pA*s)

\begin{tabular}{|c|c|c|c|c|}
\hline & Nonpolar & Minor-Nonpolar & Desulf & column \\
\hline Blank-0 & 234.472 & 171.888 & 850.718 & front \\
\hline correction & B & B & $\mathrm{B}, \mathrm{C}$ & \\
\hline Monterey-0 & 187307.826 & 16227.104 & 12330.353 & front \\
\hline correction & B & B & $\mathrm{B}, \mathrm{C}$ & \\
\hline Monterey 1 & 1314132.125 & 53396.427 & 10542.730 & front \\
\hline Monterey 2 & & & 7869.352 & \\
\hline Monterey 3 & & & 9454.325 & \\
\hline correction & $A, B$ & $A, B$ & B & \\
\hline Greenland 1 & 47662.066 & 8608.460 & 1916.234 & back \\
\hline Greenland 2 & & & 1033.257 & \\
\hline Greenland 3 & & & 849.907 & \\
\hline correction & A & A & & \\
\hline
\end{tabular}

Table 5. Corrected GC-FID Measurements (pA*s)

Blank-0

Monterey-0

Monterey 1 Monterey 2 Monterey 3

Greenland 1 Greenland 2 Greenland 3

Blank-0

Monterey-0

Monterey 1 Monterey 2

Monterey 3

Greenland 1 Greenland 2 Greenland 3
Nonpolar Non ar 11.724 8.594

Desulf 47.262

Detector \&
column 9365.391

$\begin{array}{rrrr}21902.202 & 889.940 & 527.137 & \text { front } \\ 21902.202 & 889.940 & 393.468 & \\ 21902.202 & 889.940 & 472.716 & \\ & & & \text { back } \\ 15887.355 & 2869.487 & 1916.234 & \\ 15887.355 & 2869.487 & 1033.257 & \end{array}$

Table 6. Mass calibrated (mg)

Nonpolar 0.000 Minor-Nonpolar inor-Nonpolar

0.399

0.035

0.933

0.933

0.038

0.038

0.930

0.930

0.168

0.168

0.168
Desulf

0.002

0.029

0.022

0.017

0.020

front

0.112

0.060

0.050 \begin{tabular}{l} 
Corrections \\
A Divide by 3 for triplicate design \\
B Divide by 20 for 20x concentration \\
C Multiply by $10 / 9$ for missing BSTFA aliquot \\
Calibration curves \\
front detector $y=$ \\
back detector $\quad y=$ \\
\hline
\end{tabular}

Explanation of scaling corrections:

We divided some of the non-

polar areas by 3 (correction A), because our workflow divided their most-polar fractions into 3 aliquots (Fig. 7).

We divided many of the areas by 20 (B), because for these FID runs, the volume in the sample vial was 50 $\mathrm{uL}$, twenty times as small as the volume used for the HMB calibrations (1 mL).

We multiplied some of the runs by $10 / 9(C)$, because these fractions were missing $10 \%$ of their yield (removed for a different experiment that we do not report on).

Table 7. Procedural blank subtracted (mg)

\begin{tabular}{|c|c|c|c|c|c|c|c|c|c|c|}
\hline & & \multirow{2}{*}{\multicolumn{2}{|c|}{$\begin{array}{r}\text { TOE } \\
\text { weight } \\
(\mathrm{mg})\end{array}$}} & \multirow[b]{2}{*}{$\begin{array}{c}\min \% \\
\text { yield }\end{array}$} & \multirow[b]{2}{*}{$\begin{array}{r}\max \% \\
\text { yield }\end{array}$} \\
\hline & Nonpolar & Minor-Nonpolar & Desulf & $\begin{array}{r}4 \% \text { VOC } \\
\text { residue }\end{array}$ & $\begin{array}{r}19 \% \text { VOC } \\
\text { residue }\end{array}$ & $\begin{array}{r}\text { min desuf } \\
\text { yield }\end{array}$ & & & & \\
\hline Monterey-0 & 0.398 & 0.034 & 0.027 & 0.0014 & 0.0065 & 0.0207 & 0.0258 & 7.5 & $0.28 \%$ & $0.34 \%$ \\
\hline Monterey 1 & 0.932 & 0.038 & 0.020 & 0.0015 & 0.0071 & 0.0133 & 0.0189 & 15 & $0.09 \%$ & $0.13 \%$ \\
\hline Monterey 2 & 0.932 & 0.038 & 0.015 & 0.0015 & 0.0071 & 0.0076 & 0.0132 & 15 & $0.05 \%$ & $0.09 \%$ \\
\hline Monterey 3 & 0.932 & 0.038 & 0.018 & 0.0015 & 0.0071 & 0.0110 & 0.0166 & 15 & $0.07 \%$ & $0.11 \%$ \\
\hline Greenland 1 & 0.930 & 0.168 & 0.110 & 0.0067 & 0.0319 & 0.0783 & 0.1035 & 13.9 & $0.56 \%$ & $0.74 \%$ \\
\hline Greenland 2 & 0.930 & 0.168 & 0.058 & 0.0067 & 0.0319 & 0.0266 & 0.0518 & 13.9 & $0.19 \%$ & $0.37 \%$ \\
\hline Greenland 3 & 0.930 & 0.168 & 0.048 & 0.0067 & 0.0319 & 0.0159 & 0.0410 & 13.9 & $0.11 \%$ & $0.30 \%$ \\
\hline
\end{tabular}


7. The mitochondrial electron transport chain constantly produces free radicals (superoxides) (Nelson and Cox, 2005). Perhaps these species could abstract sulfur radicals.

8. We calculated the sulfurization potentials for each of the four Monterey desulfurized fractions: $S_{M, j}$, and $S_{M 0}$

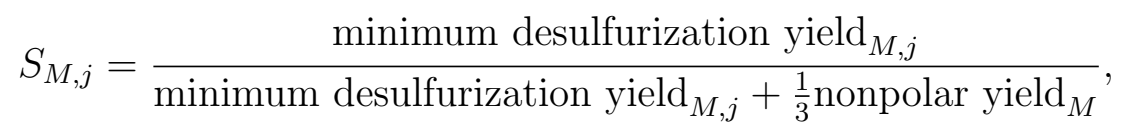

where $M$ denotes the $M$ onterey measurement set, and $1 \leq j \leq 3$. $j$ corresponds to three of the four Monterey desulfurized fractions (Sec. 2.3; Fig. 7).

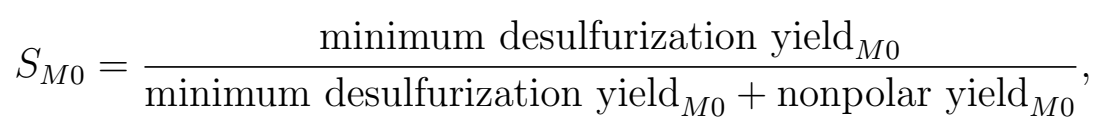

where $M 0$ denotes the $M$ onterey DS- 0 fraction, and the $M$ onterey- 0 nonpolar fraction (Sec. 2, endnote 7).

The mean sulfurization potential for the Monterey sample, $\overline{S_{M}}$, is

$$
\overline{S_{M}}=\frac{1}{4}\left(S_{M 0}+\sum_{j=1}^{3} S_{M, j}\right)
$$

The standard error of $\overline{S_{M}}$ is

$$
S . E \cdot_{M}=\frac{S \cdot D \cdot M}{\sqrt{4}}, \text { where } S \cdot D \cdot M=\sqrt{\frac{1}{3}\left(\left(\overline{S_{M}}-S_{M 0}\right)^{2}+\sum_{j=1}^{3}\left(\overline{S_{M}}-S_{M, j}\right)^{2}\right)}
$$


We calculated $S_{i, j}$, the sulfurization potentials for each of the three Greenland desulfurized fractions, for each of the two Greenland measurement sets.

$$
S_{i, j}=\frac{\text { minimum desulfurization } \text { yield }_{i, j}}{\text { minimum desulfurization yield }_{i, j}+\frac{1}{3} \text { nonpolar yield }_{i}},
$$

where $i=G A$ or $G B$, and $1 \leq j \leq 3$.

$i$ denotes one of two measurement sets: Greenland- $A$, or $G$ reenland- $B$ (see below).

$j$ denotes one of the three desulfurized fractions in each measurement set.

The mean sulfurization potential for the Greenland sample, $\overline{S_{G}}$, is

$$
\begin{gathered}
\overline{S_{G}}=\frac{1}{2}\left\langle S_{G A}\right\rangle+\frac{1}{2}\left\langle S_{G B}\right\rangle, \text { where } \\
\left\langle S_{G A}\right\rangle=\frac{1}{3} \sum_{j=1}^{3} S_{G A, j}, \text { and }\left\langle S_{G B}\right\rangle=\frac{1}{3} \sum_{j=1}^{3} S_{G B, j} .
\end{gathered}
$$

We performed the two sets of Greenland measurements, $G A$ and $G B$, as GCFID runs on September 30, 2008, and December 14, 2008, respectively. The GA data show regular isoprenoids with a high relative abundance and steroids with a low relative abundance; the $G B$ data show regular isoprenoids with a low relative abundance and steroids with a high relative abundance. We suspect that the following variations in experimental conditions contributed to this discrepancy: different split modes between $G A$ (10:1 split) and $G B$ (splitless); isoprenoid evaporation between September and December; and column replacement.

The standard error of $\overline{S_{G}}$ is

$$
\text { S.E.G } \cdot_{G}=\frac{S . D \cdot{ }_{G}}{\sqrt{2}}, \text { where } S . D \cdot G=\sqrt{\left(\overline{S_{G}}-\left\langle S_{G A}\right\rangle\right)^{2}+\left(\overline{S_{G}}-\left\langle S_{G B}\right\rangle\right)^{2}} \text {. }
$$

Our calculations of desulfurization potential each corrected for the yield of a procedural blank. 


\section{Conclusion}

Sulfurization occurs within 40 years of an organism's death in the Greenland lake Brayas $\varnothing$. The kinetics of this process seem to differ between major compound families. Alkenones in the Greenland setting are not sulfurized, although we base this conclusion on a limited sampling. Alkenone sulfurization could potentially confound paleotemperature reconstructions, which use free alkenone abundance ratios (e.g., D'Andrea and Huang, 2005). Since alkenones compose the majority of Greenland's nonpolar fraction, and the concentration of these compounds in Brayasø is the highest yet reported for lacustrine surface sediments (D'Andrea and Huang, 2005), we would be surprised if sulfurized alkenones were absent from the asphaltene or kerogen fractions.

We suspect that sulfurization progresses in the Brayas $\emptyset$ chemocline, where the availability of sunlight, oxygen, and sulfides changes rapidly. If photochemical sulfurization can occur in oxic water, then its operation is more widespread than previously recognized. Studies on the organic matter dissolved throughout Brayas $\varnothing$ 's water column would bear on our argument for photochemical sulfurization. Future study of Brayas $\varnothing$ could also desulfurize multiple sub-surface samples, which may reveal trends in the relative abundances of free and bound biomarkers. Sub-surface desulfurizations would also test for alkenone sulfurization late in diagenesis, which this study's surface desulfurizations could not have revealed.

Stable-isotope measurements often show differences between free compounds and their sulfur-bound counterparts. In view of the isotopic differences already observed between alkenones and other Brayas $\varnothing$ lipids, such measurements on the desulfurization yield would be interesting. Desulfurizing the asphaltene or kerogen fractions of Brayas $\varnothing$ 
samples may reveal sulfur-bound alkenones. Brayas $\varnothing$ kerogen may also be a useful test for the feasibility of desulfurizing meteoritic insoluble organic matter.

The 7 million year old Monterey shale that we desulfurized contains steroids, hopanoids, regular isoprenoids, and substituted PAHs. Respectively, each of these compound classes suggests input from eukaryotic, bacterial, photosynthetic, and terrestrial organisms. Sulfur-bound tocopherols may be precursors to free pristane. We observe some indicators of thermal modification to this rock, such as aromatic moieties and a dibenzothiophene. Microbial biodegradation explains the near absence of n-alkanes as free hydrocarbons in Monterey, and this process may also have modified the organic sulfur compounds.

Biomarker sulfurization efficiency may depend on sulfate availability and the activity of sulfate-reducing bacteria, as suggested by a comparison of the Monterey desulfurization yields with those from Vena del Gesso. Future work on samples from Monterey may require asphaltene precipitations, and carefully planned chromatographic separations of the desulfurized fraction (cf. Schouten et al., 2001). We suggest that future experiments proceed with an understanding of the diversity and complexity that can be present in a geochemical extract. 


\section{References}

Adam, P.; Philippe, E.; Albrecht, P. Photochemical sulfurization of sedimentary organic matter: A widespread process occurring at early diagenesis in natural environments? Geochimica et Cosmochimica Acta 1998, 62, 265-271.

Aizenshtat, Z.; Krein, E. B.; Vairavamurthy, M. A.; Goldstein, T. P. Role of sulfur in the transformations of sedimentary organic matter: a mechanistic overview. In: Geochemical transformations of sedimentary sulfur; Vairavamurthy, M. A., Schoonen, M. A. A., Eds.; American Chemical Society: Washington, DC, 1995; 16-37.

Amrani, A.; Aizenshtat, Z. Photosensitized oxidation of naturally occurring isoprenoid allyl alcohols as a possible pathway for their transformtion to thiophenes in sulfur rich depositional environments. Organic Geochemistry. 2004, 35, 693-712.

Anderson, N. J.; Leng, M. J. Increased aridity during the early Holocene in West Greenland inferred from stable isotopes in laminated-lake sediments. Quaternary Science Reviews. 2004, 23, 841-849.

Anderson, N. J.; Bennike, O.; Christoffersen, K.; Jeppesen, E.; Markager, S.; Miller, G.; Renberg, I. Limnological and palaeolimnological studies of lakes in south-western Greenland. Geology of Greenland Survey Bulletin. 1999, 183, 68-74.

Bada, J. L. Amino acid cosmogeochemistry. Phil. Trans. R. Soc. Lond. B. 1991, 333, 349358.

Back, T. G.; Yang, K.; Krouse, H. R. Desulfurization of Benzo- and Dibenzothiophenes with Nickel boride. J. Org. Chem. 1992, 57, 1986-1990.

Brocks, J. J.; Summons, R. E. Sedimentary hydrocarbons, biomarkers for early life. In Biogeochemistry 8, Treatise on Geochemistry; Schlesinger, W. H., Ed.; Elsevier: Oxford, 2004; 63-116.

Colby, B. N. Spectral Deconvolution for Overlapping GC/MS components. J. Am. Soc. Mass. Spectrom. 1992, 3, 558-562.

Conte, M. H.; Thompson, A. T.; Lesley, D.; Harris, R. P. Genetic and physiological influences on the alkenone/alkenoate versus growth temperature relationship in Emiliania huxleyi and Gephyrocapsa oceanica. Geochimica et Cosmochimica Acta. 1998, 62, 5168.

D’Andrea, W. J.; Lage, M.; Martiny, J. B. H.; Laatsch, A. D.; Amaral-Zettler, L. A.; Sogin, M. L.; Huang, Y. Alkenone producers inferred from well-preserved 18S rDNA in Greenland lake sediments. Journal of Geophysical Research. 2006, 111, G03013. 
D’Andrea, W. J. Personal communication, 11 March 2009.

D’Andrea, W. J. Personal communication, 16 April 2009.

D'Andrea, W. J.; Huang, Y. Long chain alkenones in Greenland lake sediments: Low del13C values and exceptional abundance. Organic Geochemistry. 2005, 36, 1234-1241.

Filley, T. R.; Freeman, K. H.; Wilkin, R. T.; Hatcher, P. G. Biogeochemical controls on reaction of sedimentary organic matter and aqueous sulfides in holocene sediments of Mud Lake, Florida. Geochim. Cosmochim. Acta. 2002, 66, 937-954.

Forster, A.; Sturt, H.; Meyers, P. A.; the Leg 207 Shipboard Scientific Party. Molecular Biogeochemistry of Cretaceous Black shales from the Demerara Rise: preliminary shipboard results from sites 1257 and 1258, Leg 207. In Proceedings of the Ocean Drilling Program, Initial reports. Volume 207. Erbacher, J., Mosher, D. C., Malone, M. J., et al., 2004.

Goossens, H.; de Leeuw, J. W.; Schenck, P. A.; Brassel, S. C. Tocopherols as likely precursors of pristane in ancient sediments and crude oils. Nature. 1984, 312, 440-442.

Isaacs, C. M. Depositional framework of the Monterey formation, California. In The Monterey Formation: from rocks to molecules; Isaacs, C. M., Rullkötter, J., Eds.; Columbia University Press: New York, Chichester, West Sussex, 2001, 1-30.

Jiang, C.; Alexander, R.; Kagi, R. I.; Murray, A. P. Polycyclic aromatic hydrocarbons in ancient sediments and their relationships to palaeoclimate. Org. Geochem. 1998, 29, 1721-1735.

Katz, B. J.; Royle, R. A. Variability of source rock attributes in the Monterey Formation, California. In The Monterey Formation: from rocks to molecules; Isaacs, C. M., Rullkötter, J., Eds.; Columbia University Press: New York, Chichester, West Sussex, 2001, 107-129.

Kohnen, M. E. L.; Sinninghe Damsté, J. S.; Dalen, A. C. K.; de Leeuw, J. W. Di- or polysulphide-bound biomarkers in sulphur-rich geomacromolecules as revealed by selective chemolysis. Geochimica et Cosmochimica Acta. 1991, 55, 1375-1394.

Kok, M. D.; Rijpstra, W. I. C.; Robertson, L.; Volkman, J. K.; Sinninghe Damsté, J. S. Early steroid sulfurisation in surface sediments of a permanently stratified lake (Ace Lake, Antarctica). Geochimica et Cosmochimica Acta. 2000, 64, 1425-1436.

Krijgsman, W.; Hilgen, F. J.; Raffi, I.; Sierro, F. J.; Wilson, D. S. Chronology, causes and progression of the Messinian salinity crisis. Nature. 12 August 1999, 400, 652. 
Krupcík, J.; Oswald, P.; Oktavec, D.; Armstrong, D. W. Calibration of GC-FID and IR Spectrometric methods for determination of high boiling petroleum hydrocarbons in environmental samples. Water, Air, and Soil Pollution. 2004, 153, 329-341.

Lugli, S.; Bassetti, M. A.; Manzi, V.; Barbieri, M.; Longinelli, A.; Roveri, M. The Messinian 'Vena del Gesso' evaporites revisited: characterization of isotopic composition and organic matter. Geological Society, London, Special Publications. 2007, 285, 179190.

Marlowe, I. T.; Brassell, S. C.; Eglinton, G.; Green, J. C. Long chain unsaturated ketones and esters in living algae and marine sediments. Org. Geochem. 1984, 6, 135-141.

McGowan, S.; Juhler, R. K.; Anderson, N. J. Autotrophic response to lake age, conductivity and temperature in two West Greenland lakes. J. Paleolimnol. 2008, 39, 301-317.

Metzger, P.; Rager, M. Lycopanerols H, two high molecular weight ether lipids from Botryococcus braunii comprising an alpha-tocopherol unit. Tetrahedron Letters. 2002, 43 2377-2380.

Nelson, D. L.; Cox, M. M. Lehninger Principles of Biochemistry, Fourth Edition; W. H. Freeman and Company: New York, 2005, 722.

Peters, K. E.; Walters, C. C.; Moldowan, J. M. The Biomarker Guide, Second Edition; Cambridge University Press: Cambridge, UK, 2007.

Putschew, A.; Scholz-Böttcher, B. M.; Rullkötter, J. Organic geochemistry of sulfur-rich surface sediments of meromictic Lake Cadagno, Swiss Alps; In Geochemical transformations of sedimentary sulfur; Vairavamurthy, M. A., Schoonen, M. A. A., Eds.; American Chemical Society: Washington, DC, 1995; 59-79.

Putschew, A.; Scholz-Böttcher, B. M.; Rullkötter; J. Early diagenesis of organic matter and related sulphur incorporation in surface sediments of meromictic Lake Cadagno in the Swiss Alps. Org. Geochem. 1996, 25, 379-390.

Proctor, L. M. Nitrogen-fixing, photosynthetic, anaerobic bacteria associated with pelagic copepods. Aquat. Microb. Ecol. 1997, 12, 105-113.

Roveri, M.; Manzi, V.; Ricci Lucchi, F.; Rogledi, S. Sedimentary and tectonic evolution of the Vena del Gesso basin (Northern Apennines, Italy): Implications for the onset of the Messinian salinity crisis. GSA Bulletin. April 2003, 115, 387-405.

Russell, J. M.; Werne, J. P. Climate change and productivity variations recorded by sedimentary sulfur in Lake Edward, Uganda/D. R. Congo. Chemical Geology. 2009, doi:10.1016/j.chemgeo.2009.03.020 
Sarmiento, J. L.; Gruber, N. Ocean Biogeochemical Dynamics; Princeton University Press: Princeton and Oxford, 2006.

Schaeffer, P.; Reiss, C.; Albrecht, P. Geochemical study of macromolecular organic matter from sulfur-rich sediments of evaporitic origin (Messinian of Sicily) by chemical degradations. Org. Geochem. 1995, 23, 567-581.

Schneckenburger, P.; Adam, P.; Albrecht, P. Thioketones as key intermediates in the reduction of ketones to thiols by HS- in natural environments. Tetrahedron Letters. 1998, $39,447-450$.

Schouten, S.; Pavlovic, D.; Sinninghe Damsté, J. S.; de Leeuw, J. W. Nickel boride: an improved desulphurizing agent for sulphur-rich geomacromolecules in polar and asphaltene fractions. Org. Geochem. 1993, 20, 901-909.

Schouten, S.; Schoell, M.; Rijpstra, W. I. C.; Sinninghe Damsté, J. S.; de Leeuw, J. W. A molecular stable carbon isotope study of organic matter in immature Miocene Monterey sediments, Pismo basin. Geochimica et Cosmochimica Acta. 1997, 61, 2065-2082.

Schouten, S.; De Loureiro, M. R. B.; Sinninghe Damsté, J. S.; de Leeuw, J. W. Molecular biogeochemistry of Monterey sediments, Naples Beach, California, I: Distributions of Hydrocarbons and organic sulfur compounds. In The Monterey Formation: from rocks to molecules; Isaacs, C. M., Rullkötter, J., Eds.; Columbia University Press: New York, Chichester, West Sussex, 2001, 150-173.

Schouten, S. Personal communication, 27 August 2008.

Sessions, A. L. Personal communication, 15 March 2009.

Sessions, A. L. Personal communication, 16 August 2008.

Sinninghe Damsté, J. S.; Rijpstra, W. I. C.; de Leeuw, J. W.; Schench, P. A. Origin of organic sulfur compounds and sulfur-containing high molecular weight substances in sediments and immature crude oils. Org. Geochem. 1988, 13, 593-606.

Sutton, P. A.; Lewis, C. A.; Rowland, S. J. Isolation of individual hydrocarbons from the unresolved complex hydrocarbon mixture of a biodegraded crude oil using preparative capillary gas chromatography. Organic Geochemistry. 2005, 36, 963-970.

Vai, G. B.; Ricci Lucchi, F. Algal crusts, autochthonous and clastic gypsum in a cannibalistic evaporite basin: a case history from the Messinian of Northern Apennines. Sedimentology. 1977, 24, 211-244.

Vaughan, W. E.; Rust, F. F. The photo-addition of hydrogen sulfide to olefinic bonds. $J$. Org. Chem. 1942, 07 (6), 472-476. 
Wenger, L. M.; Isaksen, G. H. Control of hydrocarbon seepage intensity on level of biodegradation in sea bottom sediments. Organic Geochemistry. 2002, 33, 1277-1292.

Werne, J. P.; Hollander, D. J.; Lyons, T. W.; Sinninghe Damsté, J. S. Organic sulfur biogeochemistry: recent advances and future research directions. In Sulfur biogeochemistry Past and present; Amend, J. P., Edwards, K. J., Lyons, T. W., Eds.; Geological Society of America: Boulder, Colorado, 2004; Special Paper 379, 135-150.

Werne, J. P.; Lyons, T. W.; Hollander, D. J.; Schouten, S.; Hopmans, E. C.; Sinninghe Damsté, J. S. Investigating pathways of diagenetic organic matter sulfurization using compound-specific sulfur isotope analysis. Geochimica et Cosmochimica Acta. 2008, 72, 3489-3502.

Yamamoto, M.; Naraoka, H.; Ishiwatari, R.; Ogihara, S. Carbon isotope signatures of bacterial 28-norhopanoic acids in Miocene-Pliocene diatomaceous and phosphatic sediments. Chemical Geology. 2005, 218, 117-133. 